JOSÉ EDUARDO PRATA

MODELAGEM DE UM ABSORVEDOR DE FILME DESCENDENTE LÍQUIDO PARA UM CICLO DE REFRIGERAÇÃO POR ABSORÇÃO AMÔNIA-ÁGUA 
JOSÉ EDUARDO PRATA

\title{
MODELAGEM DE UM ABSORVEDOR DE FILME DESCENDENTE LÍQUIDO PARA UM CICLO DE REFRIGERAÇÃO POR ABSORÇÃO AMÔNIA-ÁGUA
}

\author{
Dissertação apresentada à Escola \\ Politécnica da Universidade de São \\ Paulo para obtenção do título de \\ mestre em Engenharia \\ Área de Concentração: \\ Engenharia Mecânica de Energia e \\ Fluidos \\ Orientador: Prof. ${ }^{\circ}$ Livre Docente \\ José Roberto Simões Moreira
}


Este exemplar foi revisado e alterado em relação à versão original, sob responsabilidade única do autor e com a anuência de seu orientador.

São Paulo, 3 de janeiro de 2012

Assinatura do autor

Assinatura do orientador

\section{FICHA CATALOGRÁFICA}

Prata, José Eduardo

Modelagem de um absorvedor de filme líquido descendente para um ciclo de refrigeração por absorção amônia-água / J.E. Prata. --ed. rev.-- São Paulo, 2012.

$125 \mathrm{p}$.

Dissertação (Mestrado) - Escola Politécnica da Universidade de São Paulo. Departamento de Engenharia Mecânica.

1. Refrigeração 2. Fenômenos de transporte 3. Termodinâ mica I. Universidade de São Paulo. Escola Politécnica. Departamento de Engenharia Mecânica II. t. 


\section{DEDICATÓRIA}

Aos meus pais Eliana e José.

À minha noiva Patrícia. 


\section{AGRADECIMENTOS}

Ao Professor José Roberto Simões Moreira, pela orientação e ensinamentos que foram fundamentais para a realização deste trabalho

Aos amigos do Laboratório de Sistemas Energéticos Alternativos (SISEA) e professores do PPGEM, sempre dispostos a ajudar.

Sou grato também ao Conselho Nacional de Desenvolvimento Científico e Tecnológico (CNPq), pelo apoio financeiro. 


\section{RESUMO}

O foco deste trabalho é o desenvolvimento de um modelo físico representativo de um absorvedor de filme líquido descendente para um ciclo de refrigeração por absorção amônia-água, considerando uma capacidade de refrigeração de 5TR.

O absorvedor é constituído basicamente de feixes de tubos dispostos horizontalmente, no interior dos quais escoa água com a finalidade de retirar o calor liberado ao longo do processo de absorção. Desenvolveu-se o modelo com base na obtenção e resolução dos balanços de energia e de massa. Isso com o auxílio de correlações e analogias que possibilitaram a obtenção dos coeficientes de transferência de calor e massa. Levou-se em conta a variação das propriedades tanto do líquido como do vapor ao longo do absorvedor, assim como a resistência existente nessas duas fases.

Obtiveram-se os perfis de frações e vazões mássicas, temperatura, coeficientes de transferência e taxas de transferência de amônia. Avaliou-se a influência de parâmetros importantes em se tratando de absorvedores de filme líquido descendente, tais como número de Reynolds, temperatura do fluido de resfriamento e temperatura de entrada da solução.

Estes perfis possibilitaram a análise de alguns aspectos relevantes no que diz respeito ao projeto do absorvedor, considerando-se algumas condições operacionais e geométricas previamente estabelecidas.

Por fim, foi possível, através da obtenção do comprimento do equipamento para as diversas condições de simulação adotadas, calcular a área de troca de calor necessária para o processo absortivo.

Palavras-chave: Absorção, Amônia, Refrigeração, Transferência de Calor, Transferência de massa. 


\begin{abstract}
The goal of this work is to develop a representative physical modeling of a falling film absorber for an ammonia-water absorption refrigeration cycle, rated at cooling 5 TR.

The absorber is composed of a bundle of tubes arranged horizontally. The water flows inside these tubes in order to remove the heat released during the absorption process. The model was developed based on solving the conservation equations of energy and mass. Practical correlations and the heat and mass transfer analogy were used to find the convective coefficients. It was considered the changes of the properties of liquid and vapor along the absorber and also it was taken into account the thermal resistances in each phase.

It was found the profiles of mass fractions and mass flow rates, temperature, transfer coefficients and transfer rates of ammonia. It was evaluated the influence of important parameters such as the Reynolds number, cooling temperature and inlet temperature of the solution.

These profiles allowed the analysis of some relevant aspects regarding the design of the absorber, considering operational and dimensional conditions preestablished.

Finally, it was possible to calculate the area and other geometrical aspects to achieve the absorptive process, by analyzing the operation of the equipment at various conditions.
\end{abstract}

Keywords: Absorption, Ammonia, Refrigeration, Heat Transfer, Mass Transfer 


\section{LISTA DE FIGURAS}

Figura 3.1 - Ciclo básico de refrigeração por absorção (Chaves, 2009) ….................4

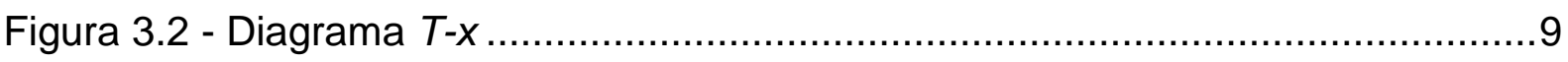

Figura 3.3 - Diagrama fração mássica-entalpia do ciclo de refrigeração por absorção

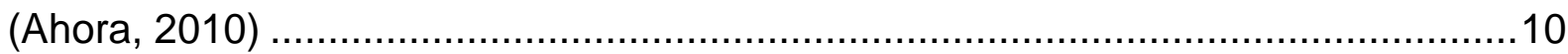

Figura 3.4 - Representação da molécula de amônia (Sahakhashiri, 2008) ..............12 Figura 3.5 - Ciclo de refrigeração por absorção simples efeito com pré-resfriador e trocador de calor de solução.

Figura 3.6 - Ciclo de refrigeração por absorção simples efeito com pré-resfriador, trocador de calor de solução e retificador

Figura 3.7 - COP do sistema em função da concentração de refrigerante no evaporador (adaptado, Fernandez-Seara e Sieres, 2006) . 18

Figura 3.8 - Ciclo de refrigeração por absorção simples efeito com pré-resfriador, trocador de calor de solução e troca de calor no retificador.

Figura 3.9 - Ciclo de refrigeração por absorção duplo efeito ...................................20

Figura 3.10 - Esquema do processo de absorção (adaptado, Herold, 1996) .............22

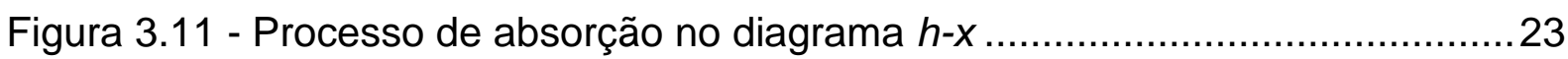

Figura 3.12 - Processo de absorção no diagrama $h-x$ com fluxo de saída subresfriado

Figura 3.13 - Conceito das duas resistências (adaptado, Treyball 1981). 26

Figura 3.14 - Absorvedor de película descendente com trocador de calor de placas (Kang et al. 2000).

Figura 3.15 - Absorvedor de tubos verticais (Carvalho, 2007) ..... .29

Figura 3.16 - (a) esquema de absorvedor de filme descendente horizontal fotografia dos tubos (c) distribuidor (Bohra, 2000) 30

Figura 3.17 - Conceito de absorvedor constituído por microcanais (Garimella, 2002)

Figura 3.18 - Absorvedor convencional de borbulhamento (Milanés, 1999) .31

Figura 3.19 - Absorvedor de borbulhamento vertical (adaptado, Infante Ferreira et al. 1984) 32

Figura 3.20 - Absorvedor evaporativo (Milanés, 2002)..... 
Figura 3.21 - Diagrama esquemático de um absorvedor de borbulhamento com tubos verticais (Fernandez-Seara et al. 2005).

Figura 3.22 - (a) anéis de Raschig, (b) selas Berl, (c) IMTP, (d) anéis Pall, (e) leito de recheio estruturado (Foust, 1982)

Figura 3.23 - Regimes de operação em absorvedores de leito empacotado (Westerlund e Dahl, 1994)

Figura 3.24 - Perfis das taxas de absorção para os regimes de filme descendente e borbulhamento (adaptado, Kang et al., 2000).

Figura 3.25 - Coeficientes de transferência de calor durante o processo de absorção em absorvedores tipo bolha e filme descendente (adaptado, Kang et al., 2000).

Figura 3.26 - Área de transferência de massa e calor em um absorvedor tipo bolha (Makiyama, 2008)

Figura 3.27 - Tipos de escoamento ao redor de tubos horizontais (Mitrovic, 2005) ..49 Figura 3.28 - Padrões de escoamento em filme descendente ao redor de tubos horizontais. (a) gotejamento; (b) gotejamento-jato; (c) jato em linha; (d) jato escalonado; (e) jato-lâmina; (f) lâmina (Hu e Jacobi, 1996)

Figura 4.1- Esquema de absorvedor de filme descendente de tubos horizontais: (a) vista em perspectiva, (b) vista perpendicular ................................................54

Figura 4.2 - Filme descendente de líquido exposto ao vapor ...............................56

Figura 4.3 - Volume de controle de uma seção do absorvedor .............................69

Figura 4.4 - Fluxograma do procedimento de cálculo ........................................74

Figura 5.1 - Vazão mássica de líquido ao longo do absorvedor para $R e_{\text {Imax }}=75$,

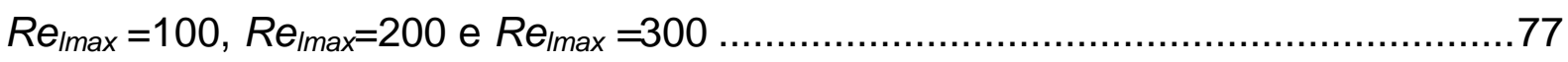

Figura 5.2 - Espessura do filme líquido ao longo do absorvedor para $R \boldsymbol{e}_{\operatorname{lmax}}=75$, $R e_{\text {Imax }}=100, \boldsymbol{e}_{\text {Imax }}=200$ e $R \boldsymbol{e}_{\text {Imax }}=300$. 79

Figura 5.3 - Coeficientes de transferência de calor modificados na fase líquida em função da espessura do filme para $R e_{I \max }=75, \quad R e_{\text {Imax }}=100, \quad R e_{\text {Imax }}=200$ e $R \boldsymbol{e}_{\text {Imax }}=300$........

Figura 5.4 - Coeficientes de transferência de massa na fase líquida em função do comprimento para $R e_{\text {Imax }}=75, R e_{I \max }=100, R e_{I \max }=200$ e $R e_{I \max }=300$.

Figura 5.5 - Coeficientes de transferência de calor na fase líquida e no fluido de resfriamento em função do comprimento para $R \boldsymbol{e}_{\operatorname{lmax}}=75, R \boldsymbol{e}_{\operatorname{lmax}}=100, \boldsymbol{e}_{\operatorname{lmax}}=200 \mathrm{e}$ $R e_{\text {max }}=300$. 
Figura 5.6 - Coeficientes de transferência de calor modificados na fase vapor ao longo do absorvedor para $R \boldsymbol{e}_{I_{\max }}=75, R \boldsymbol{e}_{\operatorname{lmax}}=100, R \boldsymbol{e}_{\max }=200$ e $R \boldsymbol{e}_{\operatorname{lmax}}=300$

Figura 5.7 - Coeficientes globais transferência de calor para $R e_{I \max }=75, R e_{\text {Imax }}=100$, $R \boldsymbol{e}_{\text {Imax }}=200$ e $\boldsymbol{R e}_{\text {Imax }}=300$

Figura 5.8 - Frações mássicas ao longo do absorvedor, para $R \boldsymbol{e}_{\text {Imax }}=300$ 85

Figura 5.9 - Coeficientes de transferência de massa na fase líquida, em função dos coeficientes de transferência de calor $h_{\imath}^{*}$ para $R e_{\text {Imax }}=75, R e_{I \max }=100, R e_{I \max }=200 \mathrm{e}$ $R e_{\text {max }}=300$. .86

Figura 5.10 - Temperaturas do filme líquido ao longo do absorvedor, para $R e_{\max }=100$ e $T C=15^{\circ} \mathrm{C}, T C=20^{\circ} \mathrm{C}, T C=25^{\circ} \mathrm{C}$ e $T C=30^{\circ} \mathrm{C}$

Figura 5.11 - Fluxo de calor ao longo absorvedor, para $R \boldsymbol{e}_{\operatorname{lmax}}=100$ e $T_{C}=15^{\circ} \mathrm{C}$, $T_{c}=20^{\circ} \mathrm{C}, T_{c}=25^{\circ} \mathrm{C}$ e $T_{c}=30^{\circ} \mathrm{C}$ 90

Figura 5.12 - Vazões mássica de líquido ao longo do absorvedor para $R e_{\max }=100 \mathrm{e}$ $T C=15^{\circ} \mathrm{C}, T C=20^{\circ} \mathrm{C}, T C=25^{\circ} \mathrm{C}$ e $T C=30^{\circ} \mathrm{C}$

Figura 5.13 - Temperaturas do filme líquido ao longo do absorvedor para $R e_{l \max }=100, T C=25^{\circ} \mathrm{C}$ e $T_{l e}=50^{\circ} \mathrm{C}, T_{l e}=80^{\circ} \mathrm{C}$ e $T_{l e}=100^{\circ} \mathrm{C}$ e $T_{l e}=116,6^{\circ} \mathrm{C}$

Figura 5.14 - Fluxo de calor retirado pelo fluido de resfriamento em função da temperatura de entrada da solução. .94

Figura 5.15 - Vazões mássica de líquido ao longo do absorvedor para $R e_{\mid \max }=100$, $T C=25^{\circ} \mathrm{C}$ e $T_{l e}=50^{\circ} \mathrm{C}, T_{l e}=80^{\circ} \mathrm{C}$ e $T_{l e}=100^{\circ} \mathrm{C}$ e $T_{l e}=116,6^{\circ} \mathrm{C}$ 95

Figura 5.16 - Fração mássica versus temperatura na interface .96

Figura 5.17 - Vazões mássica de líquido ao longo do absorvedor para $R e_{I \max }=100$, $T C=25^{\circ} \mathrm{C}$ e $T_{l e}=50^{\circ} \mathrm{C}, T_{l e}=80^{\circ} \mathrm{C}$ e $T_{l e}=100^{\circ} \mathrm{C}$ e $T_{l e}=116,6^{\circ} \mathrm{C}$ 97 


\section{LISTA DE TABELAS}

Tabela 3.1 - Pares absorvente-refrigerante (Pohlman,1979; Sresnewsky, 1983) ........7

Tabela 3.2 - Valores de COP para cada modelo implementado (Ortigosa, 2007).....19

Tabela 3.3 - Fontes de calor adequadas a cada tipo de ciclo (Foley, 2000)

Tabela 3.4 - Comparação entre absorvedores de filme descendente e tipo bolha (adaptado, Castro et al., 2009)

Tabela 3.5 - Constantes para correlação de transição de modo de escoamento (adaptado, Mohamed, 2007)

Tabela 4.1 - Parâmetros característicos para substâncias puras (Wilke e Chang, 1955) .65

Tabela 4.2 - Parâmetros de entrada para simulação do absorvedor.. .72

Tabela 4.3 - Dimensões e material dos tubos .73

Tabela 5.1 - Resultados para $T_{c}=25^{\circ} \mathrm{C}$ e $T_{l e}=116,6$, considerando diferentes valores de $R \boldsymbol{e}_{\text {Imax }}$

Tabela 5.2 - Resultados para $R e_{l \max }=100$ e $T_{l e}=116,6{ }^{\circ} \mathrm{C}$, considerando diferentes temperaturas do fluido de resfriamento

Tabela 5.3 - Resultados para $R e_{\max }=100$ e $\mathrm{T}_{\mathrm{C}}=25^{\circ} \mathrm{C}$, considerando diferentes temperaturas de entrada da solução pobre. 


\section{LISTA DE ABREVIATURAS E SIGLAS}

$\begin{array}{ll}\text { EES } & \text { Equation Engineering Solver } \\ \text { COP } & \text { Coeficiente de Desempenho } \\ \text { GAX } & \text { "Generator-Absorber heat exchanger" } \\ \text { PSSRA } & \text { Programa de Simulação de Sistemas de Refrigeração por } \\ & \text { Absorção } \\ R H X & \text { "Refrigerant Heat Exchanger" } \\ S H X & \text { "Solution Heat Exchanger" } \\ T C S & \text { Trocador de Calor de Solução } \\ V E: A & \text { Válvula de Expansão A } \\ V E: B & \text { Válvula de Expansão B } \\ V E: C & \text { Válvula de Expansão C }\end{array}$




\section{LISTA DE SÍMBOLOS}

$\boldsymbol{A}_{\boldsymbol{t}} \quad$ Área superficial total do absorvedor [m²]

$C_{p} \quad$ Calor específico $\left[\mathrm{J} / \mathrm{kg}^{\circ} \mathrm{C}\right]$

$\boldsymbol{d A} \quad$ Elemento de área $\left[\mathrm{m}^{2}\right]$

$\boldsymbol{D}_{\boldsymbol{e}} \quad$ Diâmetro externo dos tubos [m]

$\boldsymbol{D}_{\boldsymbol{i}} \quad$ Diâmetro interno dos tubos [m]

$\boldsymbol{D}_{\boldsymbol{i f f}}$ Difusividade mássica da amônia em água [ $\left.\mathrm{m}^{2} / \mathrm{s}\right]$

$\boldsymbol{d} \boldsymbol{L} \quad$ Elemento diferencial de comprimento [m]

$\boldsymbol{d}_{\boldsymbol{m}_{\mathrm{NH}_{3}}}$ Taxa de transferência de amônia [kg/s]

$\boldsymbol{d} \dot{\boldsymbol{Q}}$ Taxa de transferência de calor [W]

$\boldsymbol{e} \quad$ Espessura da parede dos tubos [m]

$N_{c} \quad$ Número de colunas [-]

$\boldsymbol{N}_{\boldsymbol{t}} \quad$ Número de tubos por coluna [-]

h Coeficiente convectivo de transferência de calor $\left[\mathrm{W} / \mathrm{m}^{2} \mathrm{C}\right]$

$\boldsymbol{h}_{\boldsymbol{l}}{ }^{*} \quad$ Coeficiente convectivo de transferência de calor na fase líquida modificado $\left[\mathrm{W} / \mathrm{m}^{2}{ }^{\mathrm{C}}\right]$

$\boldsymbol{h}_{v}{ }^{*} \quad$ Coeficiente convectivo de transferência de calor na fase vapor modificado $\left[\mathrm{W} / \mathrm{m}^{2}{ }^{\mathrm{C}}\right]$

$\boldsymbol{h}_{\boldsymbol{c} \text { lam }}$ Coeficiente convectivo de transferência de calor laminar do fluido de resfriamento $\left[\mathrm{W} / \mathrm{m}^{2} \mathrm{C}\right]$

$\boldsymbol{h}_{\boldsymbol{c} \text { turb }}$ Coeficiente convectivo de transferência de calor turbulento do fluido de resfriamento $\left[\mathrm{W} / \mathrm{m}^{2} \mathrm{C}\right]$

$\boldsymbol{H} \quad$ Entalpia específica $(\mathrm{kJ} / \mathrm{kg})$

$\boldsymbol{K}$ Coeficiente de transferência de massa $\left[\mathrm{kg} / \mathrm{m}^{2} \mathrm{~s}\right]$

Ka Número de Kaptiza [-]

$\boldsymbol{L} \quad$ Comprimento do absorvedor [m]

$\boldsymbol{k} \quad$ Condutividade térmica $\left[\mathrm{W} / \mathrm{m}^{\mathrm{C}} \mathrm{C}\right]$

$\dot{m}$ Vazão mássica $[\mathrm{kg} / \mathrm{s}]$

$\dot{\boldsymbol{m}}_{\max }$ Vazão mássica máxima do filme $[\mathrm{kg} / \mathrm{s}]$

M Massa molar

$\boldsymbol{P}$ Pressão [bar]

Pr Número de Prandtl [-] 
Re Número de Reynolds [-]

$\boldsymbol{R} \boldsymbol{e}_{\text {Imax }}$ Número de Reynolds máximo do filme líquido [-]

Sc Número de Schmidt [-]

$\boldsymbol{S}_{\boldsymbol{t}} \quad$ Número de Stanton [-]

$\boldsymbol{T}_{\boldsymbol{c}}$ Temperatura do fluido de resfriamento [ $\left[{ }^{\circ} \mathrm{C}\right]$

$\boldsymbol{T}_{\boldsymbol{l e}}$ Temperatura de entrada da solução pobre [ $\left.{ }^{\mathrm{C}} \mathrm{C}\right]$

$\boldsymbol{T}_{\boldsymbol{m l}}$ Temperatura média do filme líquido [ $\left.{ }^{\circ} \mathrm{C}\right]$

$\boldsymbol{U}$ Coeficiente global de transferência de calor $\left[\mathrm{W} / \mathrm{m}^{2} \mathrm{C}\right]$

$\boldsymbol{V}_{\text {diff }}$ Volume molar $\left[\mathrm{m}^{3} / \mathrm{kmol}\right.$

$\boldsymbol{W}$ Comprimento dos tubos [m]

$\boldsymbol{x} \quad$ Fração mássica de amônia no líquido [-]

$\boldsymbol{y} \quad$ Fração mássica de amônia no vapor [-]

\section{Letras gregas}

a Coeficiente de condutividade térmica $\left(\mathrm{W} / \mathrm{m}^{\circ} \mathrm{C}\right)$

$\boldsymbol{\mu} \quad$ Viscosidade $[\mathrm{kg} / \mathrm{m} \mathrm{s}]$

$\boldsymbol{\Gamma} \quad$ Vazão mássica por comprimento de tubo $[\mathrm{kg} / \mathrm{m} \mathrm{s}]$

$\boldsymbol{\delta} \quad$ Espessura do filme líquido [m]

$\boldsymbol{\psi} \quad$ Fator associativo da mistura [-]

$\boldsymbol{\rho} \quad$ Densidade $\left[\mathrm{kg} / \mathrm{m}^{3}\right]$

\section{Índices subscritos}

c Fluido de resfriamento

l Líquido

$v \quad$ Vapor

int Interface líquido-vapor 


\section{SUMÁRIO}

1. INTRODUÇÃO

2. OBJETIVOS 3

3. REVISÃO DA LITERATURA 4

3.1. Ciclos de refrigeração por absorção 4

3.2. Análise gráfica das propriedades termodinâmicas de misturas binárias 7

3.2.1. Processo de refrigeração por absorção no diagrama $h-X$

3.3. A Amônia 12

3.4. Ciclo de refrigeração por absorção amônia-água 13

3.5. Aspectos termodinâmicos do processo de absorção 21

3.6. Atividade química no processo de absorção da amônia 24

3.7. Transferência de Massa Gás-Líquido 25

3.8. Tipos de absorvedores $\quad 27$

3.8.1. Absorvedores de filme descendente 27

3.8.2. Absorvedores do tipo borbulhamento 31

3.8.3. Absorvedor de leito empacotado 34

3.9. Estudos numéricos, analíticos e experimentais de processos de absorção amônia-água 37

3.9.1. Estudos numéricos e analíticos 37

3.9.2. Estudos experimentais 41

3.9.3. Comparação entre regime de filme descendente e regime de bolhas $\quad 43$

4. METODOLOGIA E MODELAGEM MATEMÁTICA 52

4.1. Configuração idealizada 53

4.2. Hipóteses adotadas na modelagem 54

4.3. Espessura do filme líquido descendente 55

4.4. Determinação do número de colunas do absorvedor 58

4.5. Avaliação de coeficientes de transferência de massa e calor através de correlações e analogias $\quad 59$

4.6. Propriedades da mistura amônia-água 63

4.7. Temperatura e frações mássica na interface 65 
4.8. Balanços de massa 66

4.9. Balanços de energia 69

4.10. Condições de entrada e características geométricas 72

4.11. Procedimento de Solução 73

5. RESULTADOS E DISCUSSÃO

5.1. Influência de $\mathrm{Re}_{\text {Imax }}$

5.2. Influência da temperatura do fluido de resfriamento 87

5.3. Influência da temperatura de entrada da solução 92

6. CONCLUSÕES 98

7. TRABALHOS FUTUROS 100

REFERÊNCIAS BIBLIOGRÁFICAS 101

APÊNDICE-Conjunto de equações solucionadas no EES 106 


\section{INTRODUÇÃO}

Um esforço considerável de pesquisa tem sido investido no estudo de sistemas de refrigeração por absorção nos últimos anos. Este cenário está associado à preocupação em se desenvolver tecnologias mais eficientes do ponto de vista econômico e energético. Assim como, atender às atuais necessidades ambientais através do uso racional dos recursos não renováveis ainda disponíveis.

Sistemas de refrigeração por absorção se apresentam como uma forma alternativa aos sistemas de compressão de vapor, possuindo como principal vantagem, a utilização de calor, tipo de energia "menos nobre", substituindo parte da energia elétrica necessária para obtenção do efeito de resfriamento desejado, por meio dos sistemas tradicionais de refrigeração por compressão de vapor. Resfriadores (chillers) de absorção são extensamente utilizados em indústrias de ar condicionado, podendo ser acionados através de água quente, vapor, queima de gás natural, energia solar, biomassa, dentre outros. Assim, vindo a substituir ou reduzir significativamente o uso de eletricidade. Dessa forma, a utilização desse tipo de sistema se torna economicamente viável e bastante atraente quando existe a possibilidade de cogeração, ou seja, a produção combinada de eletricidade e calor, proporcionando o aproveitamento de mais de $70 \%$ do calor proveniente de uma fonte primária de energia, como por exemplo, através da utilização de gases de combustão oriundos de motores de combustão interna ou turbinas a gás.

Pode-se dizer que, enquanto ciclos de compressão a vapor são caracterizados por serem operados a trabalho, ciclos de refrigeração por absorção são operados a calor e, portanto, a maior parte do custo de operação está associada ao fornecimento de calor, cuja responsabilidade é liberar o vapor de uma solução líquida a alta pressão. Ou seja, a quantidade de trabalho para uma dada quantidade de refrigeração em ciclos de absorção é mínima se comparada àquela que seria necessária em um ciclo de compressão a vapor.

Sistemas de refrigeração por absorção podem utilizar diferentes pares refrigerante-absorvente. No entanto, este trabalho considera apenas o par amôniaágua, por razões que serão expostas mais adiante. O processo de absorção do vapor de amônia pela solução pobre de amônia e água ocorre no interior do 
componente denominado absorvedor, o qual deve ser criteriosamente selecionado e dimensionado de maneira a possuir conformação e regime de operação que reduzam as resistências à transferência de calor e de massa.

O desempenho do ciclo de refrigeração é altamente dependente da taxa de absorção do vapor de amônia pela solução líquida. Uma baixa taxa de absorção reduz o fluxo de refrigerante que, na prática, vem a reduzir o desempenho geral do ciclo (Sultana, 2006).

Portanto, o absorvedor se trata de um componente-chave não só no que diz respeito ao desempenho do ciclo, mas também no que se refere ao custo do equipamento como um todo, o qual é extremamente elevado em decorrência do tamanho e da complexidade existente. Frente a isso, observa-se um grande volume de trabalhos de pesquisa, principalmente nas últimas três décadas, envolvendo estudos experimentais e modelagens de absorvedores destinados a ciclos de refrigeração por absorção. Os estudos se concentram principalmente na análise combinada dos fenômenos de transferência de calor e massa, buscando configurações, condições de operação e de projeto que minimizem os custos e aumentem a eficiência do processo absortivo. 


\section{OBJETIVOS}

Como mencionado anteriormente, o absorvedor é um componente crítico dentro de um ciclo de refrigeração por absorção, dada sua importância no que se refere ao desempenho do equipamento e também quanto ao seu custo de construção. Além disso, o absorvedor é um dos componentes-chave do ciclo, já que nele se dá a ocorrência simultânea de transferência de calor e massa, requerendo atenção especial quanto ao seu dimensionamento e determinação de suas condições operacionais.

Neste sentido, este trabalho tem o intuito de contribuir com o avanço nas pesquisas na área de refrigeração por absorção amônia-água, através da abordagem específica de um absorvedor de filme líquido descendente. Esta contribuição passa, obrigatoriamente, pela melhor compreensão dos fenômenos de transferência calor e massa envolvidos nesse tipo de absorvedor.

Assim, tem-se como ponto de partida o desenvolvimento de um modelo físico, que acople as equações de transferência de massa e energia, considerando a resistência à transferência de massa tanto na fase líquida como na fase vapor. Por meio dessa modelagem, objetiva-se primariamente a obtenção do comportamento de algumas variáveis importantes ao longo da extensão do absorvedor, tais como vazões e frações mássicas de vapor e solução, coeficientes de transferência, espessura e temperatura de filme e taxas de remoção de calor e condensação do vapor de amônia. Buscar-se-á avaliar o impacto dessas variáveis no processo absortivo, analisando suas influências e impactos no tamanho final do equipamento.

Concomitantemente ao objetivo principal, serão obtidos alguns parâmetros importantes do ponto de vista de projeto, sendo eles: comprimento do absorvedor, número de colunas, número de tubos por coluna e área superficial necessária para a completa absorção da vazão de vapor. Foram realizadas simulações que avaliaram diferentes condições de escoamento (número de Reynolds), temperatura do fluido de resfriamento e temperatura de entrada da solução. 


\section{REVISÃO DA LITERATURA}

\subsection{Ciclos de refrigeração por absorção}

Um sistema simplificado de refrigeração por absorção é similar a um sistema convencional de compressão a vapor. Os dois são compostos basicamente por um condensador, um evaporador e uma válvula de expansão. O ciclo básico de absorção é descrito na Fig. 3.1.

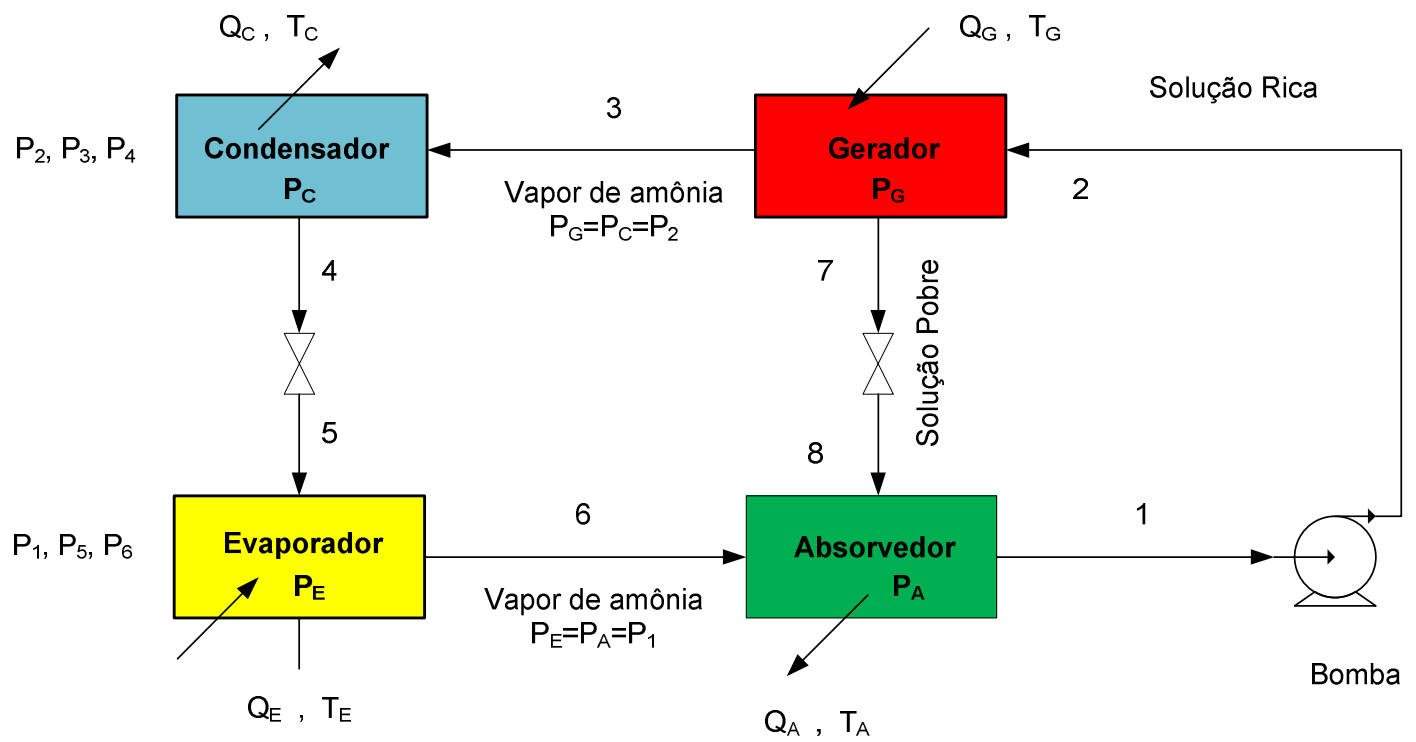

Figura 3.1 - Ciclo básico de refrigeração por absorção, (Chaves, 2009)

O sistema acima tem início na saída do evaporador (6), onde o vapor de amônia a baixa pressão é absorvido pela solução líquida no absorvedor. Essa solução é transportada pela bomba de (1) até o gerador (2). Durante esse processo, a solução tem sua pressão elevada. No gerador, o calor proveniente de uma fonte de alta temperatura, libera o vapor (3), que havia sido absorvido pela solução. A solução líquida (7), que foi separada durante esse processo, retorna por uma válvula redutora de pressão, cuja finalidade é manter as diferenças de pressão entre o gerador e o absorvedor. O vapor que saiu do gerador (3) a alta pressão é entregue ao condensador, sendo condensado e rejeitando calor para o meio. O líquido a alta 
pressão vindo do condensador (4) tem sua pressão reduzida por uma válvula de expansão até ser entregue ao evaporador (5), onde o fluido refrigerante é vaporizado ao receber calor a baixa temperatura da substância ou meio que está sendo refrigerado.

Nestes sistemas a elevação da pressão do vapor, oriundo do evaporador e destinado ao condensador, é realizada com o auxílio do fenômeno de absorção, em que o fluido refrigerante é absorvido por um fluido absorvente transformando-se em uma mistura na fase líquida. Mais adiante, este fenômeno será apresentado de forma mais específica e detalhada.

De acordo com Dossat (2001), o desempenho dos sistemas de absorção depende fortemente da escolha apropriada do par refrigerante-absorvente. As substâncias que compõem o par refrigerante-absorvente devem atender um certo número de requisitos para serem adequadas ao emprego em sistemas por absorção. Segundo a ASHRAE (ASHRAE, 1981), são eles:

- Afinidade: o absorvente deve ter grande afinidade química pelo refrigerante nas condições em que o processo de absorção ocorre. Esta afinidade acarreta um desvio negativo do comportamento previsto pela lei de Raoult e resulta em um coeficiente de atividade menor que a unidade para o refrigerante. Isto reduz a quantidade de absorvente que circula e, conseqüentemente, minimiza o desperdício de energia devido aos efeitos de variação de temperatura. Além disso, o tamanho do trocador de calor que transfere calor do absorvente para a solução refrigeranteabsorvente (existente em sistemas reais) pode ser reduzido. Por outro lado, uma elevada afinidade está associada com uma elevada entalpia de diluição, tendo como conseqüência um consumo adicional de energia (na forma de calor) no gerador para separar o refrigerante do absorvente.

- Relação de Volatilidades: o refrigerante deve ser muito mais volátil que o absorvente, de forma a permitir a separação das duas substâncias facilmente;

- Entalpia de Vaporização/Condensação: as entalpias de vaporização e condensação do refrigerante devem ser elevadas, para que as vazões de refrigerante e absorvente possam ser reduzidas ao mínimo possível; 
- Pressão: é desejável que as pressões de operação sejam moderadas, já que pressões elevadas requerem o emprego de equipamentos com paredes espessas e pressões muito baixas (vácuo) demandam equipamentos volumosos, bem como dispositivos especiais para reduzir a perda de carga nos escoamentos de refrigerante na fase vapor;

- Viscosidade: os fluidos devem ter baixa viscosidade para promover os processos de transferência de calor e massa, bem como reduzir problemas com bombeamento dos fluidos;

- Ausência de fase sólida: o par refrigerante-absorvente não deve formar uma fase sólida na faixa de composições e temperaturas nas condições de operação do sistema de absorção, pois isto poderia ocasionar parada do equipamento;

- Estabilidade: a estabilidade química deve ser praticamente absoluta, pois os fluidos são submetidos a condições severas durante os vários anos de operação do sistema. Eventuais instabilidades podem resultar na formação de substâncias danosas como gases, sólidos ou substâncias corrosivas;

- Corrosão: é particularmente importante que os fluidos de trabalho ou qualquer substância resultante de instabilidade química não ataquem os materiais empregados no sistema de absorção. Inibidores de corrosão são geralmente empregados;

- Segurança: os fluidos de trabalho não devem ser tóxicos e nem substancialmente inflamáveis caso o sistema seja operado em ambientes ocupados por pessoas. Para aplicações industriais este requisito é menos crítico.

A Tabela 3.1 apresenta alguns dos pares refrigerante-absorvente utilizados. No entanto, este estudo se concentrará no processo absortivo utilizando o par amônia-água. 
Tabela 3.1 - Pares absorvente-refrigerante (Pohlman,1979; Sresnewsky,1983)

\begin{tabular}{|c|c|}
\hline Absorvente & Refrigerante \\
\hline Água & $\begin{array}{l}\text { Amônia, metil amina ou outras aminas } \\
\text { alifáticas }\end{array}$ \\
\hline Solução de água e brometo de lítio & Água \\
\hline Solução de cloreto de lítio e metanol & Metanol \\
\hline Ácido sulfúrico & Água \\
\hline Hidróxido de sódio ou potássio & Água \\
\hline Nitrato de lítio & Amônia \\
\hline Sulfocianeto de amônia & Amônia \\
\hline Tetracloroetano & Cloreto de etila \\
\hline Dimetil éter tetraetileno glicol & Cloreto de metileno \\
\hline Óleo de parafina & Tolueno ou pentano \\
\hline Glicol etílico & Metil amina \\
\hline Éter dimetílico ou glicol tetraetílico & Monofluor dicloro metano ou diclorometano \\
\hline
\end{tabular}

\subsection{Análise gráfica das propriedades termodinâmicas de misturas binárias}

O desempenho e a eficiência de ciclos reversíveis são independentes das propriedades do fluido de trabalho. Porém, o mesmo não pode ser dito para um ciclo real, no qual as propriedades dos fluidos de trabalho exercem influência significativa. Tanto o custo inicial, quanto o custo de operação de um sistema de absorção são fortemente dependentes das propriedades da mistura utilizada. A compreensão dos fenômenos envolvidos em um ciclo de refrigeração por absorção deve, portanto, passar pelo estudo das propriedades de misturas binárias.

No estudo dos sistemas de absorção, as variáveis termodinâmicas mais importantes são: pressão $(P)$, temperatura $(T)$, fração mássica $(X)$, entalpia 
específica (h), volume específico ( $v$ ) e entropia específica (s). Inúmeros diagramas relacionam duas propriedades termodinâmicas em seus eixos, enquanto que outras variáveis são apresentadas através de curvas de propriedades constantes como isobáricas ou isotérmicas. Usualmente, diagramas $T$-s, $\ln (P)-h$ ou $h$-s são utilizados em cálculos de ciclos em que o fluido de trabalho é uma substância pura. Entretanto, em processos de absorção, uma variável adicional, a composição, deve ser considerada. Historicamente, os diagramas mais utilizados são os de temperaturafração mássica $(T-x)$ e os de entalpia-fração mássica $(h-x)$.

Considerando uma mistura de dois componentes (binária). Do ponto de vista termodinâmico, essa mistura apresenta um grau de liberdade adicional quando comparada com uma substância pura, que é a fração mássica, cuja definição é apresentada na Eq. (3.1).

$$
x=\frac{\text { massa de um dos componentes }}{\text { massa da mistura }}
$$

Nos diagramas $T-x$, quando as fases líquida e vapor coexistem em equilíbrio, a temperatura de saturação varia com a fração mássica, enquanto a pressão é mantida constante. A Fig. 3.2 apresenta um diagrama $T-x$ para uma mistura de dois componentes, $A$ e $B$, a pressão constante. A escala do eixo da fração mássica varia de 0 (onde apenas o componente A está presente) até 1 (onde apenas 0 componente $B$ está presente). A área abaixo da linha de ebulição representa um líquido sub-resfriado. A área acima da linha de condensação representa vapor superaquecido. Já a área entre as linhas de ebulição e condensação é uma região bifásica.

O ponto de bolha para uma mistura de fração mássica " $x$ " está localizado sobre a linha de ebulição na correspondente fração mássica. A linha de ebulição indica a temperatura na qual a primeira bolha de vapor é formada para a correspondente pressão e fração mássica. Os pontos de bolha para componentes puros, $T_{A}$ e $T_{B}$, são encontrados nas respectivas ordenadas e observa-se que 0 ponto de bolha do componente $A$ é mais alto do que o do componente $B$. A linha de 
condensação indica a temperatura na qual a primeira gota de líquido é formada quando uma mistura gasosa a uma dada fração mássica é resfriada.

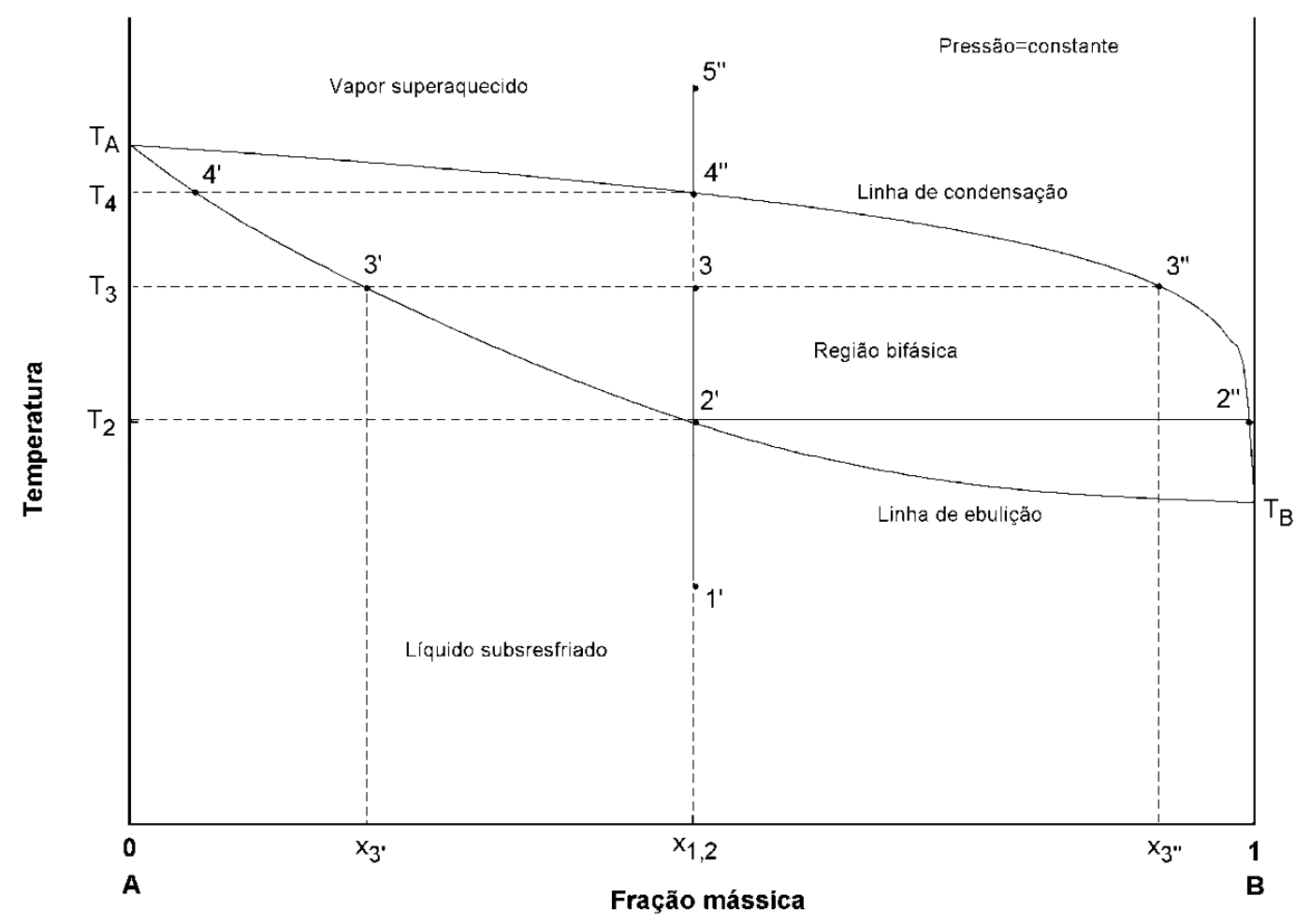

Figura 3.2 - Diagrama $T-x$

\subsubsection{Processo de refrigeração por absorção no diagrama $h-x$}

Tomando-se como referência o ciclo de refrigeração exposto na Fig. 3.1, observa-se que a pressão no evaporador $P_{E}$ é igual à pressão no absorvedor $P_{A}$ e a pressão no gerador $P_{G}$ é a mesma do condensador $P_{C}$. Na prática, o escoamento ocorre do evaporador para o absorvedor, pois $P_{E}$ é maior que $P_{A}$ e, similarmente, do gerador para o condensador, já que $P_{G}$ é maior que $P_{C}$.

Em geral, $P_{1}$ e $P_{2}$ são as pressões de saturação nas temperaturas do evaporador e condensador, respectivamente. No caso da mistura que entra no evaporador não ser composta apenas por refrigerante puro, ou seja, $x<1$, todo 0 líquido no evaporador pode não evaporar. Dessa forma, para essa mistura bifásica, 
a pressão no evaporador não corresponde à pressão de saturação da amônia pura. Durante os processos de ebulição e de condensação, a temperatura da mistura binária não se mantém constante.

No absorvedor, ocorre permanentemente a mistura da solução pobre com vapor. Assim, o estado "1", que está representado no diagrama entalpia-fração mássica $(h-x)$ da Fig. 3.3, é geralmente um estado saturado. Para o caso em questão, o estado "1" localiza-se na intersecção entre linha isobárica de 1,75 bar e a temperatura de $25^{\circ} \mathrm{C}$ na região de líquido.

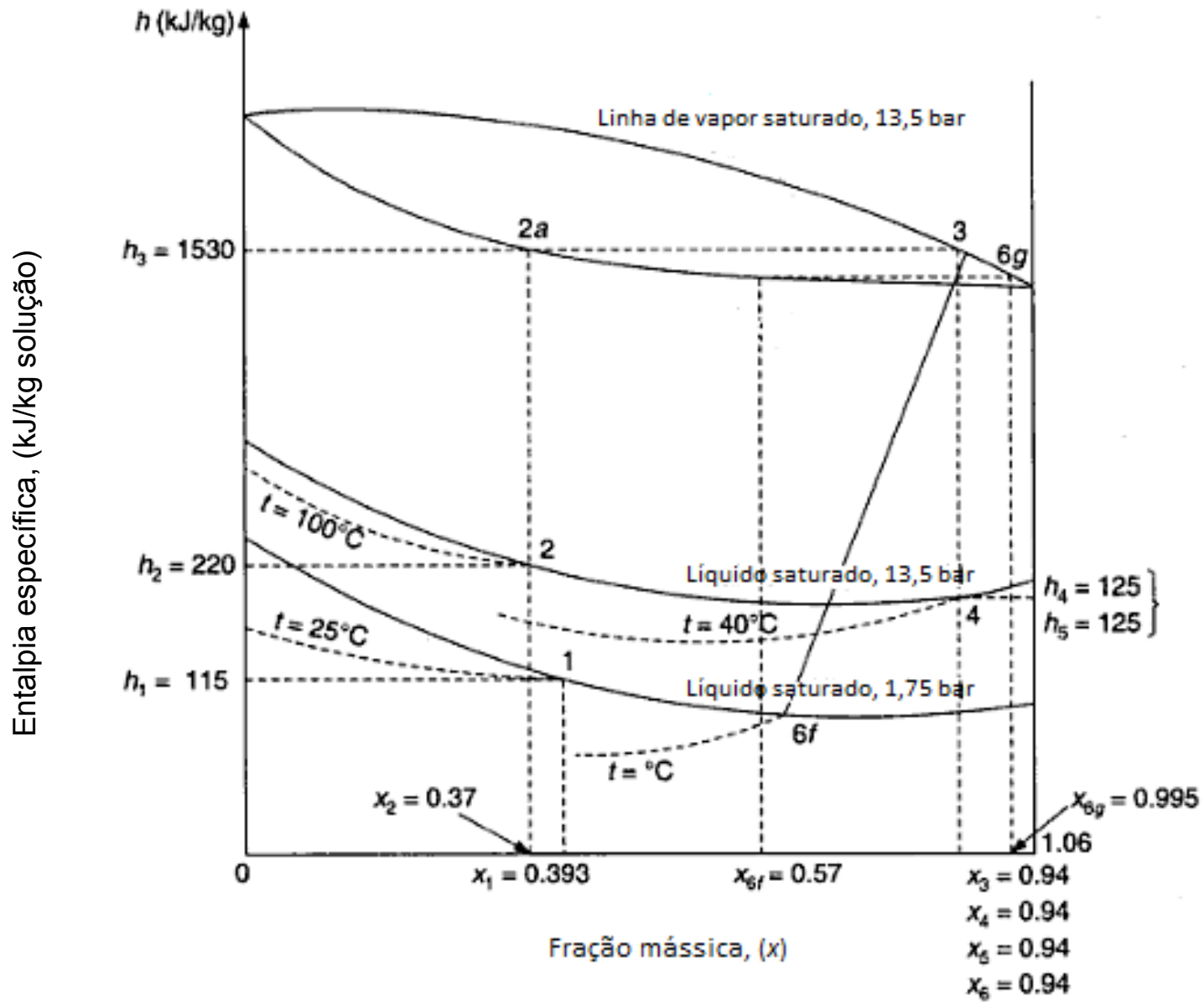

Figura 3.3 - Diagrama fração mássica-entalpia do ciclo de refrigeração por absorção (Ahora, 2010) 
No gerador ocorre a ebulição da solução rica, havendo equilíbrio entre as fases líquida e vapor. Portanto, o estado "2" é de líquido saturado, localizado na intersecção entre a isobárica de 13,5 bar e a temperatura de $100^{\circ} \mathrm{C}$ na região de líquido. Já o estado "3" é de vapor saturado e sua localização é feita através de uma linha vertical tracejada a partir de "2" interceptando a linha de líquido saturado a 13,5 bar no ponto "2a". A partir deste ponto, segue-se uma linha tracejada horizontal, a qual intercepta a curva de vapor saturado a 13,5 bar, encontrando-se o ponto "3".

A concentração de amônia não se altera no condensador, na válvula de expansão e no evaporador, desde que nenhuma quantidade de água ou de amônia seja adicionada ou removida ao longo do processo. Isso indica que os estados " 3 ", "4", "5" e "6" estarão todos alinhados na linha vertical, correspondendo a $x_{3}=x_{4}=x_{5}=x_{6}=$ constante

Se for assumido que todo o vapor é condensado no condensador, então a corrente "4" é de líquido saturado. Este ponto pode ser localizado no diagrama $h-x$ através da intersecção entre a isobárica de 13,5 bar e $x_{4}=0,94$. Neste caso, não é necessário estabelecer a temperatura na saída do condensador, já que a mesma é fixada automaticamente por $x_{3}=x_{4}$ e por $P_{2}$.

Se a solução que deixa o condensador for sub-resfriada, então sua temperatura será inferior $40^{\circ} \mathrm{C}$. Por outro lado, cas o a condensação seja incompleta, havendo mistura de líquido e vapor, necessariamente a temperatura da solução condensada será maior que $40^{\circ} \mathrm{C}$.

A entalpia se mantém constante durante o processo que ocorre na válvula de expansão, "4" para "5" (processo isoentálpico). Assim, $x_{5}=x_{4}$ e $h_{5}=h_{4}$. Se a entalpia e a concentração são as mesmas, então os pontos são coincidentes no diagrama $h$ - $x$. No entanto, $P_{4}=P_{2}>P_{1}=P_{5}$. Por isso, o estado "5" se localiza na região bifásica (líquido e vapor) a 1,75 bar.

A pressão de saturação da amônia a $0^{\circ} \mathrm{C}$ é 4,29 bar e a pressão do evaporador é 1,75 bar, menor que 4,29 bar. Dessa maneira, o estado da solução a 1,75 bar, $0^{\circ} \mathrm{C}$ e $x=0,94$ é localizado através do traçado desde a isoterma de $0^{\circ} \mathrm{C}$ pela linha $6 f-6 g$ encontrando sua intersecção com $x_{3}=x_{6}=0,94$, conforme observado na Fig. 3.3. 


\subsection{A Amônia}

A amônia, conhecida por seu odor característico e irritante, é um gás incolor resultante da combinação direta do nitrogênio com hidrogênio sob temperatura elevada, sendo comercializada normalmente na forma de solução aquosa. Possui grande aplicabilidade na indústria de fertilizantes e é fonte de vários outros compostos nitrogenados comercialmente importantes.

Sua estrutura molecular apresenta ligações covalentes polares entre os átomos de nitrogênio e hidrogênio. Em função dessa característica sua estrutura possui grande momento dipolar, o que consequentemente a caracteriza como uma molécula polar, possuindo geometria piramidal triangular. Como pode ser verificado na Fig.3.4, o átomo de nitrogênio é o vértice da pirâmide, e os átomos de hidrogênio formam a base triangular.

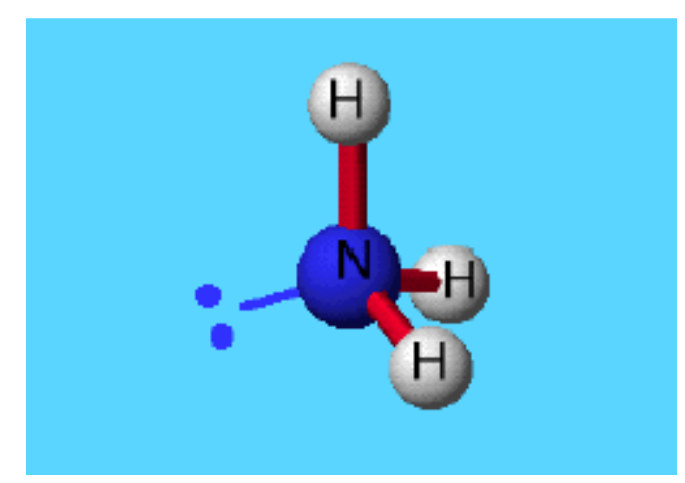

Figura 3.4 - Representação da molécula de amônia (Sahakhashiri, 2008)

O arranjo eletrônico da molécula de amônia obedece à regra do octeto. Os quatro pares de elétrons (três pares em ligação e dois sem ligação) se repelem conferindo a molécula sua geometria não-planar.

A amônia é obtida industrialmente através da reação catalítica de nitrogênio e hidrogênio (Thomas e Parks, 2006). Embora os processos produtivos tenham evoluído ao longo dos anos, atualmente o processo básico de reação é idêntico ao desenvolvido por Haber e Bosch no início do século XX. Abordando de forma simplificada, o processo Haber-Bosch é na realidade uma reação de equilíbrio químico, entre nitrogênio e hidrogênio, altamente exotérmica na direção de formação 
de amônia. O nitrogênio é obtido através do ar atmosférico previamente separado fracionadamente e o hidrogênio é produzido a partir do gás natural.

$$
\mathrm{N}_{2}(g)+3 H_{2}(g) \leftrightarrow 2 \mathrm{NH}_{3}(g) \quad \Delta H=-92 \mathrm{~kJ} / \mathrm{mol}
$$

Para se elevar a quantidade produzida de $\mathrm{NH}_{3}$ no menor tempo possível. Haber se baseou em dois fatores: pressão e catalisador. $O$ aumento da pressão desloca o equilíbrio para a direita, no sentido de menor volume, e o catalisador faz com que o equilíbrio seja alcançado no menor tempo possível. Porém esses dois fatores ainda não são suficientes, já que existe a necessidade de se aumentar a velocidade do processo. A melhor alternativa é aumentar a temperatura, porém como a reação direta é exotérmica, essa elevação da temperatura aumenta a velocidade do processo deslocando o equilíbrio para a esquerda e isso não é conveniente (a temperaturas menores a porcentagem de conversão é maior, porém a reação atinge o equilíbrio muito lentamente). É neste ponto que se destaca o mérito de Haber, que chegou a condições economicamente aceitáveis para produzir amônia conciliando três fatores fundamentais: pressões na faixa de 200 a $400 \mathrm{~atm}$, temperaturas entre $380^{\circ}$ e $450^{\circ} \mathrm{C}$ e a mistura $\mathrm{Fe}_{2} \mathrm{O}_{3}$ e $\mathrm{Fe}_{3} \mathrm{O}_{4}$ como agente catalisador.

\subsection{Ciclo de refrigeração por absorção amônia-água}

O primeiro sistema de refrigeração intermitente foi construído em 1810 por Sir John Leslie utilizando o par água-ácido sulfúrico. O equipamento era construído por dois reservatórios interligados e evacuados, sendo que a água contida em um dos reservatórios absorvia o ácido sulfúrico contido no outro (Cortez, 1998).

O primeiro registro de patente de um ciclo de refrigeração por absorção de amônia de funcionamento contínuo é datado de 1859 nos Estados Unidos por Ferdinand Carré. Este sistema era utilizado com a finalidade de produzir gelo e conservar alimentos.

O par amônia-água tem sido largamente utilizado pelo fato de ambos serem altamente estáveis em uma grande faixa de temperatura e pressão. A amônia possui 
também uma elevada entalpia de vaporização, condição fundamental para um desempenho eficiente do sistema. Além disso, permite o alcance de temperaturas de resfriamento extremamente baixas, já que seu ponto de congelamento é $-77^{\circ} \mathrm{C}$ (Darwish et al., 2008).

É importante salientar, que outros pares de substâncias funcionam como absorvente e refrigerante. Como, por exemplo, água como refrigerante e brometo de lítio ( $\mathrm{LiBr}$ ) como absorvente, utilizados em sistemas de refrigeração por absorção desde 1950. Entretanto, tais sistemas são limitados a temperaturas de refrigeração superiores a $0{ }^{\circ} \mathrm{C}$. Além disso, o brometo de lítio cristaliza-se a pressões moderadas, havendo a necessidade de o sistema operar a vácuo, fato que ocasiona infiltrações de ar no sistema.

Como a amônia é uma substância tóxica, sua utilização é limitada a áreas bem ventiladas. Por outro lado, o forte odor da amônia facilita a detecção de vazamentos, indicando a necessidade de manutenção no sistema. Apesar das restrições referentes à segurança, no emprego da amônia como refrigerante, existem muitas vantagens decorrentes da sua utilização. São elas:

- baixo peso molecular, permitindo alta velocidade através das válvulas de expansão e a utilização de um menor volume de refrigerante se comparado ao volume necessário com hidrocarbonetos na mesma faixa de pressão;

- utilização em uma grande faixa de temperaturas, desde as de congelamento até as temperaturas altas de bombas de calor;

- alta entalpia de evaporação e reduzido peso molecular, possibilitando a utilização de tubos mais estreitos, reduzindo os custos de válvulas e encaixes;

- troca de calor durante a evaporação e a condensação mais eficientes se comparadas às obtidas com hidrocarbonetos, que implica em áreas menores de troca de calor;

- vantagem da operação em pressões positivas, não havendo necessidade de sistemas de purga de ar.

O ciclo simplificado de um sistema de refrigeração por absorção já foi mostrado na Fig. 3.1. No entanto, modificações são empregadas com a finalidade de 
melhorar seu desempenho. Uma alteração bastante comum é a inserção de um trocador de calor líquido-líquido entre o absorvedor e o gerador, conhecido na literatura como Trocador de Calor de Solução - TCS (Solution Heat Exchanger SHX), o qual permite o pré-aquecimento da solução rica antes de entrar no gerador e o pré-resfriamento da solução pobre antes de entrar no absorvedor. Dessa maneira, a quantidade de calor demandada no gerador é reduzida ao mesmo tempo em que também se reduz a carga térmica a ser removida no absorvedor.

Um parâmetro fundamental na análise de sistemas de refrigeração é o coeficiente de desempenho (COP), apresentado na Eq. 3.3, definido como sendo a relação entre o efeito útil de refrigeração (calor retirada pelo evaporador) e a taxa de adição de calor ao gerador.

$$
C O P=\frac{\text { Efeito útil de refrigeração }}{\text { Taxa de adição de calor ao gerador }}=\frac{\dot{Q_{E}}}{\dot{Q}_{G}}
$$

De acordo com Srikhirin et al. (2001), o trocador de calor permite que a solução advinda do absorvedor seja pré-aquecida antes de sua entrada no gerador, através da utilização do calor proveniente da solução a maior temperatura que deixa o gerador. Dessa maneira, o valor do COP pode ser melhorado, já que a quantidade de calor que deverá ser alimentada no gerador é reduzida. Além disso, o tamanho do absorvedor pode ser reduzido, já que menor quantidade calor deverá ser rejeitada. Segundo Aphornratana (1995), estudos experimentais apontam que o COP pode ser incrementado em cerca de $60 \%$ quando um TCS é empregado no ciclo.

Outra modificação empregada é o uso de um trocador de calor entre o condensador e o evaporador, denominado na literatura de pré-resfriador (precooler ou Refrigerant Heat Exchange-RHX). Através desse incremento no ciclo, o vapor de fluido refrigerante que deixa o evaporador, resfria o fluido refrigerante líquido proveniente do condensador. Dessa forma, o desempenho do ciclo é otimizado, na medida em que diminui a quantidade de vapor de flash (vapor formado bruscamente pela descompressão na válvula de expansão) (Makiyama, 2008). Em seu trabalho, Aguilar (2010) afirma que quando a amônia passa pela válvula de expansão VE:A, 
tem sua pressão e temperatura reduzidas e no evaporador ela muda somente de estado, (líquido para vapor), conservando sua temperatura baixa. Essa temperatura será aproveitada para sub-resfriar a amônia líquida que deixa o condensador, elevando a capacidade de resfriamento do evaporador. O ciclo acrescentado dos dois trocadores de calor pode ser visualizado na Fig. 3.5.

Quando calor é fornecido ao gerador, a amônia líquida evapora com certa quantidade de água associada, formando vapor de amônia "úmido". Se essa pequena quantidade de água chegar até o evaporador, poderá ser continuamente acumulada, diminuindo a pressão de evaporação e reduzindo drasticamente a eficiência do sistema. Portanto, é importante que se obtenha um vapor de amônia tão puro quanto possível, garantindo assim a confiabilidade e eficiência do ciclo (Herold et al.,1996). A tarefa de purificar o vapor de amônia é atribuída ao componente denominado retificador, esquematizado em conjunto com o ciclo na Fig. 3.6.

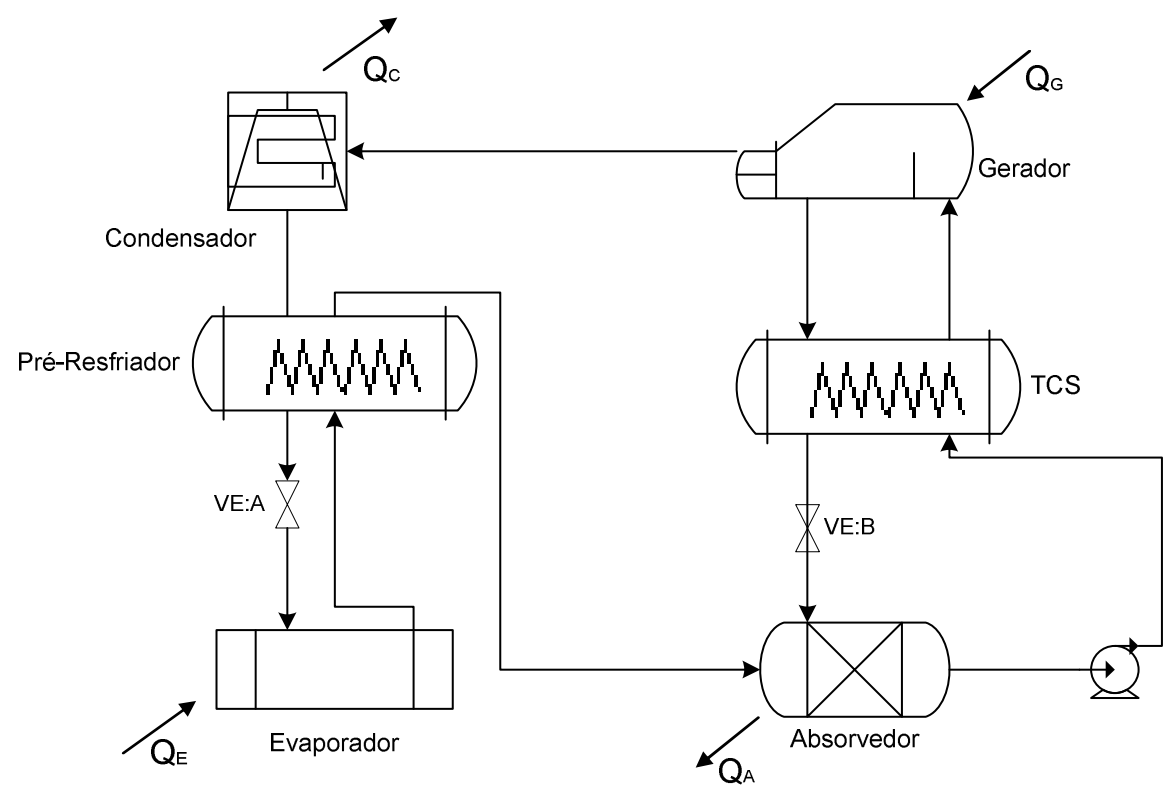

Figura 3.5 - Ciclo de refrigeração por absorção simples efeito com pré-resfriador e trocador de calor de solução.

No retificador, o vapor de água associado ao vapor de amônia é condensado através da remoção de calor. O processo envolve a condensação e retorno de uma pequena fração do vapor ao gerador, significando que uma pequena parcela da 
carga térmica fornecida ao sistema não produz efeito de refrigeração, o que consequentemente contribui para reduzir a eficiência do ciclo como um todo.

A avaliação das consequências da existência de elevadas porcentagens de água no vapor refrigerante, presente no evaporador de um chiller por absorção água-amônia, foi realizada por Fernández-Seara e Sieres (2006), onde concluíram que a água presente no vapor de amônia apresenta grande influência no COP do sistema. O comportamento do COP em função da concentração de refrigerante no evaporador é representado na Fig. 3.7, onde se observa que quanto maior a pureza do refrigerante no evaporador, maior o COP do ciclo.

Ortigosa (2008) confirma em seus resultados a influência do retificador e do TCS no ciclo de refrigeração por absorção água-amônia, através da comparação de valores de COP de um modelo simplificado, com valores de COP de modelos mais elaborados, os quais possuem retificador e TCS em suas configurações. A Tabela 3.2 apresenta os valores de COP obtidos por Ortigosa para cada modelo implementado.

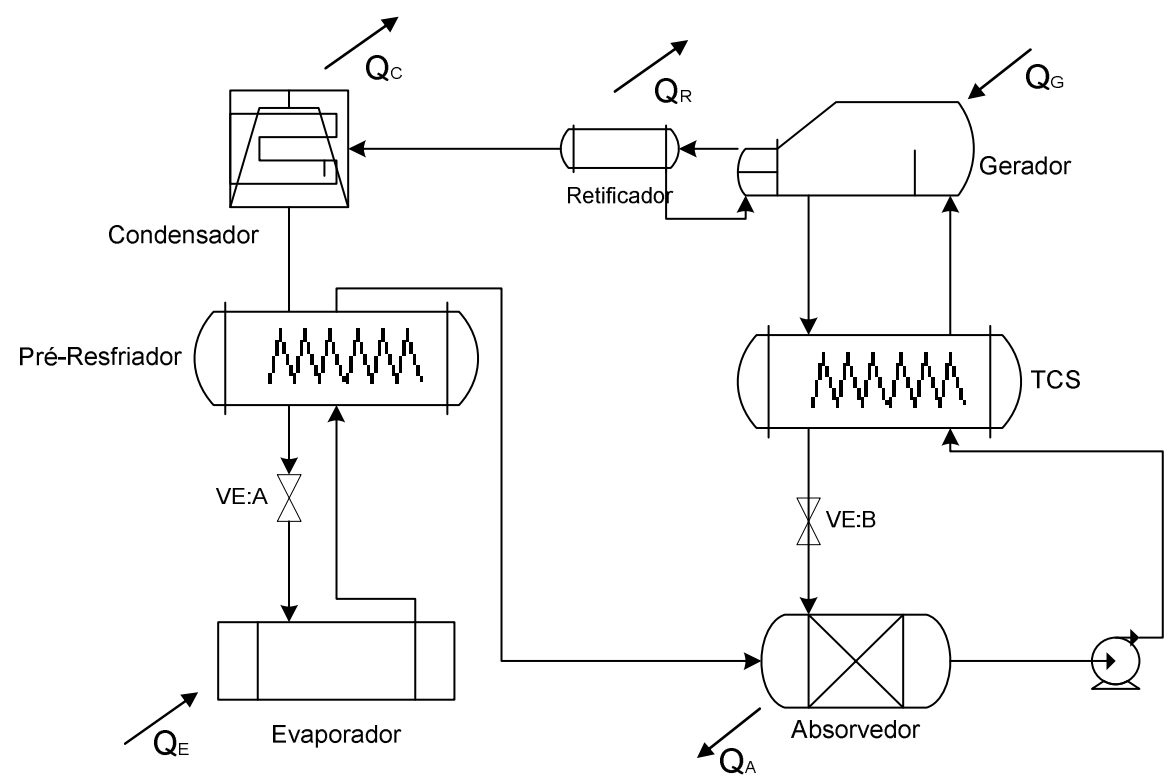

Figura 3.6 - Ciclo de refrigeração por absorção simples efeito com préresfriador, trocador de calor de solução e retificador

Em um ciclo de refrigeração por absorção, o absorvedor na maioria das vezes é resfriado com água ou ar à temperatura ambiente, fazendo com que a temperatura 
da solução advinda de seu interior gire em torno de $40^{\circ} \mathrm{C}$. Dessa forma, aproveitase essa solução para retirar calor do retificador, o qual abriga vapor de amônia "úmido", a uma temperatura superior. Após a passagem dessa corrente pelo retificador, a mesma segue para o TCS sendo pré-aquecida através da troca de calor com a solução pobre à alta temperatura que deixa o gerador em direção ao absorvedor. Essa alteração no ciclo é esquematizada na Fig. 3.8.

Com a finalidade de melhorar o desempenho dos ciclos de refrigeração por absorção, são empregadas configurações "multi-efeito", ou seja, o sistema é arranjado de forma que energia térmica a uma temperatura mais alta seja utilizada como alimentação em um estágio de temperatura mais baixa, gerando efeito de refrigeração adicional.

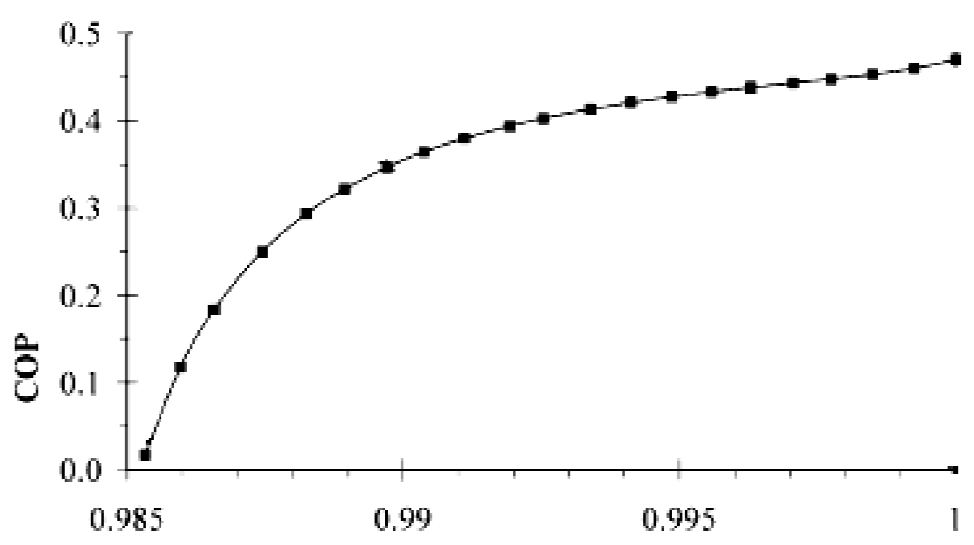

Figura 3.7 - COP do sistema em função da concentração de refrigerante no evaporador (Fernandez-Seara e Sieres, 2006)

Um ciclo de absorção amônia-água de duplo-efeito pode ser considerado a combinação de dois ciclos de simples-efeito separados, onde evaporador e condensador podem ser considerados uma única unidade. Dessa forma, existem apenas dois níveis de pressão no sistema, e a pressão máxima pode ser limitada a um nível aceitável. 
Tabela 3.2 - Valores de COP para cada modelo implementado (Ortigosa, 2007)

\begin{tabular}{cc}
\hline Modelo & COP \\
\hline Simplificado & 0,1886 \\
Com retificador & 0,1929 \\
Com retificador e TCS & 0,5031 \\
Ciclo Comercial & 0,6259 \\
\hline
\end{tabular}

Observa-se na Fig. 3.9 que, calor da fonte externa é fornecido somente ao gerador "1" e o calor de absorção do absorvedor "1" é quem alimentará o gerador "2". Neste caso, evaporador e condensador têm suas demandas redobradas, já que recebem amônia de duas unidades de retificação.

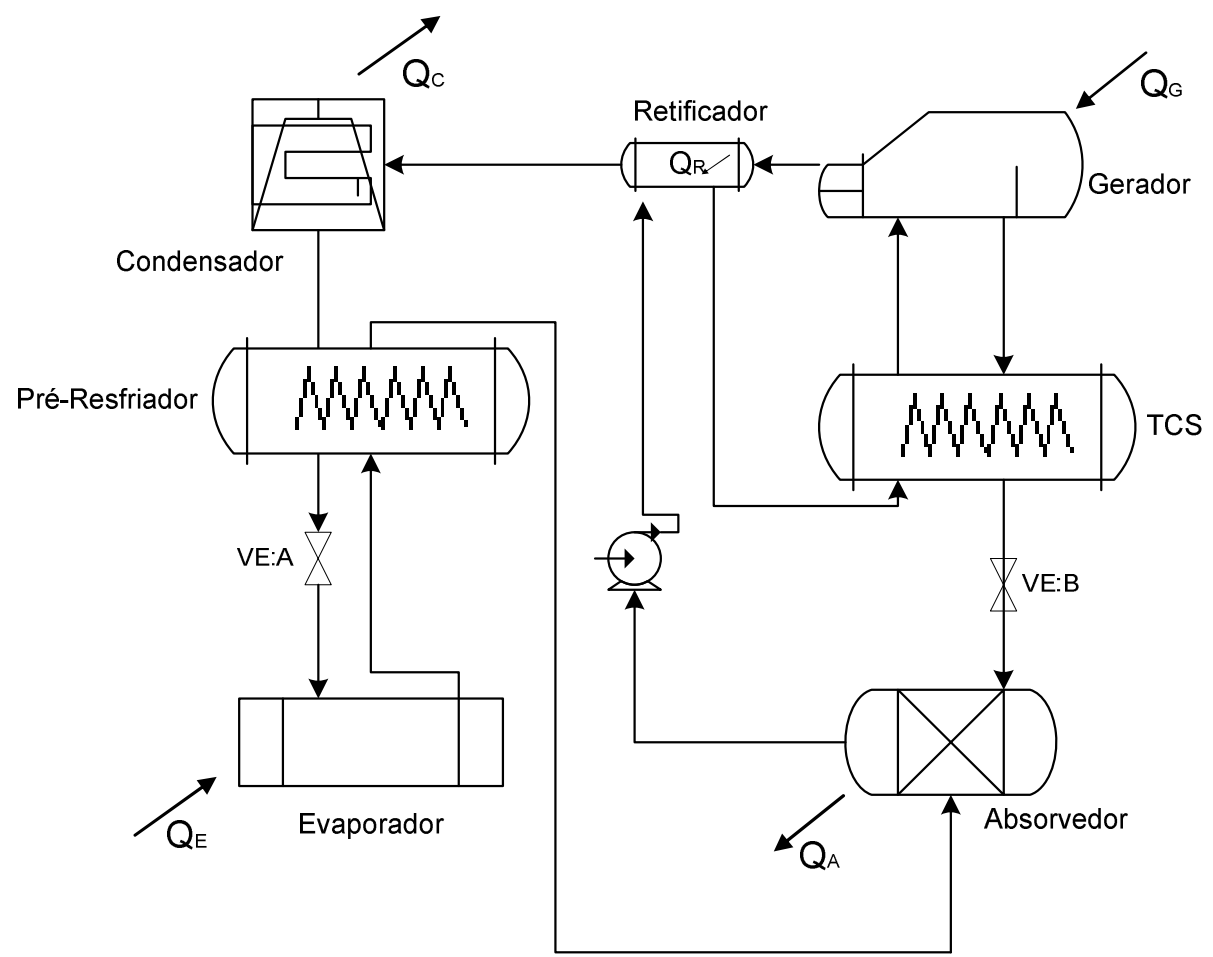

Figura 3.8 - Ciclo de refrigeração por absorção simples efeito com préresfriador, trocador de calor de solução e troca de calor no retificador 
Srikhirin et al. (2001) afirmam que, pelo fato da água ser o absorvente, não existe problema de cristalização nos absorvedores, situação bastante frequente em ciclos que operam com o par brometo de lítio-água. Assim, o absorvedor "1” pode trabalhar à alta temperatura rejeitando calor suficiente para o gerador " 2 ".

Existem diversos estudos a respeito de ciclos de triplo-efeito e quádruploefeito. No entanto, segundo Grossman et al. (1995), o aumento do COP não está diretamente relacionado ao incremento do número de efeitos, observando que, quando há um aumento desse número, o COP de cada efeito não será proporcionalmente elevado. Além disso, um maior número de efeitos é responsável por elevar demasiadamente a complexidade do sistema.

Deve-se considerar a temperatura da fonte térmica ao se selecionar o tipo de ciclo de refrigeração por absorção. Foley et al. (2000) apresentam, na Tabela 3.3, os tipos de ciclos correspondentes a cada faixa de temperatura, assim como 0 equipamento capaz de originar a fonte de calor correspondente.

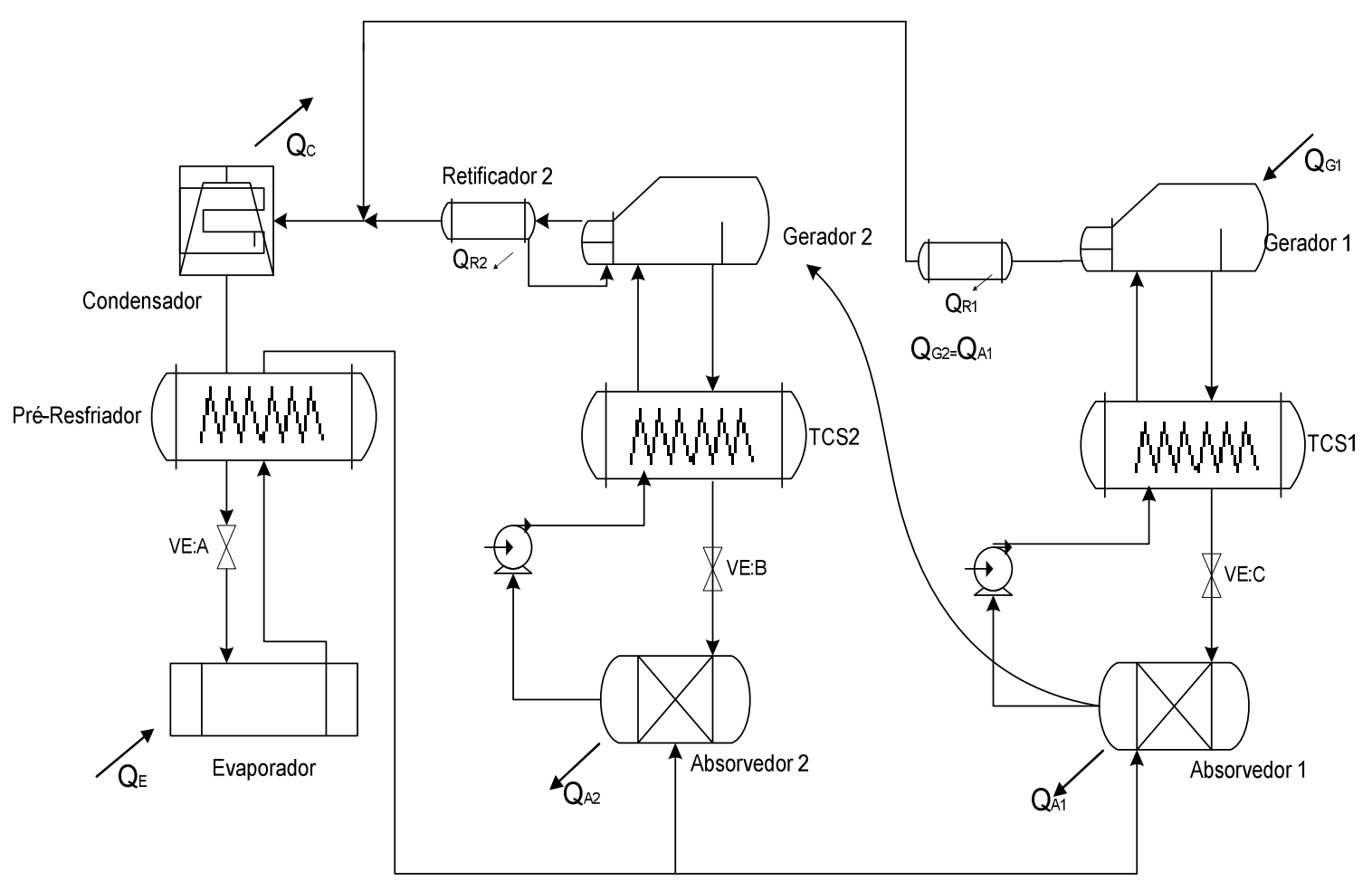

Figura 3.9 - Ciclo de refrigeração por absorção duplo efeito

Uma modificação que tem sido muito pesquisada e empregada é o sistema GAX (Generator-absorber heat exchanger), patenteado em 1914 por Altenkirch e 
Tenckhoff, o qual é caracterizado pelo pré-aquecimento e pré-resfriamento das soluções rica e pobre, que é realizado da seguinte forma: a solução à menor temperatura, depois de deixar o absorvedor, é introduzida novamente no meio do mesmo absorvedor de forma que, através das paredes de tubos finos, receba calor da absorção desta seção do absorvedor, sendo assim pré-aquecida antes de entrar no gerador. A solução de maior temperatura, que deixa o gerador, é introduzida novamente na seção do meio do gerador, no qual, através das paredes dos tubos, rejeita calor para a solução sendo pré-resfriada. O resultado dessa configuração é que a demanda de resfriamento e aquecimento externos é reduzida. O TCS é suprimido e a troca de calor entre as duas soluções oriundas desses componentes é feita no interior dos mesmos (Makiyama, 2008).

Tabela 3.3 - Fontes de calor adequadas a cada tipo de ciclo (Foley, 2000)

\begin{tabular}{ccc}
\hline Fonte de Calor & Temperatura $\left({ }^{\circ} \mathbf{C}\right)$ & Tipo do Ciclo \\
\hline Turbina a gás & $>540$ & $\begin{array}{c}\text { Triplo, duplo e simples } \\
\text { efeito }\end{array}$ \\
$\begin{array}{c}\text { Células de combustível de } \\
\text { óxido sólido }\end{array}$ & $\sim 490$ & $\begin{array}{c}\text { Triplo, duplo e simples } \\
\text { efeito }\end{array}$ \\
Micro-turbina & $\sim 315$ & $\begin{array}{c}\text { Triplo, duplo e simples } \\
\text { efeito }\end{array}$ \\
$\begin{array}{c}\text { Células de combustível de } \\
\text { ácido fosfórico } \\
\text { Motor de combustão } \\
\text { interna }\end{array}$ & $\sim 120$ & Duplo e simples efeito \\
Células de Combustível & $\sim 82$ & Simples efeito \\
\hline
\end{tabular}

\subsection{Aspectos termodinâmicos do processo de absorção}

Herold et al.(1996) explicam que o termo absorção descreve a transferência de uma substância no estado de vapor para uma substância no estado líquido ou sólido. O processo é semelhante à condensação, uma vez que pré-existe uma fase condensada na entrada do absorvedor, conforme se visualiza na Fig. 3.10. 
A corrente de vapor, denominada pelo subscrito "2", entra no absorvedor acompanhada da corrente de líquido, subscrito "1". Após o vapor ser absorvido pela fase líquida, no interior do equipamento, e a energia térmica de absorção liberada, obtém-se a corrente de solução líquida rica "3". Realizando-se o balanço de energia do absorvedor obtém-se a quantidade de calor liberada por unidade de massa de vapor absorvido no processo, dada pela Eq. 3.3.

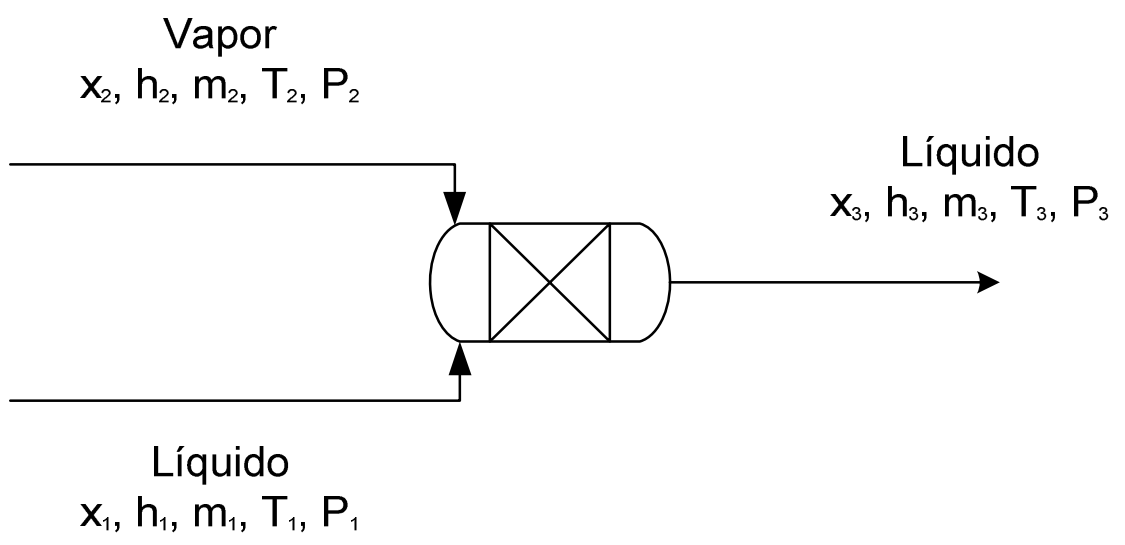

Figura 3.10 - Esquema do processo de absorção (adaptado, Herold, 1996)

Nesta equação existem dois termos. O primeiro $\left(h_{2}-h_{1}\right)$ representa a mudança de fase do vapor e o segundo $f\left(h_{1}-h_{2}\right)$ representa o resfriamento da solução. $O$ processo de absorção pode ser mais bem compreendido no diagrama $h$-x presente na Fig. 3.11.

$$
q=h_{2}-h_{1}+f\left(h_{1}-h_{3}\right)
$$

Onde $f$ é a razão $\dot{m_{3}} / \dot{m}_{2}$

Assume-se que as correntes "1" e "3" são de líquido saturado e o ponto "2" no diagrama representa o vapor à mesma pressão das correntes líquidas, Contudo, esse vapor não está necessariamente em equilíbrio termodinâmico. Na verdade, o vapor poderia ser superaquecido (o ponto "2" estaria localizado acima da linha 
isobárica), poderia conter gotículas de líquido (o ponto "2" estaria localizado na região bifásica) ou poderia ter uma fração mássica diferente da indicada na figura.

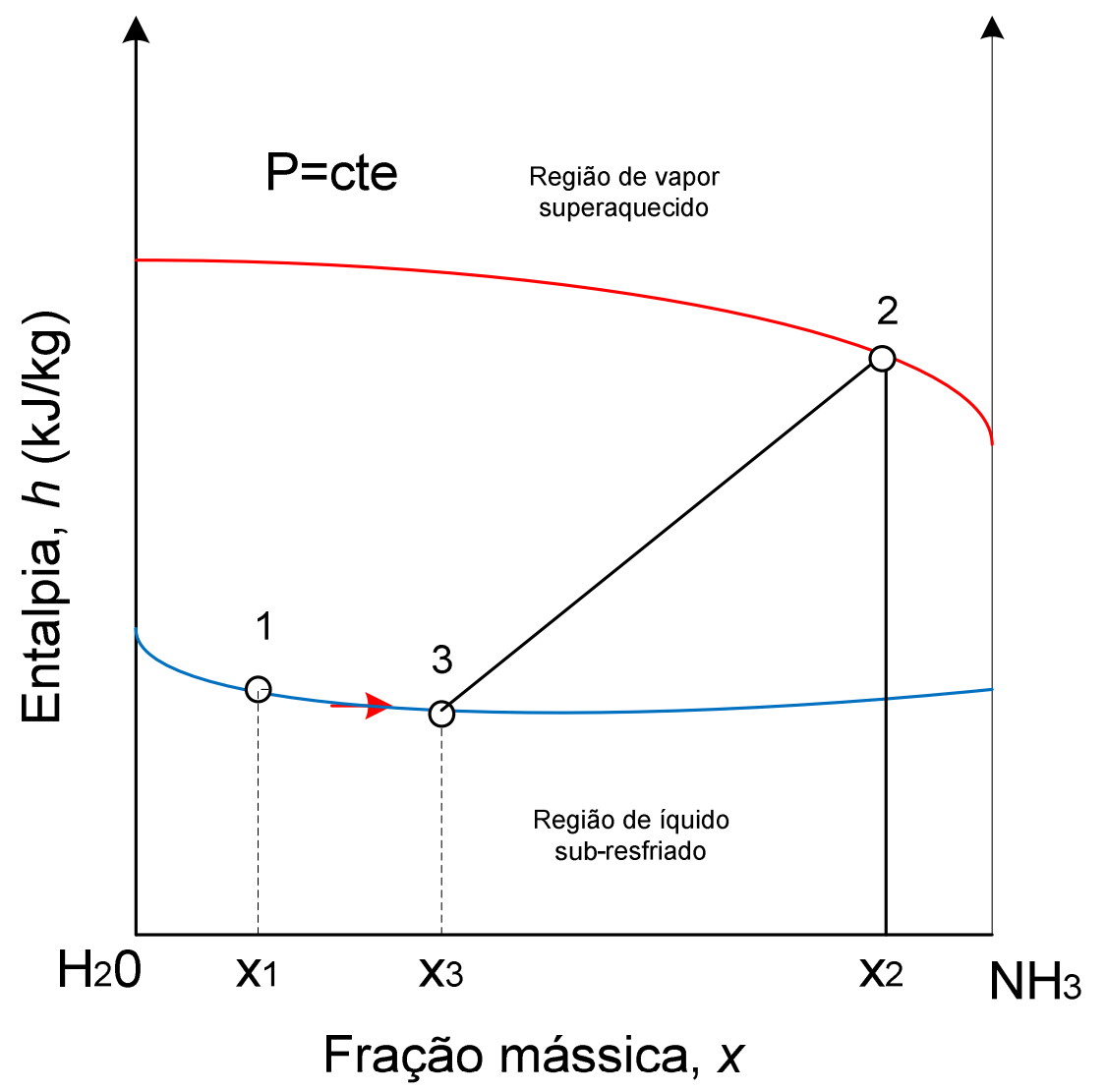

Figura 3.11 - Processo de absorção no diagrama $h$-x

A quantidade de calor liberada no absorvedor pode ser mostrada graficamente na Fig. 3.12. Para isso, a Eq. 3.3 é rearranjada de maneira a introduzir $h_{a}$

Do diagrama, temos que:

$$
q=h_{2}-h_{a}
$$

Onde:

$$
h_{a}=h_{1}-f\left(h_{1}-h_{3}\right)
$$




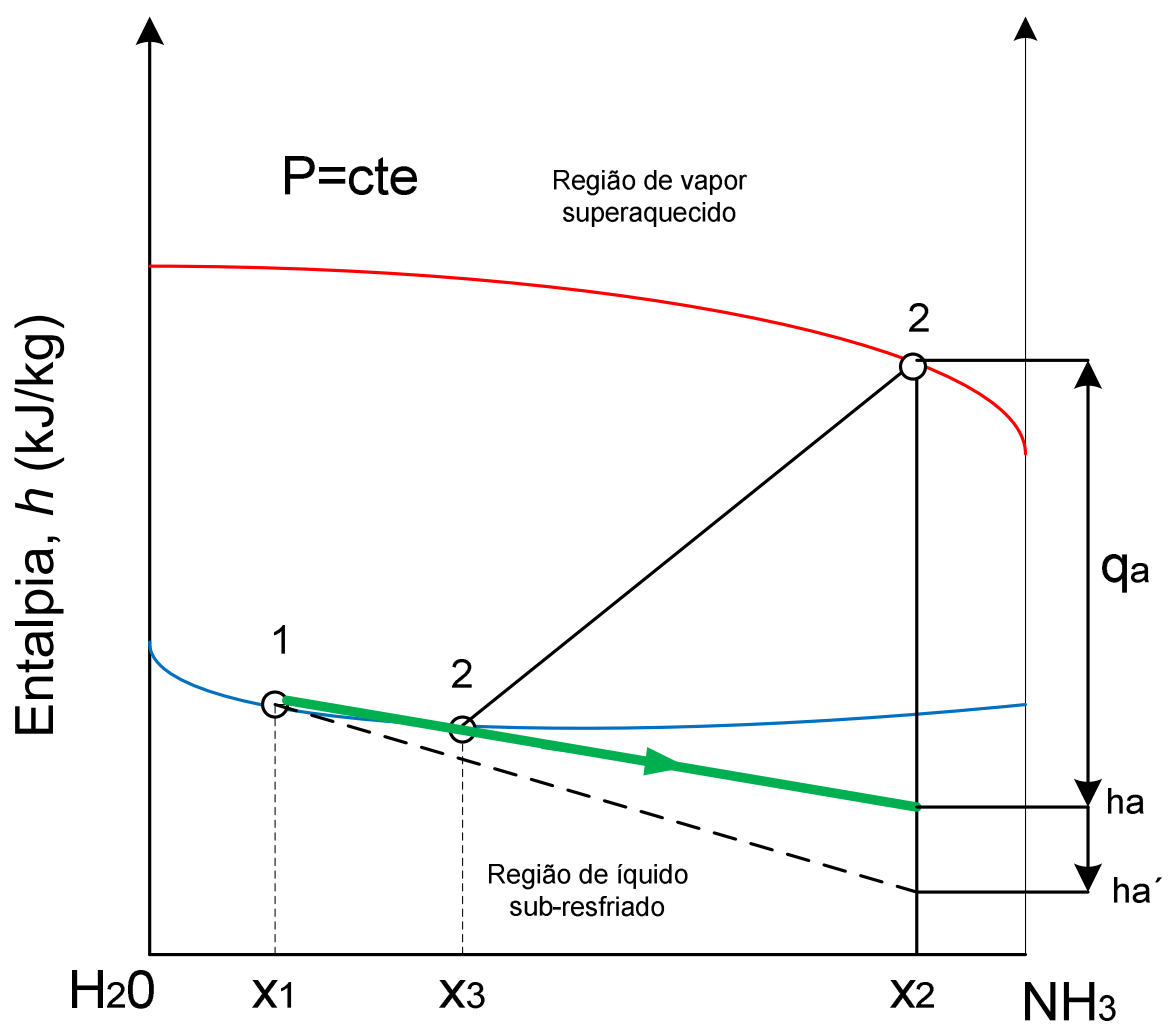

Figura 3.12 - Processo de absorção no diagrama $h$-x com fluxo de saída sub-resfriado

\subsection{Atividade química no processo de absorção da amônia}

Segundo Seader e Henley (1998), em qualquer processo de absorção, antes de se iniciar a análise dos fenômenos de transferência de calor e massa é necessário se certificar de que o refrigerante e o absorvente não possuam tendência a reagir significativamente, resultando na dissociação das espécies envolvidas. Geralmente, quando água e hidrocarbonetos são utilizados como absorventes, nenhuma reação química significativa ocorre e o processo é considerado uma absorção física. Portanto, a absorção do vapor de amônia pela solução pobre é uma absorção física. Essa condição pode ser verificada através da constante de equilíbrio da reação, que ocorre quando amônia e água são misturadas.

$$
\mathrm{NH}_{3}+\mathrm{H}_{2} \mathrm{O} \Leftrightarrow \mathrm{NH}_{4}^{+}+\mathrm{OH}^{-}
$$


Esta reação tem constante de equilíbrio $K_{C}$, igual a $1,8 \times 10^{-5}$ (adimensional), valor bastante pequeno, o que significa que a maioria da amônia se mantém intacta quando absorvida pela solução pobre de amônia e água. Portanto, a possibilidade de dissociação das espécies pode ser seguramente desprezada.

\subsection{Transferência de Massa Gás-Líquido}

Treyball (1981) apresenta uma abordagem clássica das operações que envolvem transferência de massa, fornecendo os fundamentos e servindo como base para praticamente todas as modelagens que envolvam esses processos. $O$ mesmo autor afirma que, na maior parte das operações que envolvem transferência de massa, duas fases insolúveis estão em contato com o intuito de permitir a transferência de um de seus constituintes de uma fase à outra. A taxa de difusão de um constituinte em cada fase, depende do seu gradiente de concentração nesta fase e, ao mesmo tempo, o gradiente de concentração do sistema bifásico é o indicativo do desequilíbrio que existe entre as duas fases. Estabelecido o equilíbrio, o gradiente de concentração e a taxa de difusão tendem a zero. Deve-se, entretanto, considerar as características do equilíbrio de uma operação em particular. Para o processo de absorção de amônia dissolvida em ar ou em água, as concentrações de equilíbrio na fase líquida e na fase vapor dependem apenas da temperatura e da pressão em que se encontra o sistema e não depende da quantidade de água ou ar. No equilíbrio, as concentrações de amônia nas duas fases não são iguais, ao passo que seu potencial químico sim. Em outras palavras, o que reduz a zero a transferência líquida de amônia de uma fase a outra é a igualdade dos potenciais químicos. Em um sistema distante do equilíbrio, a taxa de difusão pode, em termos da força motriz, ser determinada.

Considerando-se um filme líquido de água descendente e uma mistura de ar e amônia em contracorrente, a concentração de amônia muda ao longo da altura. Em regime permanente, em qualquer ponto fixo, a concentração de amônia não muda. Havendo difusão de amônia da fase gasosa para a fase líquida, deve haver um gradiente de concentração na mesma direção da transferência de massa dentro de cada fase. A Fig. 3.13 apresenta as concentrações em cada fase para esse sistema. 
A taxa de transferência de massa, entre as fases, não pode ser descrita em termos da diferença entre as concentrações no meio de cada fase, uma vez que as concentrações no vapor e no líquido estão diferentemente relacionadas ao potencial químico, que é a verdadeira força motriz atuante. Assume-se que há resistência à transferência de massa apenas nos fluidos e, como resultado dessa hipótese, as concentrações na interface $y_{A i}$ e $y_{A i}$ são valores de equilíbrio, dados pela curva de distribuição de equilíbrio do sistema. Em situações comuns, o equilíbrio de fato existe na interface, e as concentrações são aquelas dadas pela curva de distribuição de equilíbrio. $O$ aumento de $y_{A i}$ para $x_{A i}$ na interface não corresponde a uma barreira à transferência de massa na direção gás-líquido. $\mathrm{Na}$ interface as concentrações são de equilíbrio e, portanto, correspondem a potenciais químicos iguais aos da substância $A$ nas duas fases.

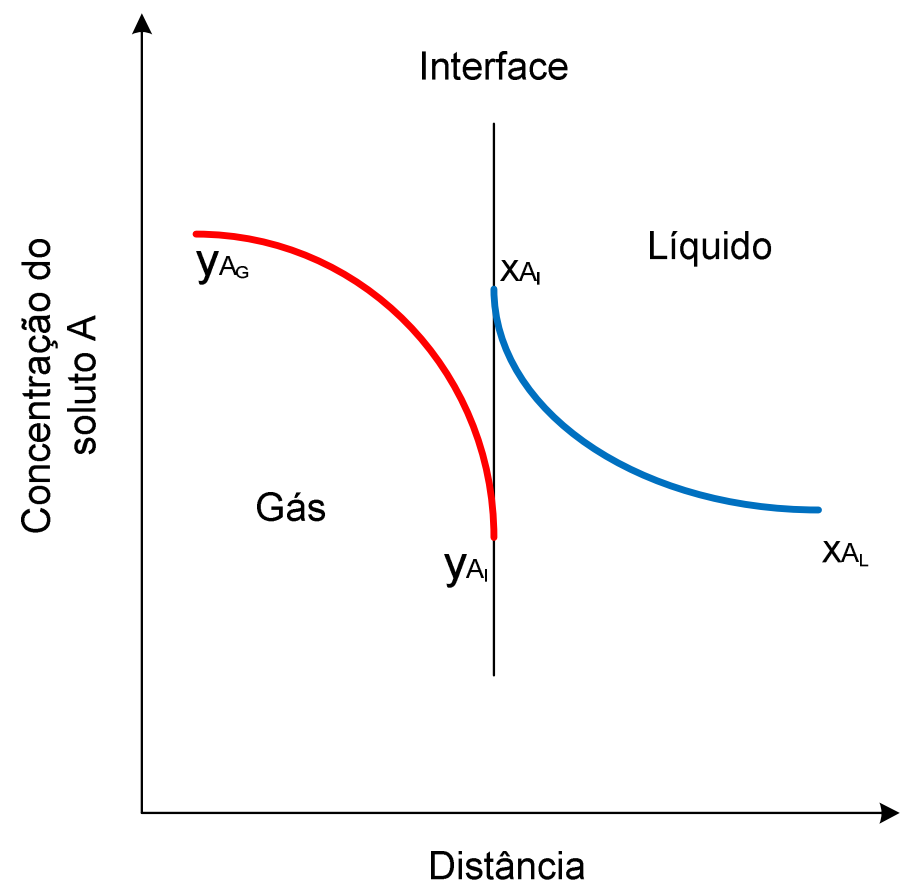

Figura 3.13 - Conceito das duas resistências (adaptado, Treyball 1981) 


\subsection{Tipos de absorvedores}

A necessidade de se elevar as taxas de transferência de calor e massa, aliada à exigência de componentes cada vez mais compactos e eficientes, faz com que os pesquisadores idealizem, modelem e avaliem experimentalmente diversas configurações distintas de absorvedores. Neste item, serão apresentadas as particularidades de cada tipo de absorvedor, assim como o regime de absorção de cada um.

Dentre os tipos de absorvedores mais difundidos e estudados, destacam-se os que operam em regime de filme descendente e os que operam em regime de bolhas. Existem ainda, os chamados absorvedores de leito empacotado ou de recheio, menos comuns em refrigeração por absorção, sendo mais utilizados em processos de separação.

\subsubsection{Absorvedores de filme descendente}

De acordo com Kang et al. (2000) absorvedores de filme descendente possuem altos coeficientes de transferência de calor e massa e são bastante estáveis durante a operação. Entretanto, possuem problemas associados à dispersão da fase líquida, necessitando de adequados distribuidores na região de entrada do fluxo líquido no equipamento. Os mesmos autores apresentam a modelagem de um absorvedor de película descendente com trocador de calor de placas, esquematizado na Fig. 3.14, no qual o filme de solução amônia-água escoa em contra-corrente com o vapor de amônia. No referido estudo, utiliza-se como fluido de resfriamento etileno glicol, o qual escoa no interior das placas e retira o calor gerado pelo processo de absorção.

Carvalho (2007), com base nos estudos de Andberg e Vliet (1983), realizou a modelagem física de um absorvedor de filme descendente composto por tubos verticais para um ciclo de refrigeração operando com água e brometo de lítio. Nesse absorvedor, como se pode observar na Fig. 3.15, a película descendente de líquido se desenvolve ao longo do comprimento dos tubos, com as vazões de vapor de água e solução pobre de brometo de lítio, escoando concorrentemente até a base do 
absorvedor. No interior dos tubos, ar escoa concomitantemente, retirando calor proveniente do processo de absorção.

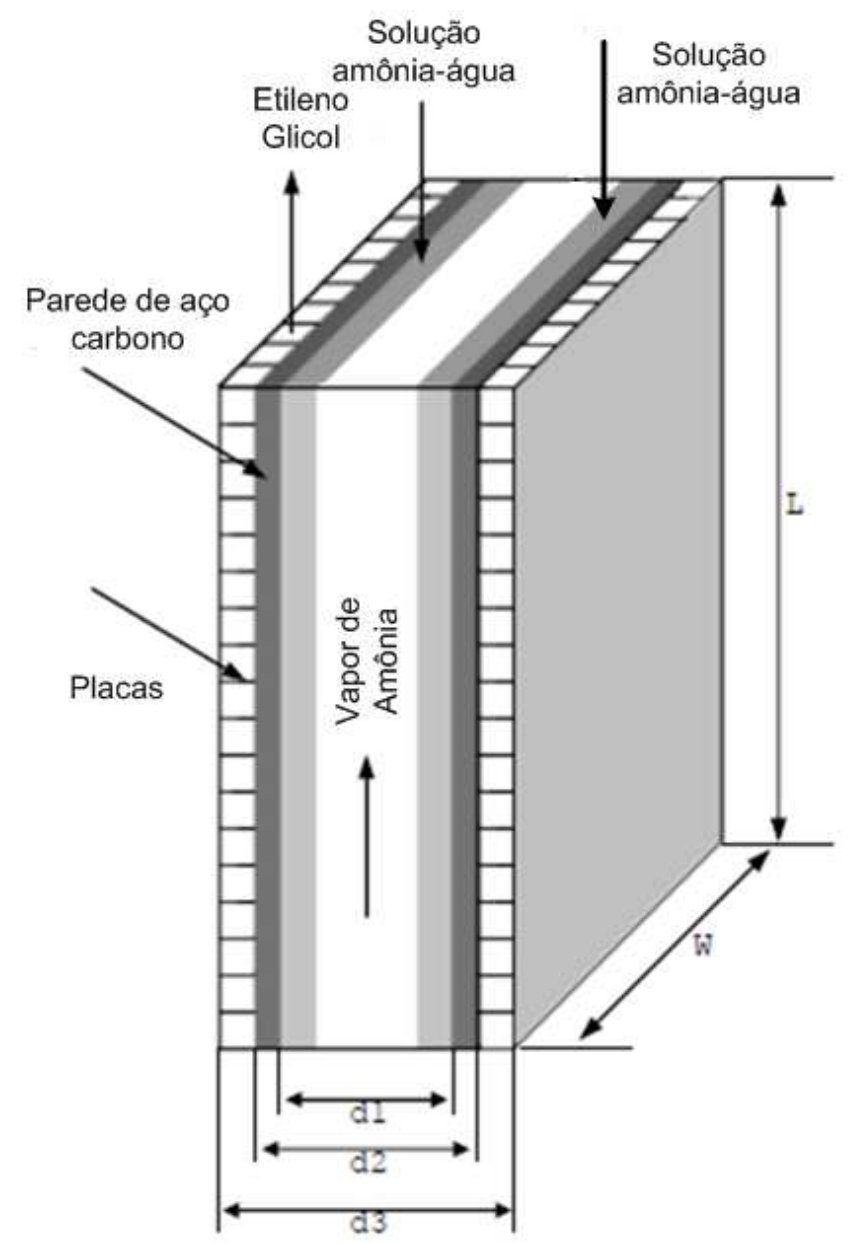

Figura 3.14 - Absorvedor de película descendente com trocador de calor de placas (Kang et al. 2000)

Bohra (2007) apresenta em sua tese de doutoramento o estudo experimental de um absorvedor casco-tubos horizontal, operando em regime de película descendente com o par amônia-água. Água fria escoa no interior dos tubos e a solução pobre é aspergida do lado casco na parte superior por um distribuidor, enquanto o vapor é injetado na parte inferior, como pode ser visualizado na Fig. 3.16. 


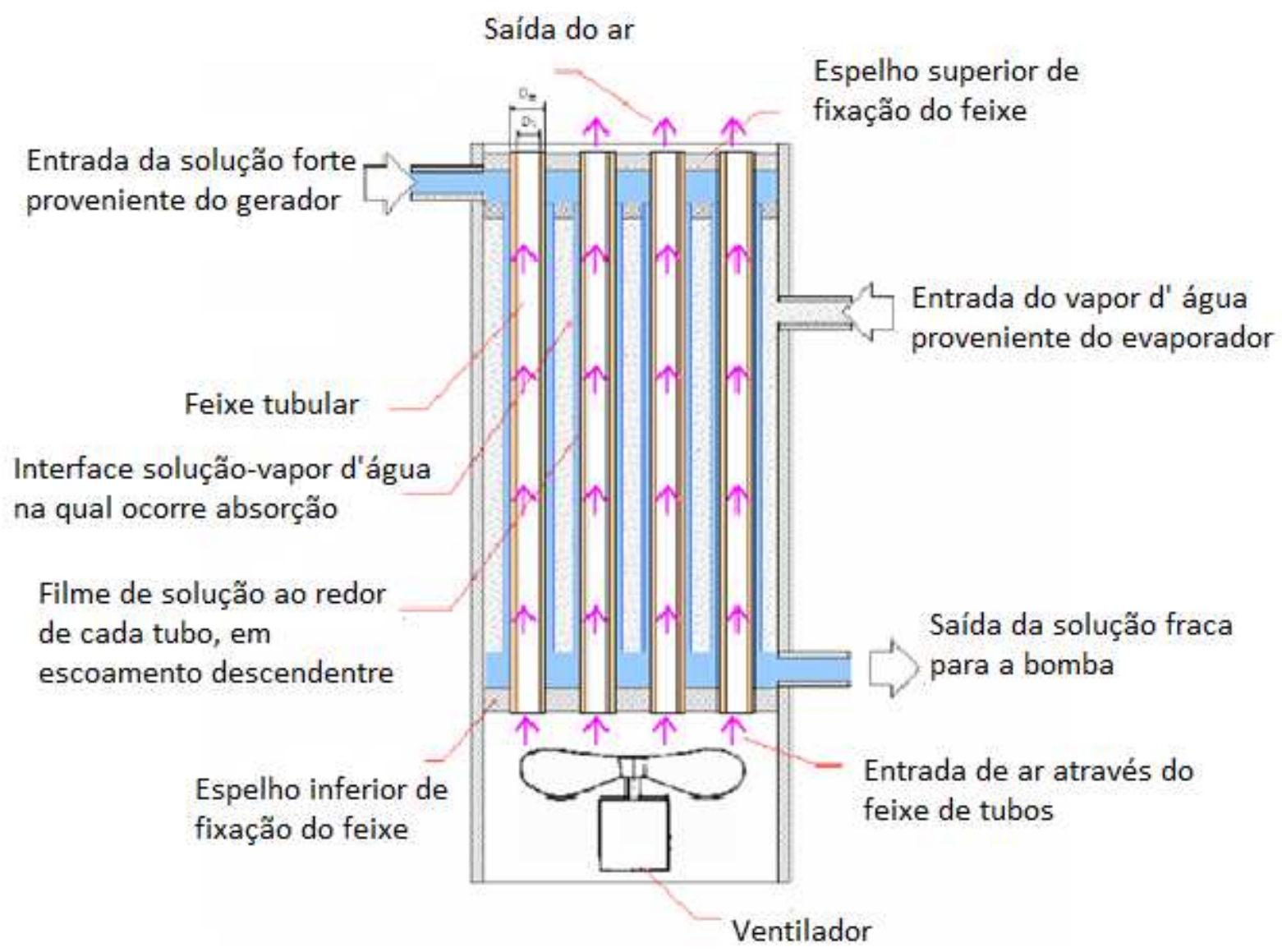

Figura 3.15 - Absorvedor de tubos verticais (Carvalho, 2007)

Mais recentemente Garimella (2003) realizou estudos envolvendo tecnologia de miniaturização em absorvedores amônia-água. Essa tecnologia utiliza tubos de comprimento e diâmetro bastante reduzidos (microcanais), localizados numa espécie de matriz associada a várias outras matrizes empilhadas verticalmente, Fig. 3.17.

O vapor de amônia escoa ascendentemente através da estrutura formada pelo banco de pequenos tubos e em contra-corrente, escoa a solução pobre de amônia, formando o filme descendente. O contato entre as fases se torna mais efetivo, ao passo que ocorre minimização das resistências à transferência de calor e massa. Além disso, as correntes de vapor e solução se auto-distribuem, fazendo com que problemas associados à existência de regiões secas sejam reduzidos. 


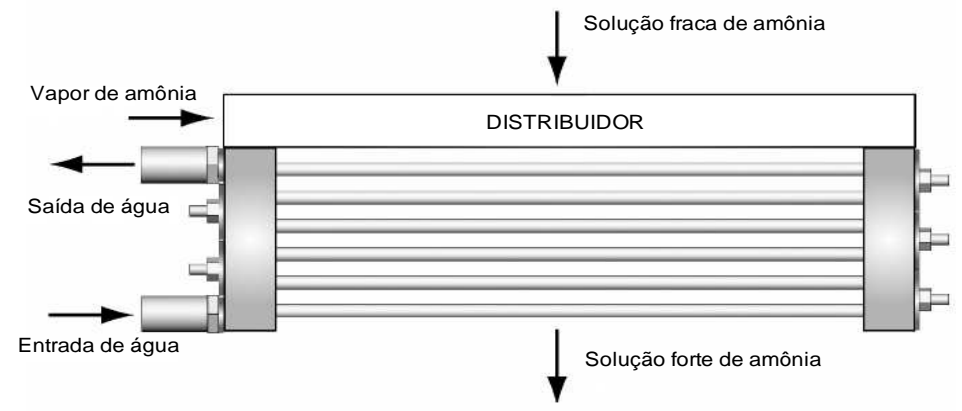

(a)

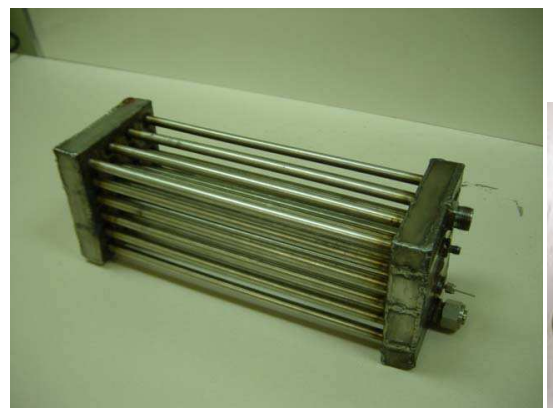

(b)

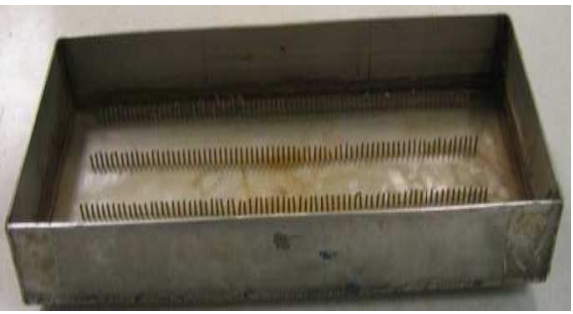

(c)

Figura 3.16 - (a) esquema de absorvedor de filme descendente horizontal (b) fotografia dos tubos (c) distribuidor (Bohra, 2000)

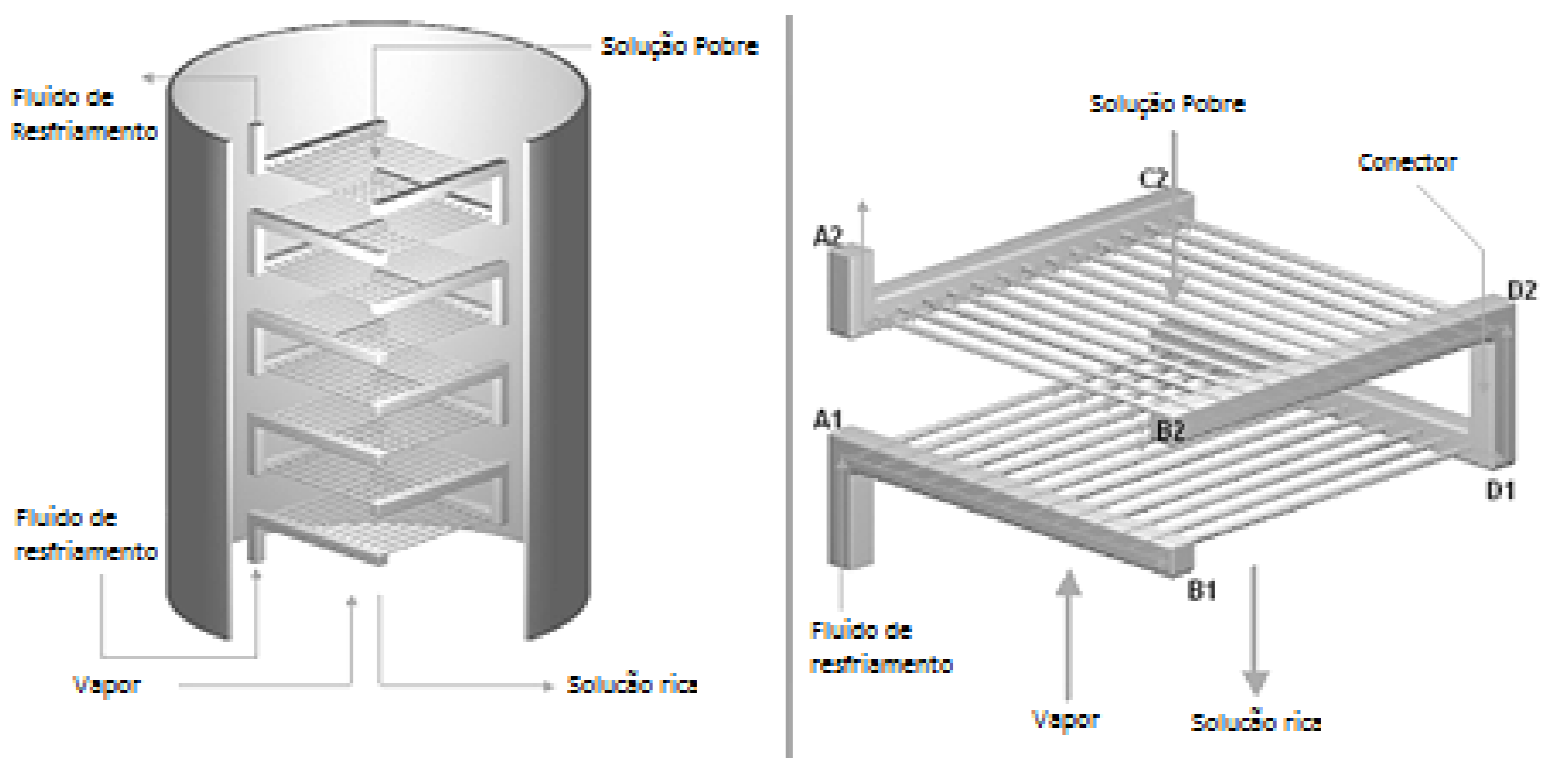

Figura 3.17 - Conceito de absorvedor constituído por microcanais (Garimella, 2002) 


\subsubsection{Absorvedor de borbulhamento}

Dentre os absorvedores que operam no regime de borbulhamento, ou tipo bolha, os mais empregados são os de casco e tubos. No interior dos tubos escoa o fluido de resfriamento, e na carcaça a solução ocupa em torno de $85 \%$ do volume. A solução pobre é aspergida pela parte de cima do trocador e o vapor de amônia é injetado na parte de baixo na forma de bolhas, o que permite grande área de contato entre as duas fases. Essa configuração de absorvedor pode ser visualizada na Fig. 3.18.

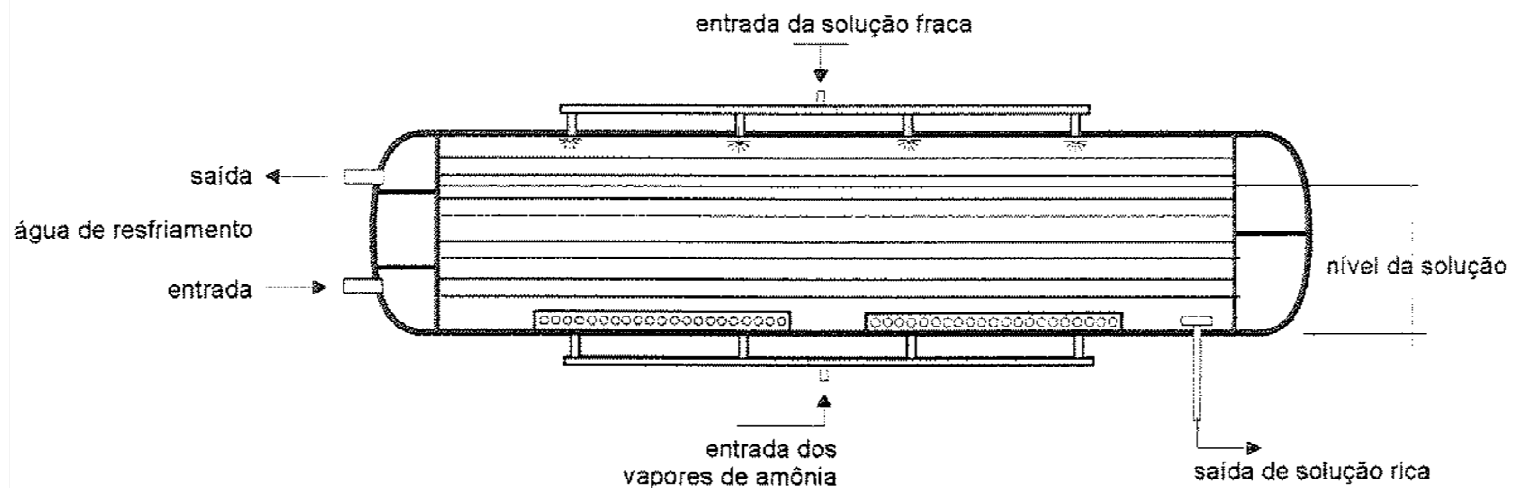

Figura 3.18 - Absorvedor convencional de borbulhamento (Milanés, 1999)

Existem também os absorvedores de borbulhamento vertical, onde se utilizam colunas, nas quais a solução pobre escoa em contracorrente ou paralelamente ao vapor, e o fluido de resfriamento escoa pelo lado externo da coluna. Infante Ferreira et al. (1984) realizaram um estudo experimental através de um protótipo de absorvedor de borbulhamento vertical. O equipamento, ilustrado na Fig. 3.19, é composto por dois tubos concêntricos. Na região anular escoa metanol e em contracorrente, no interior do tubo, escoam a solução pobre juntamente com o vapor de amônia, estes injetados na parte inferior do equipamento. A escolha do metanol reside na possibilidade de obtenção de temperaturas bastante reduzidas, não havendo congelamento do fluido, sendo que neste estudo foram utilizadas temperaturas em torno de $-40^{\circ} \mathrm{C}$. De acordo com os autores, esse tipo de absorvedor é caracterizado pela alteração do padrão de escoamento bifásico em seu interior. Observa-se um fluxo de espuma imediatamente após a entrada no 
bocal, seguido de uma região em que o escoamento é intermitente, e finalmente, uma região de escoamento borbulhante.

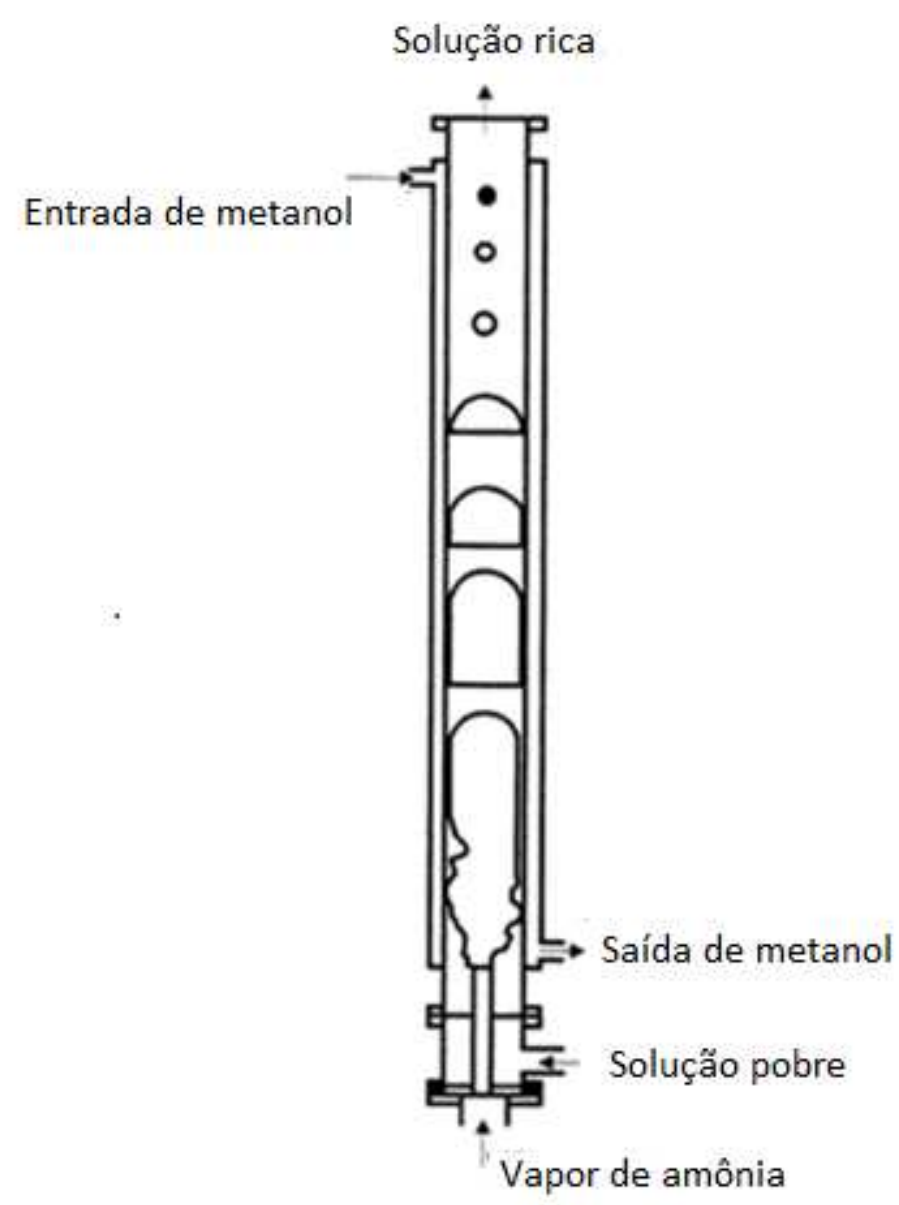

Figura 3.19 - Absorvedor de borbulhamento vertical (adaptado, Infante Ferreira et al. 1984)

Milanés (2002) desenvolveu um modelo matemático para o absorvedor de borbulhamento horizontal, esquematizado na Fig. 3.20, com escoamento em paralelo das correntes de vapor e líquido. O absorvedor consiste basicamente de um tubo longo triplamente curvado. Em uma das extremidades entram a solução pobre e o vapor de amônia. Na outra extremidade sai a solução rica. Nesse caso, o processo de absorção se desenvolve ao longo do escoamento bifásico no interior do tubo. A água de resfriamento é introduzida por cima e o ar é ventilado por baixo, consistindo dessa forma, em um absorvedor chamado de evaporativo. 


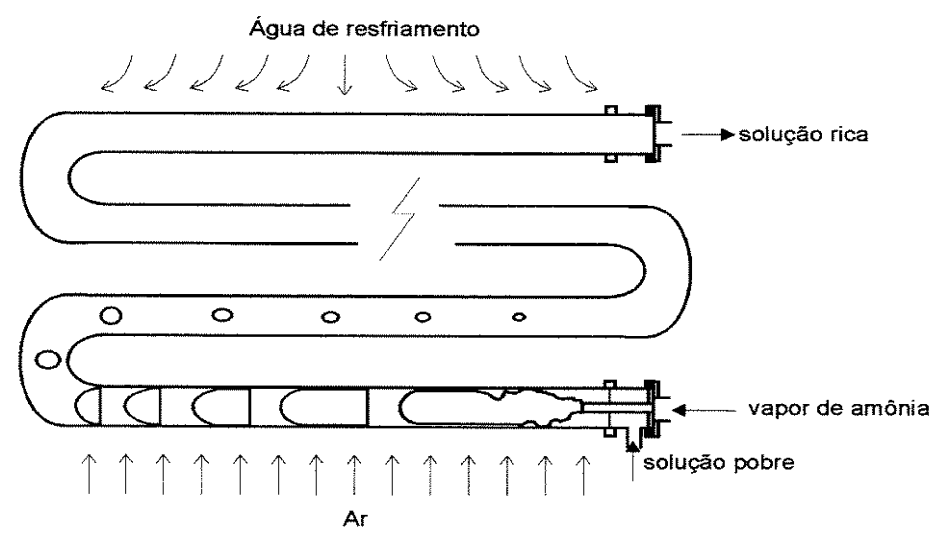

Figura 3.20 - Absorvedor evaporativo (Milanés, 2002)

Fernandez-Seara et al. (2005) realizaram o estudo numérico de um absorvedor de borbulhamento composto por tubos verticais. A configuração proposta pelos autores se assemelha bastante à estudada por Carvalho (2007), com o diferencial de que o escoamento da solução pobre e do vapor de amônia ocorre no interior dos tubos, com o vapor sendo injetado por borbulhamento e o fluido de resfriamento escoando no lado casco. Pode-se verificar o esquema desse absorvedor na figura 3.21.

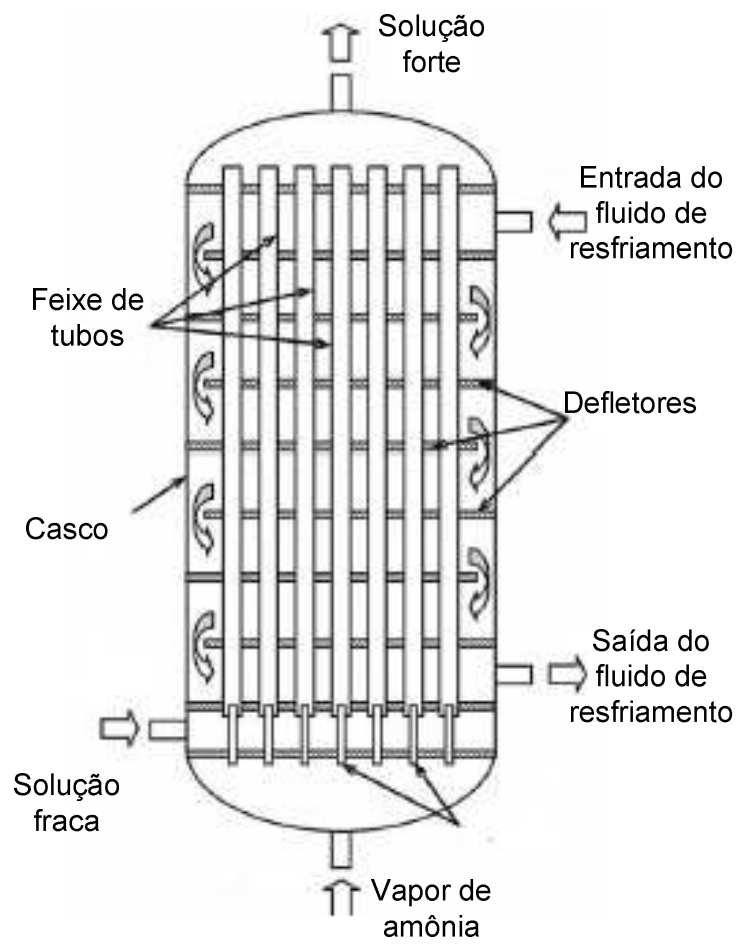

Figura 3.21 - Diagrama esquemático de um absorvedor de borbulhamento com tubos verticais (Fernandez-Seara et al. 2005) 


\subsubsection{Absorvedor de leito empacotado}

Absorvedores de leito empacotado não apresentam grande aplicabilidade em sistemas de refrigeração por absorção, muito em função da elevada perda de carga imposta ao escoamento em seu interior. Além disso, de acordo com Govindaraju (2005), são absorvedores que, por conta de sua estrutura interna, não possibilitam a presença de elementos trocadores de calor em seu interior, dificultando assim a remoção de calor proveniente do processo de absorção.

Contudo, são amplamente utilizados em indústrias químicas para operações de absorção gasosa. Caracterizados por uma construção simples e flexível, consistem basicamente de um leito preenchido por um recheio composto de pequenas peças de metal, cerâmica, vidro ou plástico, as quais proporcionam o aumento da área superficial de contato entre as fases vapor e líquida. Existe uma grande variedade de materiais, dimensões e formas de recheios, os quais devem ser escolhidos, avaliando-se as condições de operação e os fluidos envolvidos no processo, visto que esses elementos são responsáveis pela maximização das trocas de calor e massa no interior do equipamento.

O recheio de um absorvedor de leito empacotado deve, primordialmente, possuir as seguintes características (Foust, 1982):

- grande área superficial por unidade de volume para o contato das fases;

- grande volume de vazios (porosidade), o que propicia altas vazões das fases, minimizando a perda de carga;

- resistência mecânica e à corrosão;

- devem ser quimicamente inertes aos produtos com os quais entrarão em contato;

- baixa densidade (menor carga sobre a coluna);

- baixa retenção de líquido;

- baixo custo.

Os tipos de recheio mais frequentemente utilizados são os anéis de Raschig, as selas Berl, os anéis Pall, Intalox Metal Tower Packing (IMTP) e os recheios estruturados, podendo ser dispostos randomicamente (colocados ao acaso no 
interior da torre) ou de forma estruturada (montagem cuidadosa em estruturas superpostas). Como nenhum recheio possui todas as qualidades desejáveis e possíveis para a transferência de massa, vários aspectos devem ser considerados na escolha. Em geral, o recheio não deve ser maior do que 1/8 do diâmetro da torre por razões de melhor distribuição do líquido, utilizando-se no mínimo recheios de 13 $\mathrm{mm}$. Outros dispositivos também são utilizados em torres recheadas. O suporte de recheios (pratos perfurados ou grades) permite a existência de um espaço vazio no fundo da coluna para que o gás seja convenientemente distribuído. Distribuidores de líquido são utilizados no topo e ao longo da coluna para impedir o fenômeno da canalização, fato que pode levar ao baixo desempenho de grandes torres recheadas.

Para a maioria dos recheios de arranjo randômico, a perda de carga é função das vazões de gás e de líquido, em virtude do escoamento descendente de líquido ocupar os mesmos canais que o escoamento ascendente de gás. É importante ressaltar que um dos maiores problemas associados a equipamentos compostos por leitos de recheios é a formação de caminhos preferenciais pelo escoamento. Tal problema pode ser originado por uma alimentação inadequada, seja da vazão de gás ou de líquido, ou pela distribuição não homogênea dos elementos constituintes do recheio.

Semelhantemente à outros tipos de absorvedores, a direção do escoamento das correntes líquida e vapor pode variar. Acrescentando-se que, em absorvedores de leito empacotado, o fluxo de vapor pode ser direcionado tranversalmente, conforme observa-se na Fig. 3.24. Westerlund e Dahl (1994) realizaram um estudo comparativo entre as operações em fluxo contra-corrente e transversal, concluindo que a perda de carga é até $25 \%$ menor em escoamentos tranversais, porém a área de contato necessária para o processo se torna significativamente maior. 


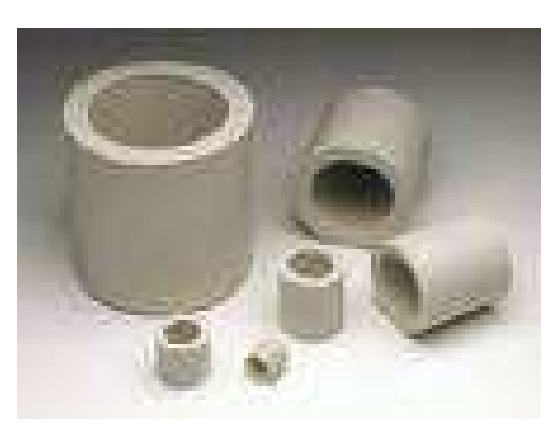

(a)

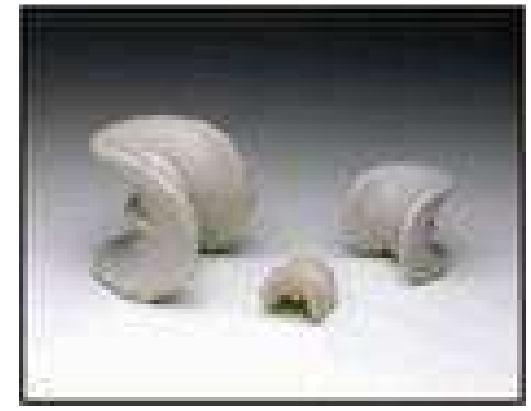

(b)

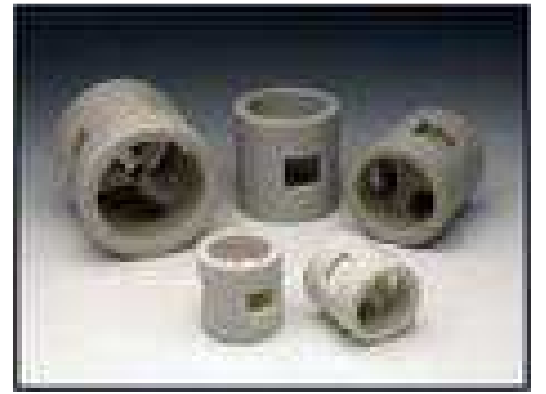

(d)

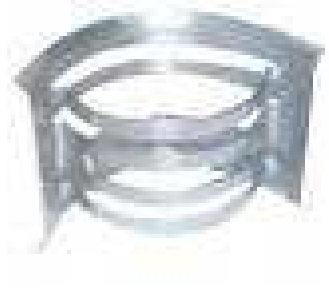

(c)

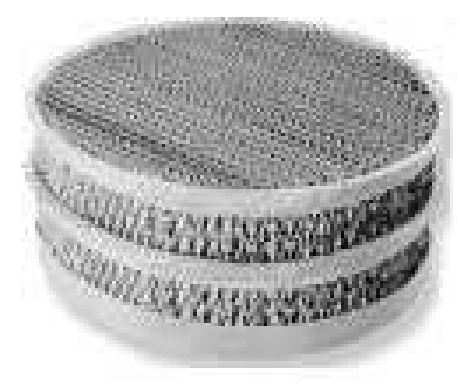

(e)

Figura 3.22 - (a) anéis de Raschig, (b) selas Berl, (c) IMTP, (d) anéis Pall, (e) leito de recheio estruturado (Foust, 1982)

Em operações com leitos empacotados é importante assegurar que o escoamento tanto da solução líquida como do gás sejam bem distribuídos de maneira a evitar o chamados caminhos preferenciais no interior do leito. A boa distribuição pode ser alcançada através de bocais de injeção bem localizados, tanto para o vapor como para o líquido. 


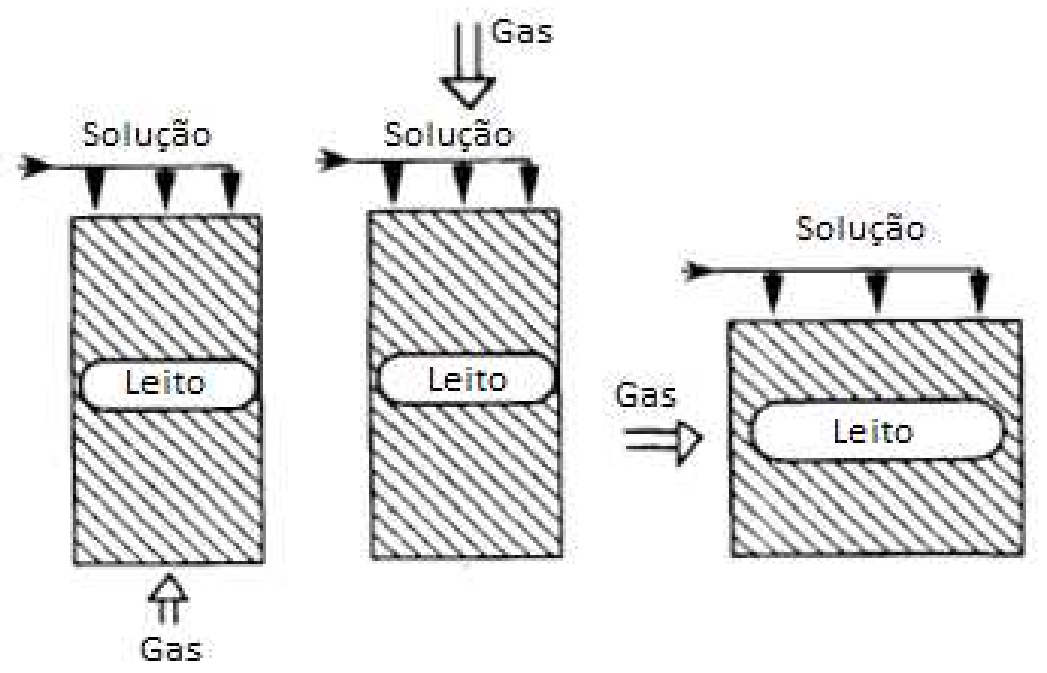

Figura 3.23 - Regimes de operação em absorvedores de leito empacotado (Westerlund e Dahl, 1994)

\subsection{Estudos numéricos, analíticos e experimentais de processos de absorção amônia-água}

\subsubsection{Estudos numéricos e analíticos}

No tratamento analítico e numérico do processo de absorção amônia-água, existem algumas hipóteses gerais encontradas na maioria dos estudos. Essas hipóteses comuns são listadas a seguir:

- absorção em estado estacionário ou em regime permanente;

- sistema a pressão constante;

- equilíbrio termodinâmico na interface líquido-vapor;

- transferência de massa devida somente ao gradiente de concentração (efeitos de temperatura e gradientes de pressão são negligenciados);

- difusão de calor e massa na direção do fluxo de solução são insignificantes;

- nenhum vapor não condensável.

Segundo Bohra (2007) a maioria dos modelos analíticos é baseada na metodologia originalmente desenvolvida por Colburn e Drew (1937) e mais tarde adaptada por Price e Bell (1973) para o projeto de condensadores de misturas binárias. O processo de absorção é semelhante ao de condensação, exceto pelo 
fato de que na absorção, a camada de líquido existe desde o início do processo. A metodologia Colburn-Drew é mais adequada à análise do processo de condensação ou absorção de misturas binárias quando a taxa é elevada ou a diferença de temperatura entre o vapor e o fluido de resfriamento é alta. Em qualquer uma dessas situações, o processo será dominado pelo lado do vapor e a premissa de que existe mistura perfeita na fase líquida é justificável. A hipótese de que a concentração do líquido na interface seja igual à concentração no seio do filme líquido, permite o cálculo da temperatura na interface e, portanto, a concentração de vapor na interface é necessária para se calcular a taxa de condensação ou absorção. As equações de Colburn-Drew para transferência de massa e calor são aplicáveis localmente, sendo a análise local necessária em função da não uniformidade da composição em ambas as fases. Em geral, a concentração no seio do fluido irá também mudar ao longo do condensador ou absorvedor. Price e Bell (1973) desenvolveram um método computacional no qual a metodologia Colburn-Drew é implementada e utilizada no projeto de condensadores e absorvedores de misturas binárias de vapor. Nessa metodologia, as taxas de transporte são integradas ao longo de todo o processo, de maneira a se obter o tamanho do equipamento.

Bhavaraju et al. (1978) desenvolveram procedimentos para predição do coeficiente global de transferência de massa para sistemas com gases pulverizados em líquidos de alta e baixa viscosidade. Dividiram o volume em que se dá a absorção em duas regiões. A primeira região corresponde ao volume acima do orifício de aspersão, onde as propriedades das bolhas são determinadas pelo processo de formação da bolha no orifício. Essa região é caracterizada por bolhas grandes, baixa retenção e distribuição não uniforme das bolhas pela seção transversal do distribuidor onde há múltiplos orifícios. A segunda região, acima da primeira, é o volume no qual as propriedades das bolhas são definidas pelo movimento do líquido como um todo. As correlações apresentadas são especificadas para cada região. Distinguiram três diferentes regimes de formação de bolhas com base nas vazões de vapor. Para cada regime determinaram diferentes correlações em função do diâmetro da bolha.

- vazões baixas de vapor, onde são formadas bolhas de volume constante, cujo tamanho é função do diâmetro do orifício, tensão superficial e empuxo; 
- vazões moderadas de vapor, onde com aumento da vazão, a tensão superficial se torna desprezível e o tamanho da bolha é determinado pelo balanço entre o empuxo e as forças viscosas e inerciais;

- vazões altas de vapor, na primeira região as bolhas aumentam de tamanho próximo ao orifício formando um aparente jato de gás, já na segunda região o tamanho das bolhas diminui devido ao rompimento de bolhas maiores.

Selim e Elsayed (1999) desenvolveram um modelo matemático para quantificar a transferência de massa uma mistura de vapor de amônia e água e uma solução na fase líquida, no interior de um absorvedor de leito empacotado. O modelo utilizou a massa molal, os coeficientes de transferência de calor nas fases líquida e gasosa, a concentração molal da solução e do vapor na interface e a temperatura na interface. O coeficiente de transferência de calor foi corrigido para se levar em conta o efeito da transferência de massa sobre a transferência de calor. O modelo também foi utilizado para a derivação de um coeficiente de transferência de massa adequado, baseado na concentração mássica no meio do líquido. Foi previsto também, o desempenho de um sistema de refrigeração por absorção de amônia em água em um absorvedor de leito empacotado.

Kang et al. (2000) estudaram absorvedores de filme descendente e tipo bolha. No modelo adotado, consideraram transferência de massa e calor e realizaram uma análise paramétrica para se avaliar os efeitos de importantes variáveis, tais como área de transferência de massa e calor e taxa de absorção. Constataram que a taxa de absorção local do absorvedor tipo bolha é maior, levando à necessidade de um trocador de calor com área 48,7\% menor. Para o absorvedor de filme descendente, a resistência à transferência de massa é considerável no filme líquido. No vapor, tanto a resistência à transferência de calor quanto a resistência à transferência de massa são consideráveis. Para o absorvedor tipo bolha, a resistência à transferência de massa foi dominante no líquido e a resistência à transferência de calor foi dominante na região de vapor.

Killion e Garimella (2001) apresentaram uma revisão crítica de vários modelos utilizados no estudo da transferência simultânea de calor e massa em sistemas de absorção. Eles apontam que a maioria dos modelos negligencia ou a resistência a transferência de massa do lado líquido ou a do lado vapor. Além disso, a maioria 
desses modelos fazem uso de correlações empíricas para a determinação dos coeficientes de transferência de calor e massa. Concluíram que embora os estudos mais recentes busquem remover algumas das simplificações padrão, existe ainda uma carência de modelos que considerem os desvios de comportamento do fluxo idealizado, tais como formação de gotas e filmes ondulados.

Lee et al. (2003) avaliaram o processo de absorção em um absorvedor tipo bolha, onde gás foi injetado no fundo do absorvedor a uma vazão constante. A região de absorção de gás foi estimada numericamente e experimentalmente. $O$ modelo matemático desprezou o fluxo de água do vapor para o líquido. Os resultados indicaram que vazões de gás mais altas levam a uma região de absorção maior. Determinaram desta forma, as dimensões necessárias do absorvedor, chegando à conclusão que diminuindo a temperatura e a concentração da solução de entrada, a região de absorção do gás diminui e o desempenho de um absorvedor em contracorrente é superior ao desempenho de um absorvedor com escoamento paralelo. Os valores obtidos na simulação estavam de acordo com os resultados experimentais obtidos.

Fernández-Seara et al. (2005) realizaram uma análise detalhada do processo de transferência de calor e massa durante a absorção da amônia em água em um absorvedor vertical tubular de correntes paralelas. O absorvedor corresponde a um trocador de calor casco-tubos, onde foi utilizada água como meio de resfriamento. Os autores desenvolveram um modelo matemático diferencial baseado nos balanços de energia e massa e nas equações de transferência. O modelo leva em conta os diferentes padrões de escoamento (agitado, pistonado e borbulhante), preditos experimentalmente nesse tipo de processo de absorção dentro de tubos verticais. Considera também o processo de transferência de calor e massa nas fases liquida e vapor, assim como a transferência de calor para fluido de resfriamento. Os autores utilizaram o método de diferenças finitas para resolução das equações.

Kim et al. (2007) analisaram numericamente os fenômenos combinados de transferência de calor e massa envolvidos no processo de absorção de amônia com a adição de surfactantes e nano-partículas em um absorvedor de placas, operando no regime de borbulhamento. O estudo avalia o desempenho do processo de absorção em função da adição de surfactantes e nano-partículas. Foi concluído que, 
a presença desses constituintes faz com que o processo ocorra radicalmente perto da entrada do sistema absortivo. Consequentemente, os autores observaram que o tamanho do absorvedor pode ser sensivelmente reduzido.

\subsubsection{Estudos experimentais}

Os trabalhos experimentais referentes à absorção em filme descendente podem ser divididos em duas categorias:

a) absorção no interior ou na região externa de tubos verticais;

b) absorção na região ao redor de tubos horizontais ou ao longo de bancos de tubos.

Correlações adimensionais para o tamanho médio da bolha, área interfacial específica gás-líquido e coeficiente de transferência de massa para a fase líquida foram propostas por Akita e Yoshida (1974). Para o cálculo da área interfacial específica, utilizaram dados experimentais da distribuição do tamanho das bolhas e coeficiente de retenção em coluna de bolhas com secção transversal inferior a $30 \times 30 \mathrm{~cm}$ e velocidade superficial do gás menor que $150 \mathrm{~cm} / \mathrm{h}$.

Kim e Kang (1995) investigaram experimentalmente a absorção de vapor de amônia no interior de um tubo vertical com comprimento de $80 \mathrm{~cm}$. Calcularam os números de Nusselt e de Sherwood a partir de dados experimentais para a faixa de número de Reynolds de 11,25 a 75. Os autores compararam os resultados obtidos com os resultados gerados por correlações propostas por Chun e Seban (1971) e por Ohm e Kashiwagi (1993).

Dentre os estudos experimentais de absorção de amônia, se destaca o trabalho realizado por Hoffman e Ziegler (1996), que construíram um sistema que permitia experimentos de absorção dentro de uma grande faixa de concentração e vazão. O aparato era constituído de absorvedor, retificador e gerador, todos localizados em um único bloco cilíndrico bastante compacto.

Existem também estudos que se baseiam em métodos de visualização. Kang et al. (2000) visualizaram o comportamento das bolhas e avaliaram o desempenho do processo de absorção água-amônia através da investigação de algumas 
características, tais como diâmetro e velocidade das bolhas. Chegando à conclusão de que o formato de surgimento das bolhas se torna hemisférico à medida que a velocidade do vapor aumenta. O formato de surgimento tende a ser esférico quando a tensão superficial é dominante no escoamento e hemisférico quando as forças inerciais são dominantes. O diâmetro inicial das bolhas é diretamente proporcional a concentração do líquido, sendo que o tempo de residência aumenta com a elevação do diâmetro inicial.

Miller e Keyhani (2001) buscaram, através de estudos experimentais, avaliar e entender melhor os mecanismos responsáveis pelos processos de transferência de calor e massa envolvidos na absorção de amônia em filme descendente. Eles mostraram que o gradiente de concentração no filme na direção perpendicular ao escoamento é aproximadamente constante e também determinaram o perfil de temperatura ao longo do absorvedor de tubos verticais. Correlações para o modelo acoplado de transferência de calor e massa foram obtidas através dos resultados experimentais.

Lee et al. (2002) realizaram uma análise experimental do processo de absorção amônia-água em um absorvedor de placas planas operando no regime bifásico de bolhas. Os experimentos avaliaram os efeitos das vazões de vapor e solução no desempenho do absorvedor. Foi constatado que o aumento da vazão de solução afeta muito pouco a transferência de massa. No entanto, melhora sensivelmente a transferência de calor. Com o aumento da vazão de vapor, 0 desempenho da transferência de massa e calor é sensivelmente melhorado.

Kwon e Jeong (2004) estudaram o efeito da direção da vazão de vapor na transferência de calor e massa em um absorvedor de filme descendente helicoidal. Foram conduzidos experimentos utilizando três diferentes concentrações de solução pobre, sendo elas 0,$03 ; 0,14$ e 0,3 com uma variação da vazão de solução na faixa de 0,0043 a 0,09 kg/s. A pressão do equipamento variou entre 17 e $193 \mathrm{kPa}$. Foi notado que as taxas de transferência de calor e massa se elevam proporcionalmente a vazão de solução e sua temperatura e independem da direção da corrente de vapor. O volume específico do vapor que está em equilíbrio com a solução (a $\left.50^{\circ} \mathrm{C}\right)$, eleva-se quase 10 vezes de 0,679 a 6,797 m³/kg quando a concentração da solução muda de 0,3 para 0,031. Um alto volume específico resulta em altas velocidades da 
corrente de vapor, condição que promove distribuição desfavorável do filme descendente ao longo do absorvedor.

Islam (2007) avaliou experimentalmente um absorvedor tubular operando em regime de filme descendente. Realizou uma avaliação paramétrica das variáveis de operação, tais como temperatura de entrada da solução, vazão de solução, temperatura de entrada do fluido de resfriamento e vazão de refrigerante, investigando seus efeitos no desempenho do absorvedor. Nos experimentos, 0 absorvedor operava a uma pressão ligeiramente menor que a pressão do vapor do refrigerante no evaporador, de maneira a fornecer a diferença de pressão necessária para que houvesse o deslocamento do vapor. Uma maior pressão do vapor aumenta a concentração de equilíbrio na interface do filme, o que ocasiona uma maior taxa de absorção da amônia.

Cerezo et al. (2008) estudaram experimentalmente o comportamento de um trocador de calor de placas, atuando como absorvedor e operando sob condições típicas em um sistema de refrigeração por absorção convencional, movido por uma fonte de calor de baixa temperatura. Utilizaram um trocador de calor com placas corrugadas, de três canais, onde a amônia é injetada na forma de bolhas na solução líquida no canal central. Os resultados obtidos para o fluxo de absorção ficaram na faixa de $0,0025-0,0063 \mathrm{~kg} / \mathrm{m}^{2} \mathrm{~s}$, o coeficiente de transferência de calor da solução água-amônia variou entre 2,7 e $5,4 \mathrm{~kW} / \mathrm{m}^{2}{ }^{\circ} \mathrm{C}$ e a carga térmica do absorvedor de 0,5 a $1,3 \mathrm{~kW}$.

\subsubsection{Comparação entre regime de filme descendente e regime de bolhas}

Para sistemas de refrigeração por absorção que operam com o par amôniaágua, Kang et al. (2002) recomendam fortemente a utilização tanto de absorvedores de filme descendente como de absorvedores de coluna de bolhas. Sua justificativa se baseia no fato de que esses dois tipos elevam sensivelmente o desempenho dos processos de transferência de calor e massa.

A revisão bibliográfica apresentada indicou que os dois regimes de escoamento mais utilizados em absorvedores para sistemas de refrigeração por 
absorção, são filme descendente e de bolhas. Por esse motivo, torna-se interessante analisar comparativamente esses dois tipos de regime, buscando-se confrontar suas vantagens e desvantagens.

Castro et al. (2009) realizou um estudo no qual faz a modelagem matemática e compara o desempenho de absorvedores resfriados a ar operando nos regimes de filme descendente e bolha. Na Tabela 3.4 são apresentadas as vantagens e de desvantagens de cada forma de absorção, sendo possível observar que os dois tipos de absorvedores possuem características bastante distintas, além do modo de escoamento. Observa-se que o regime de bolhas favorece amplamente o contato entre as fases, já que as bolhas de vapor escoam diretamente no interior da coluna líquida. Posto isto, o contato entre as fases é muito mais efetivo elevando a área interfacial frente ao superior grau de mistura existente. Porém, nesse tipo de regime de absorção, a superfície de transferência de calor é inferior a área de contato entre as fases.

Em contrapartida, em absorvedores de filme descendente a área de contato entre o líquido e o vapor é restrita a área de transferência de calor, visto que a película líquida se desenvolve ao longo da superfície de resfriamento, sendo circundada pelo vapor.

Como mencionado acima, outro trabalho bastante interessante do ponto de vista comparativo é o realizado por Kang et al. (2000). Esse estudo avaliou, através de uma simulação numérica, o desempenho dos dois tipos de regime de escoamento em um absorvedor de placas planas. Os resultados mostraram que a taxa de absorção local eleva-se gradualmente no regime de filme descendente, enquanto que no regime de bolhas essa taxa é maior próxima à entrada de vapor, decrescendo abruptamente no comprimento de $5 \mathrm{~cm}$ e aumentando novamente ao longo do comprimento do absorvedor. O comportamento das taxas de absorção pode ser visualizado na Fig. 3.24. 
Tabela 3.4 - Comparação entre absorvedores de filme descendente e tipo bolha (adaptado, Castro et al., 2009)

\section{Filme descendente}

\begin{tabular}{|c|c|c|}
\hline Área interfacial & Pequena & Grande \\
\hline $\begin{array}{c}\text { Área de transferência de } \\
\text { calor }\end{array}$ & $\begin{array}{c}\text { Semelhante à área } \\
\text { interfacial }\end{array}$ & $\begin{array}{c}\text { Menor do que a área } \\
\text { interfacial }\end{array}$ \\
\hline Mistura entre as fases & Ruim & Excelente \\
\hline Distribuidor de líquido & Sim & Não \\
\hline Distribuidor de vapor & Não & Sim \\
\hline Inundação & $\begin{array}{c}\text { Sim para operação em } \\
\text { contra-corrente/Não para } \\
\text { operação em paralelo }\end{array}$ & Sim \\
\hline $\begin{array}{c}\text { Transferência de calor e } \\
\text { massa }\end{array}$ & Líquido e Vapor & Líquido e Vapor \\
\hline Compacidade & Boa & Excelente \\
\hline
\end{tabular}

\section{Tipo bolha}




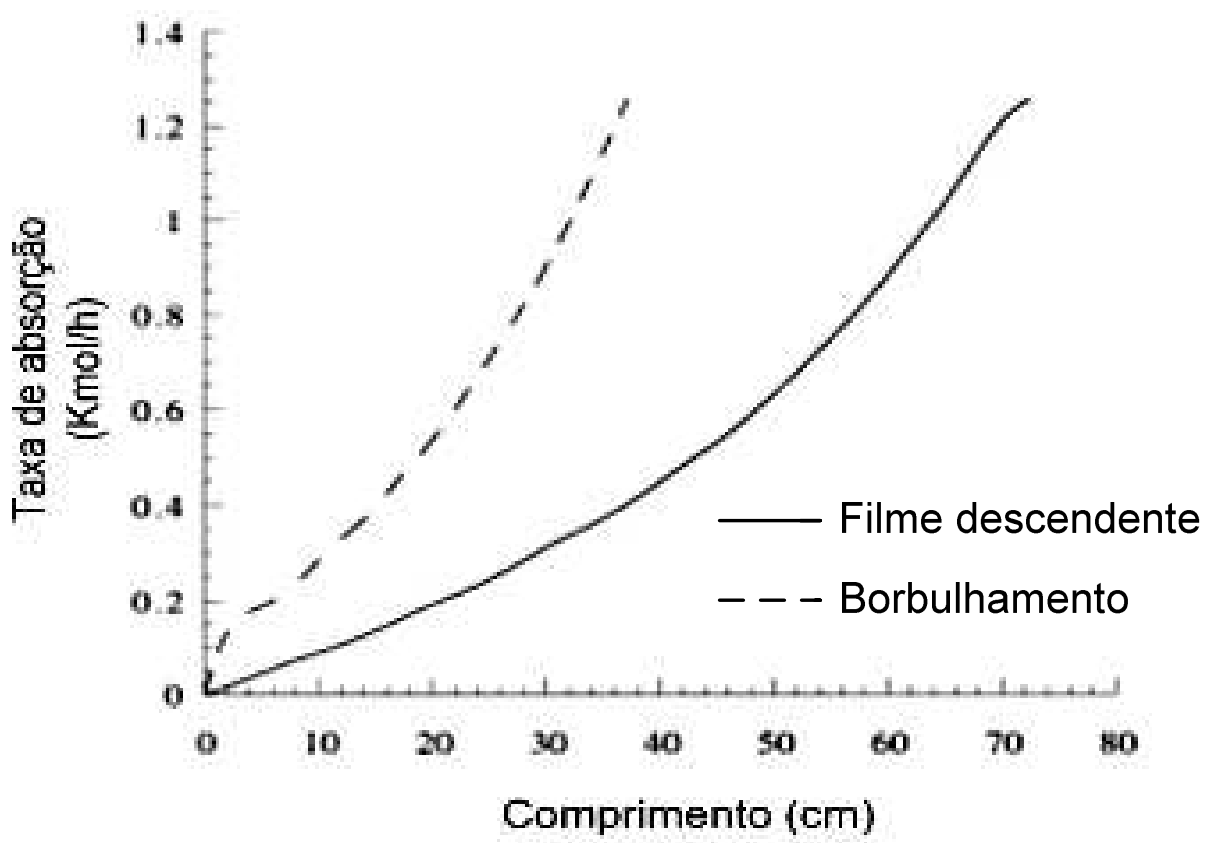

Figura 3.24 - Perfis das taxas de absorção para os regimes de filme descendente e borbulhamento (adaptado, Kang et al., 2000)

A menor área necessária obtida para o regime de borbulhamento se deve à maior área de transferência de massa. Além disso, essa área varia ao longo da superfície, sendo sempre maior que a área de transferência de calor. Enquanto na operação em filme descendente a área de transferência de massa é igual à área de transferência de calor. A Fig. 3.26 apresenta a área de transferência de massa e calor por unidade de comprimento ao longo do absorvedor tipo bolha, modelado por Makiyama (2008). 


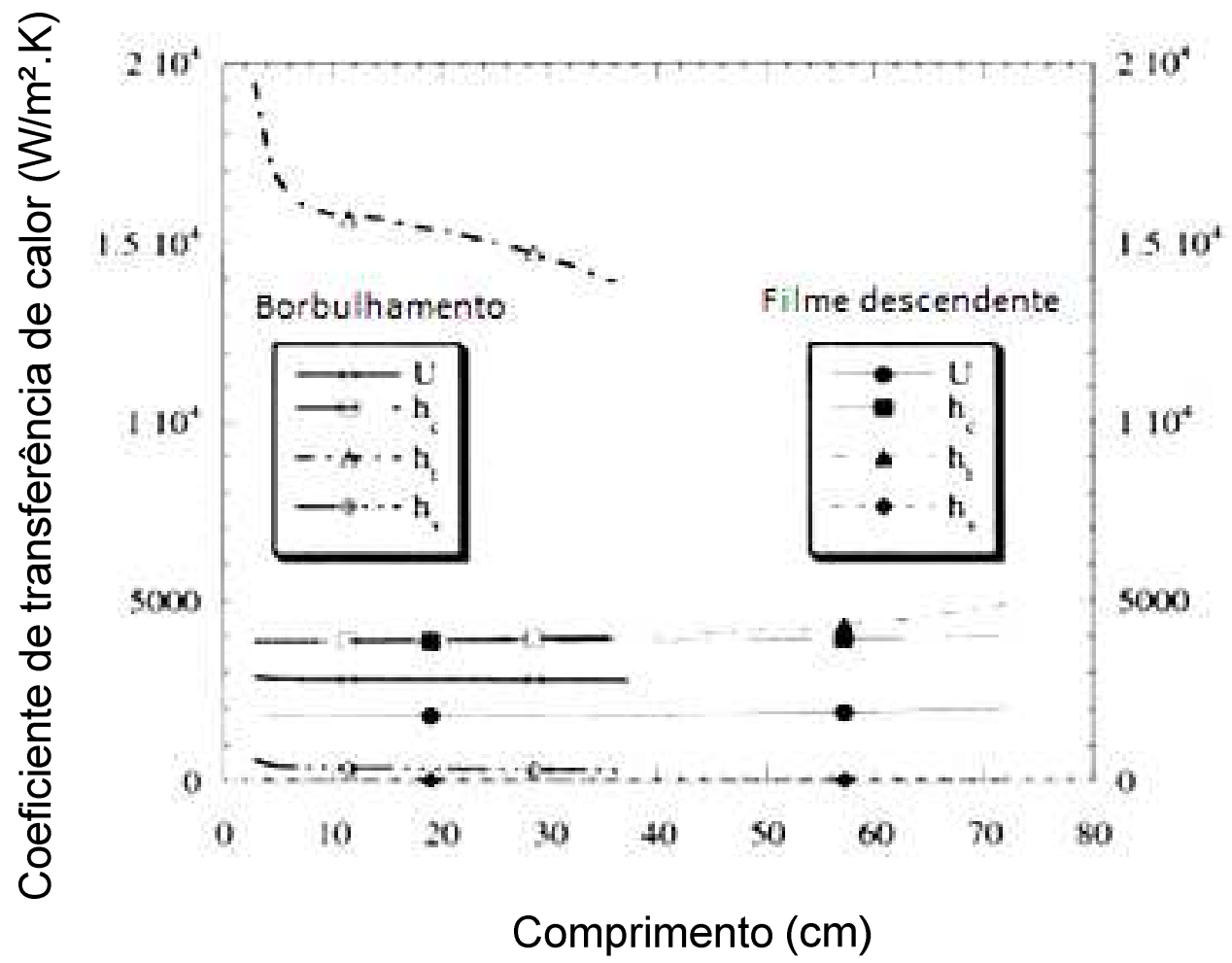

Figura 3.25 - Coeficientes de transferência de calor durante o processo de absorção em absorvedores tipo bolha e filme descendente (adaptado, Kang et al., 2000)

Conforme exposto anteriormente, absorvedores do tipo bolha se mostram mais eficientes em relação aos de filme descendente no que se refere a aspectos como transferência de calor, transferência de massa e custo de construção (menor área necessária). No entanto, a modelagem matemática desse tipo de absorvedor é extremamente difícil em decorrência da complexidade verificada na dinâmica das bolhas ao longo do absorvedor. Além disso, absorvedores de filme descendente se mostram mais robustos, em função de sua maior estabilidade operacional. 


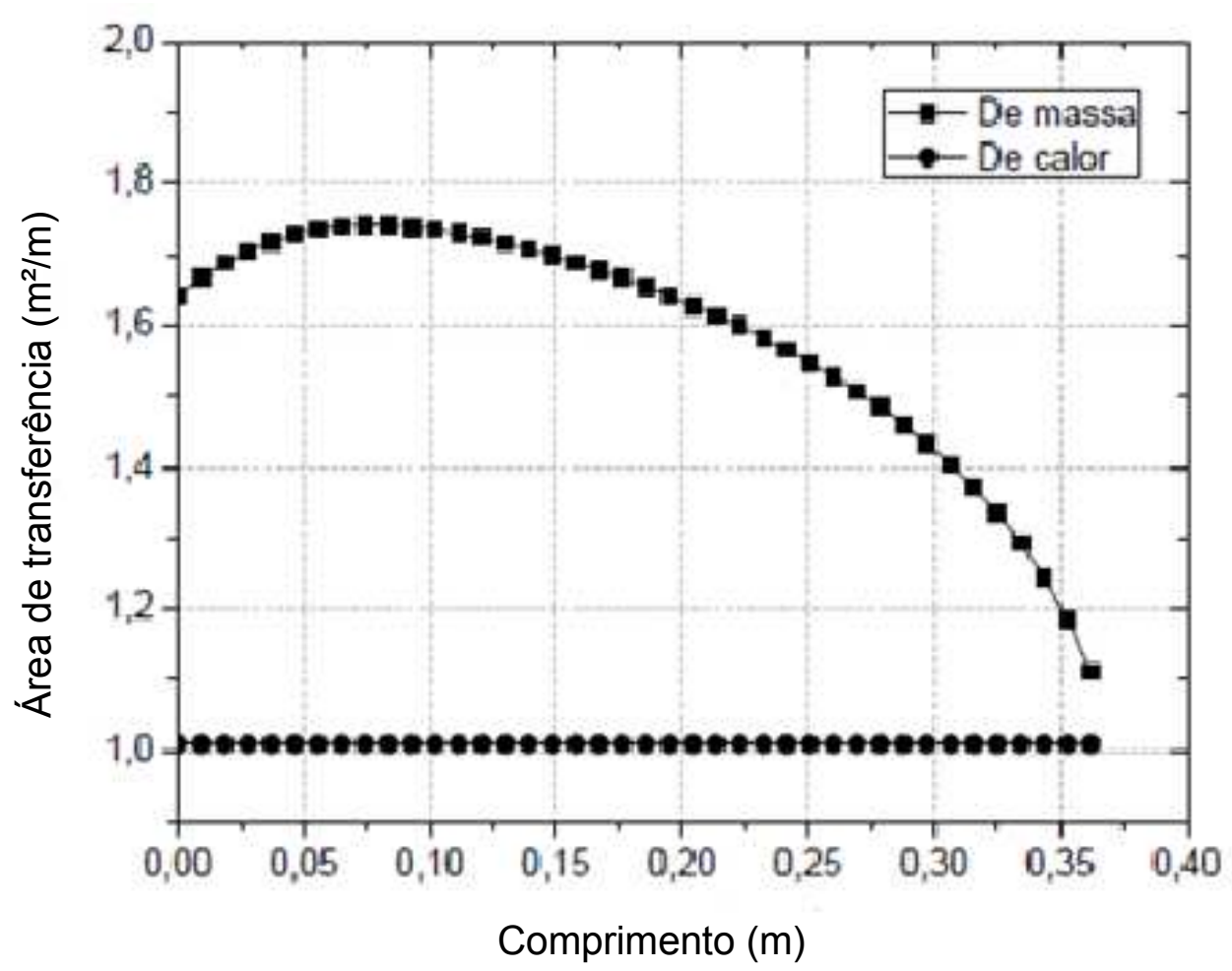

Figura 3.26 - Área de transferência de massa e calor em um absorvedor tipo bolha (Makiyama, 2008)

\subsubsection{Modos de escoamento em filme descendente}

De acordo com Bohra (2007), boa parte da literatura tem tratado o escoamento da solução ao redor dos tubos de absorvedores de filme descendente, como uma película laminar lisa. Porém, na realidade, o que acontece é bastante diferente. Em geral, o padrão de escoamento depende da vazão da solução, de suas propriedades físicas e do espaçamento existente entre os tubos (Mitrovic 2005). Alguns pesquisadores afirmam que a presença de vapor na vizinhança da película pode afetar significantemente o padrão de escoamento. Os principais regimes de escoamento em filme descendente, apresentados na Fig. 3.27, são os seguintes: gotejamento "droplet", jato "jet" e lâmina "sheet". Nessa figura, $\lambda$ é a distância existente entre duas colunas adjacentes de gotejamento, $d$ é o diâmetro do tubo e $s$ é o espaçamento vertical entre dois tubos. 


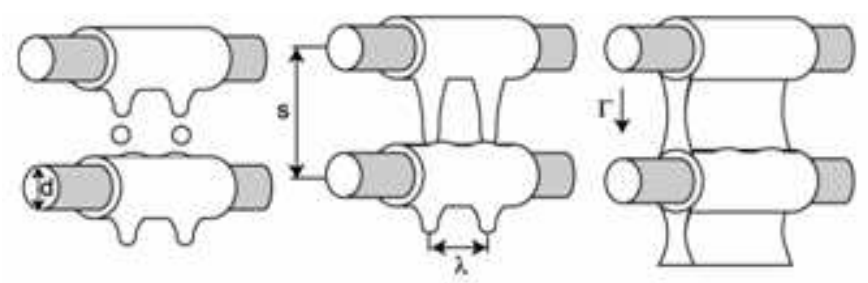
a) Gotejamento
b) Jato
c) Lâmina (Sheet)

Figura 3.27 - Padrões de escoamento ao redor de tubos horizontais (Mitrovic, 2005)

Os principais parâmetros utilizados para o desenvolvimento dos critérios de transição do escoamento são o número de Reynolds do filme $\left(R e_{l}\right)$ e o número de Kapitza $(K a)$ ), definidos pelas Eqs. (3.5) e (3.6), respectivamente.

$$
\begin{gathered}
R e_{l}=\frac{4 \Gamma}{\mu_{l}} \\
K a_{l}=\frac{\sigma_{l}^{3} \rho_{l}}{\mu_{l}^{4} g}
\end{gathered}
$$

Onde:

$$
\Gamma=\frac{\dot{m}_{l}}{2 W}
$$

Sendo $\dot{m}_{l}$ a vazão mássica do filme líquido, $W$ o comprimento dos tubos horizontais, $\mu_{l}$ e $\rho_{l}$ viscosidade e densidade da fase líquida, respectivamente, e $\sigma_{l}$ a tensão superficial da solução.

Sultana (2006) reporta em sua tese de doutoramento, com base nos experimentos realizados por Hu e Jacobi (1996), que para o escoamento em filme descendente de brometo de lítio 54\% em massa, quando o número de Reynolds é menor que 24,83 o regime de escoamento observado é o de gotejamento ou "droplet". Para números de Reynolds superiores a 24,83, porém menores que 36,86, o regime é o de fluxo misturado ou "droplet-jet". Quando o número de Reynolds é maior que 36,86 porém inferior a 125,6 o modo de escoamento existente se dá na 
forma de jato ou "jet flow" e quando Reynolds é maior que 125,6, observa-se o escoamento em jato-lâmina ou "jeet sheet".

A transição, entre tipos de regime, em escoamentos em filme descendente vem sendo estudada experimentalmente por inúmeros autores, que utilizam a forma genérica do critério de transição, apresentada na Eq.(3.8).

$$
R e_{l}=a K a_{l}^{b}
$$

Mohamed (2007) realizou um trabalho experimental em que correlacionou os números de $R e_{\text {l }}$ e $K a_{l}$, e apresentou as constantes empíricas a e $b$, para a transição dos modos de escoamento, incluindo também os modos intermediários. A Tabela (3.5) apresenta os coeficientes referentes a cada tipo de transição.

Hu e Jacobi (1996a) definem de forma mais refinada e específica os modos de escoamento em filme descendente ao redor de tubos horizontais. Como se observa na Fig. (3.28), os autores identificam seis tipos de escoamento, sendo eles: gotejamento ("droplet"), gotejamento-jato ("droplet-jet"), jato em linha ("in-line jet"), jato escalonado ("staggered jet), jato-lâmina ("jet-sheet") e lâmina ("Sheet").

Tabela 3.5 - Constantes para correlação de transição de modo de escoamento (adaptado, Mohamed, 2007)

\begin{tabular}{ccccc}
\hline & $\begin{array}{c}\text { Gotejamento/ } \\
\text { Gotejamento-Jato }\end{array}$ & $\begin{array}{c}\text { Gotejamento- } \\
\text { Jato/Jato }\end{array}$ & $\begin{array}{c}\text { Jato/ } \\
\text { Jato-Lâmina }\end{array}$ & $\begin{array}{c}\text { Jato- } \\
\text { Lâmina/Lâmina }\end{array}$ \\
\hline a & 0,0785 & 0,0978 & 1,5031 & 1,491 \\
b & 0,2965 & 0,2998 & 0,2273 & 0,2353 \\
\hline
\end{tabular}

Segundo Jeong e Garimella (2002), o regime de gotejamento proporciona elevado grau de mistura, alcançado durante a formação e o impacto das gotículas ao longo das superfícies de resfriamento, condição que favorece elevação dos coeficientes de transferência de massa e calor entre as fases vapor e líquida. Os 
autores demonstraram que o gotejamento pode ser responsável por mais de $50 \%$ da taxa total de absorção, dependendo da vazão de operação.

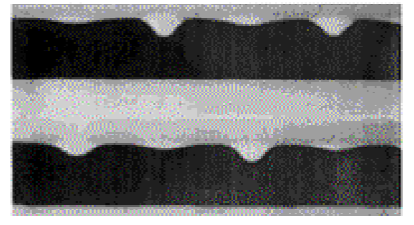

(a)

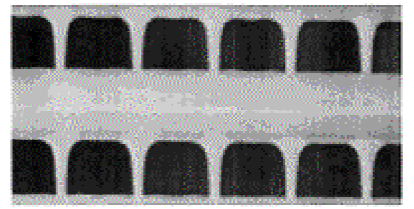

(c)

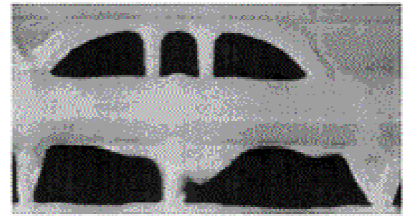

(e)

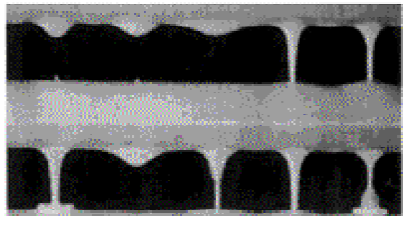

(b)

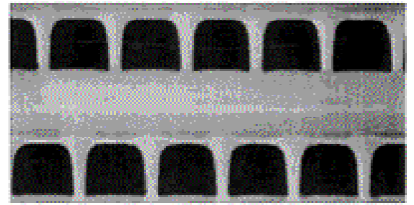

(d)

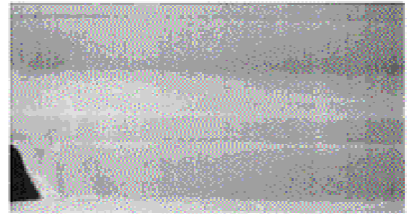

(f)

Figura 3.28 - Padrões de escoamento em filme descendente ao redor de tubos horizontais. (a) gotejamento; (b) gotejamento-jato; (c) jato em linha; (d) jato escalonado; (e) jato-lâmina; (f) lâmina (Hu e Jacobi, 1996)

Hu e Jacobi (1996b) realizaram um estudo experimental que visava prever os vários tipos de escoamento ao redor de tubos horizontais. Os ensaios foram conduzidos utilizando-se água, etileno glicol, óleo e etanol como correntes líquidas, tanto na presença como na ausência de ar na corrente gasosa. Os autores observaram que em baixas vazões os sítios originários das gotas não estavam todos ativos simultaneamente e as mesmas caíam alternadamente. Com a elevação da vazão, os sítios se tornavam todos ativos e a queda das gotas passava a apresentar maior simultaneidade. Não foi encontrada influência significativa do fluxo de ar nos modos de escoamento para a maioria das condições de operação. Os autores avaliaram também a transição do modo de escoamento através da elevação e da diminuição da vazão de solução, buscando-se identificar a presença ou não de histerese, como por exemplo, gotejamento para jato versus jato para gotejamento. Embora tenha sido encontrada histerese na transição de todos os modos de escoamento, seu efeito no número de Reynolds se mostrou desprezível. 


\section{METODOLOGIA E MODELAGEM FÍSICA}

Nos capítulos anteriores foi apresentada a revisão bibliográfica dos conceitos termodinâmicos e fenômenos de transferência de calor e massa envolvidos no processo absortivo amônia-água. Discutiu-se também as diversas possibilidades de escoamento em filme descendente ao redor de tubos circulares, assim como também foram abordados outros tipos de absorvedores utilizados em ciclos de absorção.

Neste capítulo são apresentadas as correlações necessárias para se avaliar os coeficientes convectivos de transferência de calor nas fases líquida e vapor. A avaliação desses coeficientes é extremamente importante, visto que, através da aplicação da analogia de Chilton-Colburn serão obtidos os coeficientes convectivos de transferência de massa. São apresentadas, também, equações que avaliam as propriedades da mistura amônia-água para condições de temperatura e frações mássicas variáveis ao longo do absorvedor. Dessa forma, as propriedades, tanto da fase vapor quanto da fase líquida, não são consideradas constantes ao longo do equipamento e se modificam em conseqüência das alterações de concentração e temperatura.

Balanços de massa e energia foram realizados levando-se em conta um volume de controle representativo de um absorvedor de filme descendente constituído por colunas de tubos horizontais. Todos esses balanços, juntamente com as equações de propriedades e correlações, foram solucionados no EES (Engineering Equation Solver). Tal software é uma ferramenta capaz de resolver simultaneamente sistemas de equações não lineares, além de possuir uma vasta biblioteca de propriedades termodinâmicas que compreende as condições de equilíbrio da mistura amônia-água e todas as propriedades das mesmas substâncias puras.

As condições de entrada da simulação são definidas com base em resultados provenientes do software PSSRA (Programa de simulação de sistemas de refrigeração por absorção) desenvolvido por Simões Moreira e Ortigosa (2008), o qual fornece estados termodinâmicos relevantes, tais como pressão, temperatura, 
vazão mássica e fração mássica das correntes de vapor e solução pobre que ingressam no absorvedor.

\subsection{Configuração idealizada}

Buscou-se neste trabalho, principalmente, analisar aspectos relacionados aos fenômenos de transferência, que ocorrem ao longo do processo absortivo, considerando-se basicamente os processos que ocorrem na interface líquido-vapor ao longo do escoamento, ao redor de tubos horizontais. Dessa maneira, foi admitida uma configuração aproximada do equipamento, que possibilitou o desenvolvimento do modelo.

O esboço do sistema em questão é constituído basicamente de um banco de tubos dispostos horizontalmente, no interior dos quais escoa água com a finalidade de retirar o calor gerado no processo de absorção. A solução pobre é alimentada no topo do absorvedor e escoa descendentemente ao redor dos tubos horizontais resfriados, formando uma película líquida de fina espessura.

Como exposto ao longo da revisão bibliográfica, essa película se desenvolve, sob influência da gravidade, desde o topo até a base do equipamento. O vapor de amônia é alimentado também no topo, escoando e sendo absorvido concorrentemente pelo filme líquido. A Fig. 4.1 é apresentada com intuito de se visualizar os aspectos básicos do absorvedor, não determinando necessariamente as quantidades de colunas e tubos que serão consideradas ao longo do desenvolvimento e na resolução das equações mais adiante. 


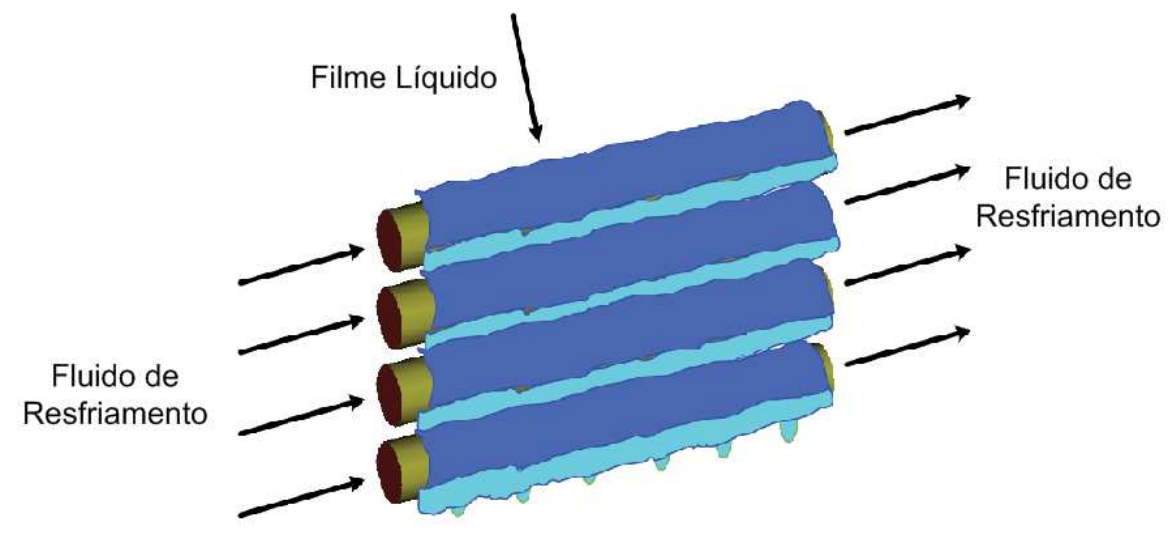

(a)

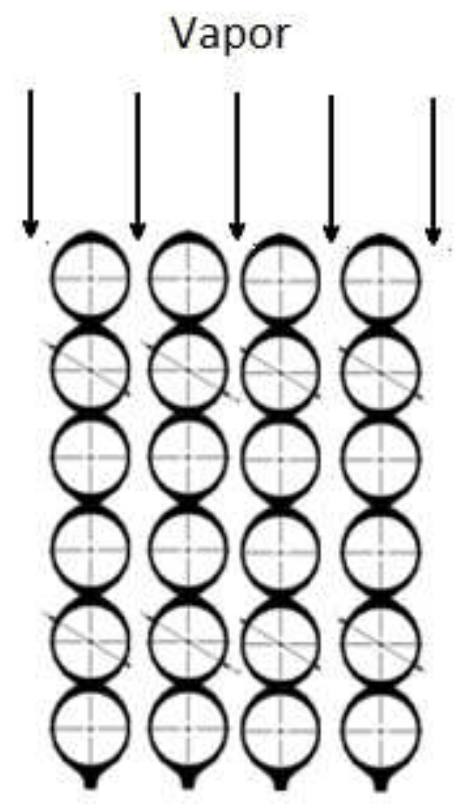

(b)

Figura 4.1- Esquema de absorvedor de filme descendente de tubos horizontais: (a) vista em perspectiva, (b) vista perpendicular

\subsection{Hipóteses adotadas na modelagem}

O desenvolvimento de modelos matemáticos representativos de absorvedores amônia-água torna-se um grande desafio, à medida que se faz necessária a 
consideração simultânea dos fenômenos de transferência de massa e calor em duas fases, associada ao escoamento de misturas binárias.

O modelo proposto leva em conta as resistências à transferência de massa nas fases líquida e vapor e utiliza correlações empíricas para predizer os coeficientes necessários, que serão utilizados na resolução das equações de transporte. As seguintes hipóteses são consideradas no desenvolvimento e utilização das equações que constituem do modelo:

- pressão do sistema constante;

- processo de absorção em estado estacionário;

- ausência de água na fase vapor, ou seja, $\mathrm{y}=1$;

- equilíbrio termodinâmico na interface líquido-vapor;

- absorção completa da fase vapor;

- perda de calor para o ambiente negligenciável;

- não ocorre inundação do absorvedor;

- efeito de vapores não absorvíveis é ignorado;

- superfície dos tubos lisa;

- região entre dois tubos subseqüentes desprezada;

- escoamento turbulento no interior dos tubos;

- temperatura do fluido de resfriamento constante;

- absorvedor perfeitamente nivelado;

- a superfície dos tubos é completamente molhada, não havendo

transferência direta de calor entre o vapor e os tubos.

\subsection{Espessura do filme líquido descendente}

Para a determinação da espessura do filme descendente será utilizada solução de Nusselt, apresentada por Treybal (1981), a qual é baseada na solução das equações de quantidade de movimento (equações de Navier-Stokes). A Fig. (4.2) ilustra o escoamento de uma película de líquido descendente exposta ao vapor de amônia, simbolizado por " $A$ ”, o qual vai sendo absorvido pela solução ao longo do comprimento do absorvedor. Naturalmente, em decorrência da adição de massa 
(amônia), a película tem sua espessura aumentada gradativamente ao longo dos tubos até a base do equipamento.

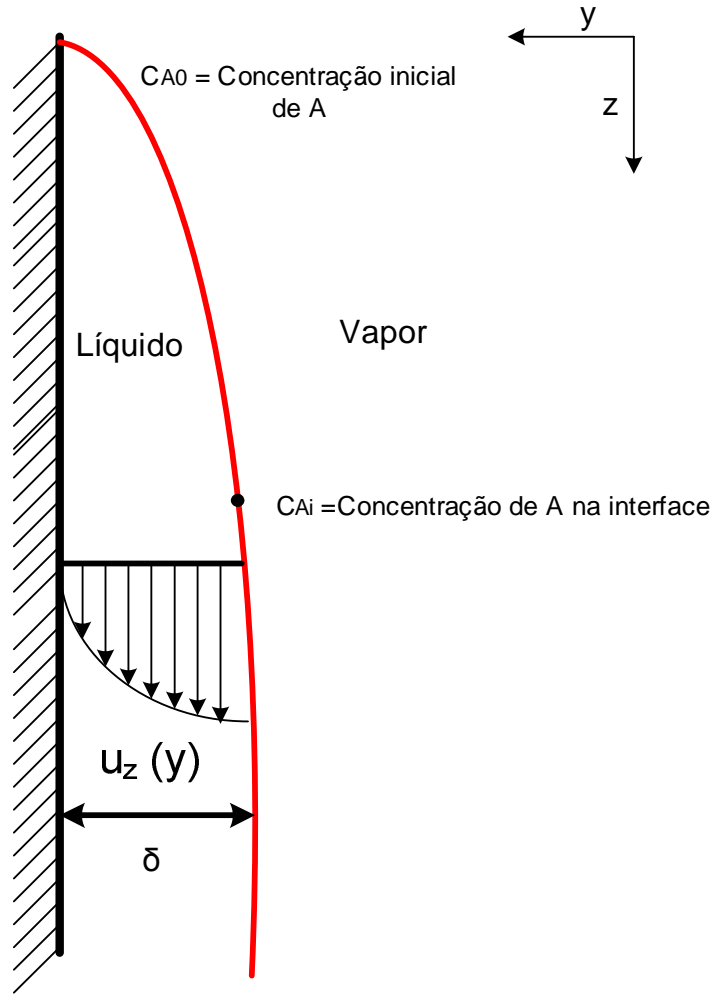

Figura 4.2 - Filme descendente de líquido exposto ao vapor

A velocidade do filme líquido descendente é representada por $u_{z}$ e sua espessura por $\delta$. As equações de transporte, sob as condições do processo de absorção em filme descendente, se reduzem a Eq. (4.1) fornecida por Treybal (1981).

Avalia-se que não há necessidade de se explicitar todos os passos do desenvolvimento matemático para a obtenção das equações, bastando suas apresentações.

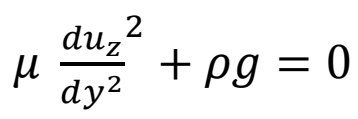


A solução da Eq. (4.1) é obtida aplicando-se as seguintes condições de contorno:

- a velocidade do filme líquido é nula na parede, ou seja, $u_{z}=0$ em $y=\delta$;

- a derivada da velocidade, em relação ao eixo $y$, na parte externa do filme líquido é nula, ou seja, $\frac{d u_{z}}{d y}=0$ em $y=0$.

Dessa forma, a solução da Eq.(4.1) é dada pela Eq. (4.2), também apresentada por Treybal (1981), a qual fornece a espessura do filme descendente em função de propriedades da fase líquida e de condições operacionais estabelecidas.

$$
\delta=\left(\frac{3 \Gamma \mu_{l}}{\rho_{l}^{2} g}\right)^{1 / 3}
$$

Onde, $\mu_{l}$ é a viscosidade do líquido, $\rho_{l}$ sua densidade e $g$ a aceleração gravitacional. Com $\Gamma$ representando a razão entre a vazão mássica do filme líquido $\left(\dot{m}_{l}\right)$ e o produto do comprimento dos tubos $(W)$ e o número de colunas de tubos presentes no absorvedor $\left(N_{C}\right)$.

Considerando-se que o fluxo mássico de solução se distribui uniformemente ao redor das duas faces das colunas de tubos é necessário dividi-lo por dois. Dessa forma, tem-se a Eq. (4.3).

$$
\Gamma=\frac{\dot{m}_{l}}{2 N_{c} W}
$$




\subsection{Determinação do número de colunas do absorvedor}

A determinação do número de colunas do absorvedor é realizada a partir da definição prévia do comprimento dos tubos e da admissão de um número máximo de Reynolds para o escoamento do filme, o qual é fornecido pela Eq. (4.4).

$$
R e_{\operatorname{lmax}}=\frac{4 \Gamma_{\max }}{\mu_{l}}
$$

Assumindo-se que a vazão mássica máxima é a soma das vazões de solução e de vapor, ou seja, é a vazão obtida no final do absorvedor, têm-se que:

$$
\dot{m}_{l \max }=\dot{m}_{l}+\dot{m}_{v}
$$

Assim, a vazão mássica por unidade de comprimento $\Gamma_{\max }$ é dada por:

$$
\Gamma_{\max }=\frac{\dot{m}_{\operatorname{lmax}}}{2 N_{c} W}
$$

Dessa maneira, fazendo a substituição de (4.6) em (4.4) e isolando $N_{c}$, obtémse (4.7), equação que fornece o número de colunas constituintes do absorvedor para determinada condição de $R e_{l \max }$ adotada.

$$
N_{c}=\frac{4 \dot{m}_{l \max }}{2 W \operatorname{Re}_{l \max } \mu_{l}}
$$


Optou-se por essa metodologia de cálculo em virtude da vazão total de solução ao final do absorvedor ser fixa, levando-se em consideração um ciclo de 5TR de capacidade de refrigeração. Neste caso, toma-se mais adiante, como condição de avaliação paramétrica, a variação do número máximo de Reynolds, o que consequentemente resulta em absorvedores de números de colunas diferentes e comportamentos distintos no que se refere ao desenvolvimento dos coeficientes de transferência.

\subsection{Avaliação de coeficientes de transferência de massa e calor através de correlações e analogias}

A similaridade entre os processos de transferência de massa e calor pode ser utilizada para deduzir os coeficientes análogos. A analogia é particularmente útil quando há dificuldade em se obter um dos coeficientes. Nesse caso, os coeficientes de transferência de massa nas fases líquida $K_{b}$ e na fase vapor $K_{v}$, são obtidos através da utilização da analogia de Chilton-Colburn, aplicada separadamente para ambas as fases. Tal analogia é válida para gases e líquidos dentro das faixas de $0,6<S c<2500$ e $0,6<\operatorname{Pr}<2500$. Sc e $\operatorname{Pr}$ representam os números de Schmidt e Prandtl, respectivamente, os quais serão definidos logo mais adiante.

De acordo com Welty et al. (2001) a analogia de Chilton-Colburn define o fator de transferência de massa $j_{D}$, dado pela Eq. (4.8) a seguir:

$$
j_{D} \equiv \frac{K}{v_{\infty}}(S c)^{2 / 3}
$$

Onde $K$ é o coeficiente convectivo de transferência de massa e $v_{\infty}$ é a velocidade no seio do fluido.

O fator $j_{D}$ é análogo ao fator de transferência de calor $j_{H}$, definido na Eq. (4.9):

$$
j_{H} \equiv S t(P r)^{\frac{2}{3}}
$$


St é o chamado número de Stanton, um adimensional que mede a relação entre o calor transferido para um fluido e sua capacidade calorífica, sendo utilizado na caracterização de processos que envolvem convecção forçada, definido pela Eq.(4.10).

$$
S t=\frac{h}{\rho v_{\infty} C_{p}}
$$

A espessura relativa das camadas limite hidrodinâmica e térmica é descrita pelo adimensional conhecido como número de Prandtl $\mathrm{Pr}$, dado pela Eq. (4.11). Esse adimensional varia de aproximadamente $10^{-2}$, para metais líquidos, até mais de $10^{5}$ para óleos pesados. Para gases e vapores, seu valor gira em torno da unidade, indicando que tanto a quantidade de movimento quanto a de calor, dissipam-se à mesma taxa. Segundo Çengel (2009) um número de Pr próximo da unidade indica que a transferência de quantidade de movimento e de calor por difusão são comparáveis e que as camadas limite hidrodinâmica e térmica quase coincidem.

$$
\operatorname{Pr}=\frac{C_{p \mu}}{\alpha}
$$

O número de Schmidt Sc representa as magnitudes relativas à difusão molecular de quantidade de movimento e de massa nas camadas limite hidrodinâmica e de concentração, respectivamente. Analogamente ao que acontece com o número de Prandtl, quando Sc se aproxima da unidade, a transferência de quantidade de movimento e de massa por difusão são comparáveis e as camadas limite hidrodinâmica e de concentração quase coincidem.

$$
S c=\frac{\mu}{\rho D_{i f f}}
$$

Nos adimensionais descritos, $\rho$ é a densidade, $C_{p}$ o calor específico, $D_{\text {iff }}$ a difusividade, $\alpha$ a condutividade térmica e $\mu$ a viscosidade. 
Assim, igualando-se os dois fatores de transferência definidos nas Eqs. (4.8) e (4.9), obtém-se a expressão (4.13), que relaciona transferência convectiva de calor e massa. De tal modo, é possível encontrar os coeficientes convectivos de transferência de massa $K_{V}$ e $K_{l}$, os quais serão utilizados na determinação do fluxo de amônia.

$$
\begin{gathered}
j_{D}=j_{H} \\
\frac{K}{v_{\infty}}(S c)^{2 / 3}=\frac{h}{\rho v_{\infty} C_{p}}(P r)^{\frac{2}{3}}
\end{gathered}
$$

Assim, temos que:

$$
\begin{aligned}
& K_{v}=\frac{h_{v}}{C_{p_{v}} \rho_{v}\left(\frac{S c_{v}}{P r_{v}}\right)^{\frac{2}{3}}} \\
& K_{l}=\frac{h_{l}}{C_{p_{l}} \rho_{l}\left(\frac{S c_{l}}{P r_{l}}\right)^{\frac{2}{3}}}
\end{aligned}
$$

Como observado nas Eqs. (4.14) e (4.15), há a necessidade de se obter os coeficientes convectivos de transferência de calor para a obtenção dos coeficientes de transferência de massa. Incropera e DeWitt (2002) fornecem a correlação (4.16) para obtenção de $h_{v}$ entre a fase vapor e o filme descendente ao redor de tubos cilíndricos horizontais, sendo esta equação válida para $40<R e_{\sqrt{ }}<4000$.

$$
h_{v}=\left(\frac{\alpha_{v}}{D_{e}}\right) 0,683 R e_{v}^{0,466} \operatorname{Pr}_{v}^{\frac{1}{3}}
$$


Sendo que, $\alpha_{\mathrm{v}}$ é a condutividade térmica do vapor e $D_{e}$ o diâmetro externo dos tubos.

O coeficiente convectivo de transferência de calor no filme líquido $h_{\uparrow}$ é obtido a partir da correlação desenvolvida por Wilke, fornecida por Yih (1986), Eq. (4.18). Tal correlação se aplica a escoamentos em regime laminar, condição de escoamento adotada neste trabalho, e é estabelecida para $\operatorname{Re}_{l<2460} \operatorname{Pr}^{-0,646}$. O valor de $R e_{\text {, n no }}$ caso de escoamento em filme descendente ao redor de tubos é obtido através da Eq. (4.17) a seguir:

$$
\begin{gathered}
R e_{l}=\frac{4 \Gamma}{\mu_{l}} \\
h_{l}=1,88\left(\frac{\alpha_{l}}{\delta}\right)
\end{gathered}
$$

Onde, $\alpha_{l}$ é a condutividade térmica da fase líquida e $\delta$ é a espessura do filme líquido em escoamento laminar, determinada pela Eq. (4.2).

O cálculo coeficiente convectivo de transferência de calor do fluido de resfriamento, $h_{c}$, pode ser realizado considerando-se escoamento laminar ou turbulento no interior dos tubos. Para tubos circulares, o escoamento é laminar quando $R e_{c}<2300$ e passa a ser turbulento para $R e_{c}>4000$. Dessa forma, são consideradas duas correlações, (4.19) e (4.20), obtidas do trabalho de Islam (2007), sendo a primeira destinada à obtenção do coeficiente em escoamento laminar, e a segunda para obtenção do coeficiente em escoamento turbulento. Porém, de acordo com Suryanarayana (1995), na prática, se torna mais interessante a utilização de escoamento turbulento, dado o alcance de maiores coeficientes de transferência de calor.

$$
\begin{gathered}
h_{\text {clam }}=4,364\left(\frac{\alpha_{c}}{D_{i}}\right) \\
h_{c \text { turb }}=\frac{\alpha_{c}}{D_{i}}\left(0,024 \operatorname{Re}_{c}{ }^{0,8} \operatorname{Pr}_{c}{ }^{\frac{1}{3}}\right)
\end{gathered}
$$


Onde, $\alpha_{c}$ é a condutividade térmica do fluido de resfriamento e $D_{i}$ o diâmetro interno dos tubos.

\subsection{Propriedades da mistura amônia-água}

Reiterando o que foi apresentado na revisão bibliográfica, o processo de absorção em película descendente possui a presença de duas fases distintas, com os fenômenos de transferência de calor e massa ocorrendo simultaneamente. Nesse contexto, torna-se imprescindível o cálculo das propriedades requeridas em ambas as fases, considerando-se a variação de temperatura e composição ao longo de todo o absorvedor.

Conforme Perez-Blanco (1988), para valores típicos de taxa de absorção, a correção de Ackerman indica que a distorção do perfil de temperatura devido à transferência de massa no filme é mínima e se desvia do correspondente em escoamento laminar somente nas regiões de entrada e desenvolvimento da película líquida.

Tanto a fase líquida como a fase vapor irão possuir diferentes temperaturas e concentrações de amônia ao longo do absorvedor, sendo necessária a correção das propriedades para essas diferentes condições. Admitem-se condições de idealidade para a mistura água-amônia. Assim, calor específico, condutividade térmica, densidade e viscosidade das fases líquida e vapor, são avaliadas através das seguintes leis de mistura:

$$
\begin{gathered}
C_{p l}(T, x)=x C_{p N H_{3}}\left(T_{N_{3}}\right)+(1-x) C_{p H_{2} O}\left(T_{H_{2} O}\right) \\
C_{p v}(T, y)=y C_{p N H 3}\left(T_{N H 3}\right)+(1-y) C_{p H_{2} O}\left(T_{H_{2} O}\right) \\
k_{l}=x k_{N H_{3}}+(1-x) k_{H_{2} O} \\
k_{v}=y k_{N H_{3}}+(1-y) k_{H_{2} O}
\end{gathered}
$$




$$
\begin{aligned}
& \rho_{l}=x \rho_{N_{3}}+(1-x) \rho_{H_{2} O} \\
& \rho_{v}=y \rho_{N H_{3}}+(1-y) \rho_{H_{2} O}
\end{aligned}
$$

A difusividade mássica da amônia em água é obtida através da Eq. (4.27), proposta por Wilke e Chang (1955)

$$
D_{i f f}=117,282 \times 10^{-8} T_{l} \frac{\sqrt{\psi_{l} M_{l}}}{\mu_{l} V^{0,6} d i f f}
$$

Onde $\psi_{l}$ é chamado de fator associativo da mistura, $\mu_{l}$ a viscosidade dinâmica, $M_{l}$ a massa molecular da mistura e $V_{\text {diff }} O$ volume molar da amônia. Assumindo condições de idealidade os valores de $\psi_{l}, \mu_{l}$ e $M_{l}$ são fornecidos pelas Eqs. (4.28), (4.29) e (4.30), respectivamente.

$$
\begin{aligned}
& \psi_{l}=x \psi_{N H_{3}}+(1-x) \psi_{H_{2} O} \\
& M_{l}=x M_{N H_{3}}+(1-x) M_{H_{2} O} \\
& \mu_{l}=x \mu_{N H_{3}}+(1-x) \mu_{H_{2} O}
\end{aligned}
$$

Os parâmetros característicos para as substâncias puras são fornecidos pela Tabela 4.1. 
Tabela 4.1 - Parâmetros característicos para substâncias puras (Wilke e Chang, 1955)

\begin{tabular}{ccc}
\hline & $\psi$ & $M$ \\
\hline $\mathrm{NH3}$ & 1,7 & 17,03 \\
$\mathrm{H} 2 \mathrm{O}$ & 2,6 & 18,02 \\
\hline
\end{tabular}

O volume molar $V_{\text {diff }}$ é dado pela razão entre a massa molar da amônia e sua densidade na temperatura da mistura.

$$
V_{\text {diff }}=\frac{M_{N_{3}}}{\rho_{N H_{3}}}
$$

\subsection{Temperatura e frações mássica na interface}

A resistência à transferência de massa ocorre apenas nos fluidos e não na interface. Como resultado dessa hipótese, as frações mássicas $y_{\text {int }}$ e $x_{\text {int }}$ são decorrentes do equilíbrio termodinâmico, e dadas pela curva de distribuição de equilíbrio do sistema. Assim, temperatura, fração mássica e pressão da mistura binária estão acopladas uma as outras na temperatura de saturação.

Dessa maneira, as frações mássicas na interface da amônia nas fases vapor e líquida na interface podem ser expressas como:

$$
\begin{aligned}
& x_{i n t}=f\left(T_{i n t}, P\right) \\
& y_{i n t}=f\left(T_{i n t}, P\right)
\end{aligned}
$$


Para a determinação da temperatura na interface utilizou-se a Eq. (4.35) apresentada por Perez-Blanco (1988), a qual determina essa temperatura através da igualdade dos fluxos convectivos de calor nas fases líquida e vapor, apresentada na Eq.(4.34).

$$
d A h_{l}\left(T_{i n t}-T_{l}\right)=d A h_{v}\left(T_{v}-T_{i n t}\right)
$$

Realizando-se as devidas operações algébricas, obtém-se a Eq. (4.35).

$$
T_{\text {int }}=\frac{\left(\frac{h_{v}}{h_{l}}\right) T_{v}+T_{l}}{1+\frac{h_{v}}{h_{l}}}
$$

De posse da temperatura na interface e da pressão, considerada constante no sistema, pode-se obter facilmente, através da imposição de condição de equilíbrio, as frações mássicas $x_{\text {int }}$ e $y_{\text {int. }}$. Tais frações possibilitam a obtenção dos gradientes de concentração existentes, tanto entre a interface e o seio do fluido, como entre interface e o seio do vapor.

\subsection{Balanços de massa}

A transferência de massa entre o vapor e a solução não é consequência apenas do gradiente de concentração existente entre as fases. É também ocasionada pelo processo difusivo através da interface e ao longo do filme. Assim, para estado estacionário, o fluxo total de vapor absorvido pela solução pobre é dado pelas equações (4.36) e (4.37), desenvolvidas por Colburn e Drew e apresentadas por Erickson et al. (1998).

Pode-se notar que esta formulação considera que o vapor de água associado que migra em conjunto com a amônia da fase vapor para a fase líquida. 


$$
\begin{gathered}
d \dot{m}_{N_{3}}+d \dot{m}_{H_{2} O}=K_{l} d A \ln \left(\frac{z-x}{z-x_{i n t}}\right) \\
d \dot{m}_{N_{H_{3}}}+d \dot{m}_{H_{2} O}=K_{v} d A \ln \left(\frac{z-y_{i n t}}{z-y}\right)
\end{gathered}
$$

Como os vapores de amônia e água podem ser absorvidos e desorvidos, o fluxo molar e mássico é constituído de ambos. A fração mássica de amônia na absorção/desorção é definida como z, expressa pela Eq.(4.38).

$$
Z=\frac{d \dot{m}_{\mathrm{NH}_{3}}}{d \dot{m}_{\mathrm{NH}_{3}}+d \dot{m}_{\mathrm{H}_{2} \mathrm{O}}}
$$

No entanto, conforme exposto nas hipóteses de desenvolvimento do modelo, com o intuito de simplificar os esforços de cálculo, considera-se que a fase vapor é constituída apenas de vapor de amônia ausente de água, ou seja, z é igual a 1.

Como consequência desta hipótese, não ocorre migração de água da fase vapor para a fase líquida. Dessa maneira, as equações (4.36) e (4.37) podem ser reescritas como:

$$
\begin{aligned}
& d \dot{m}_{N H_{3}}=K_{l} d A \ln \left(\frac{1-x}{1-x_{i n t}}\right) \\
& d \dot{m}_{N H_{3}}=K_{v} d A \ln \left(\frac{1-y_{i n t}}{1-y}\right)
\end{aligned}
$$

Os balanços de massa e energia são realizados levando-se em consideração um volume de controle representativo de comprimento $d L$ que compreende a superfície de resfriamento, o filme líquido, a interface e o vapor. Através do volume 
de controle esquematizado na Fig. (4.3), visualiza-se o desenvolvimento das equações de balanço mais facilmente. Nessa formulação, $i$ denota a entrada a do volume de controle e $i+1$ a sua saída. Assim, cada uma das correntes (vapor e solução pobre) terá uma vazão, temperatura, fração mássica e entalpia correspondente a posição em que se encontra, ou seja, na saída ou na entrada do volume de controle.

Portanto, aplicando-se o princípio de conservação de massa para o volume estabelecido, temos as seguintes equações de balanço:

Balanço de massa total na fase líquida

$$
\dot{m}_{l(i+1)}=\dot{m}_{l(i)}+d \dot{m}_{N H_{3}(i)}
$$

Balanço de massa total na fase vapor

$$
\dot{m}_{v(i+1)}=\dot{m}_{v(i)}-d \dot{m}_{N H_{3}(i)}
$$

Balanço de amônia na fase líquida

$$
\dot{m}_{l(i+1)} x_{(i+1)}=\dot{m}_{l(i)} x_{(i)}+d \dot{m}_{N H_{3}(i)}
$$

Balanço de amônia na fase vapor

$$
\dot{m}_{v(i+1)} y_{(i+1)}=\dot{m}_{v(i)} y_{i}-d \dot{m}_{N H_{3}(i)}
$$




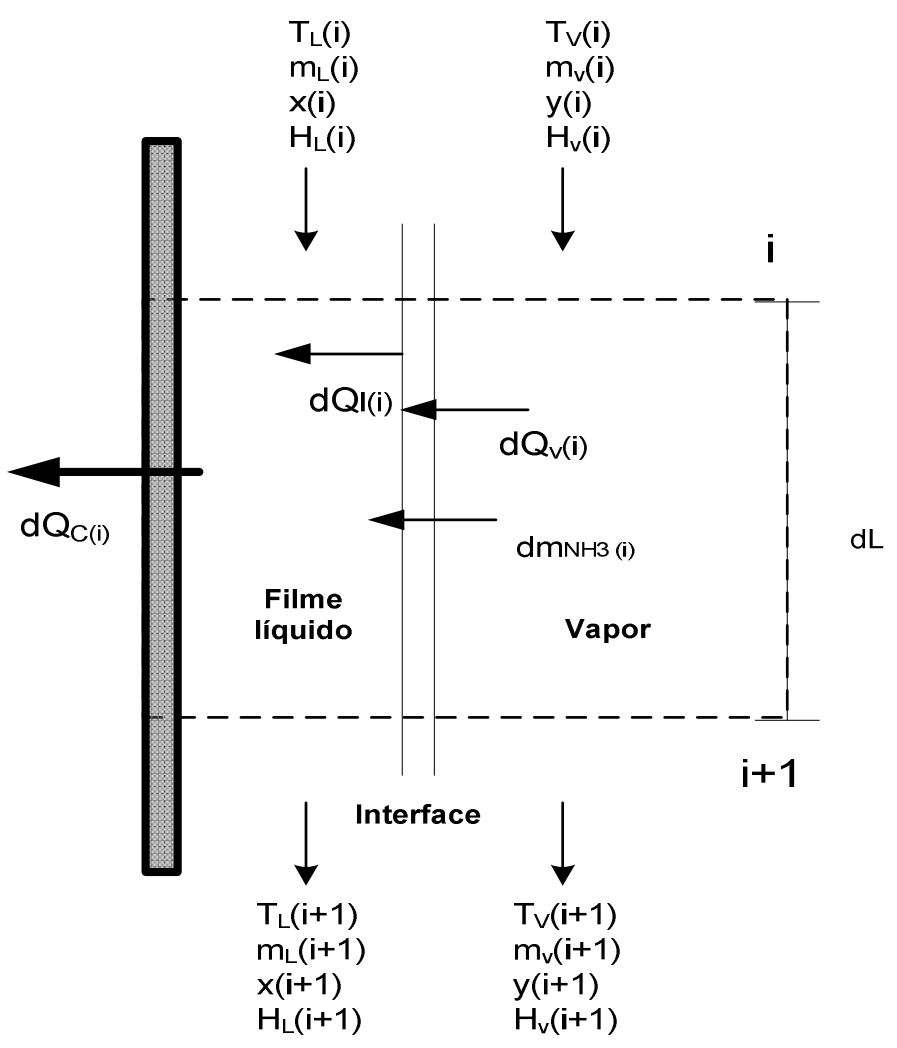

Figura 4.3 - Volume de controle de uma seção do absorvedor

\subsection{Balanços de energia}

A transferência de calor entre o filme e o vapor ocorre em consequência da contribuição combinada da transferência convectiva e da carga de calor sensível transferida conjuntamente com a massa de amônia através da interface. 0 coeficiente convectivo de transferência de calor comum é devido ao gradiente de temperatura entre o fluido em movimento e a superfície que o delimita. Se esse coeficiente é também acompanhado por transferência de massa, uma quantidade extra de calor será também transportada.

Assim, o coeficiente convectivo de transferência de calor deve ser modificado de maneira a contabilizar os efeitos da transferência simultânea de massa. Treybal (1980) apresenta a Eq.(4.45), que fornece o coeficiente convectivo modificado. 


$$
h^{*}=h \frac{c}{1-e^{-c}}
$$

Onde, $c$ é dado por:

$$
c=\frac{d \dot{m}_{N_{3}(i)} C_{p N H_{3}(i)}}{h_{(i)}}
$$

Portanto, o fluxo de calor convectivo existente entre a interface e o filme pode ser obtido pela Eq. (4.47), que utiliza o coeficiente modificado $h_{l}{ }^{*}$.

$$
d \dot{Q}_{l(i)}=h_{l}^{*} d A\left(T_{i n t}-T_{m l}\right)
$$

Onde, $T_{m l}$ é a temperatura média do líquido entre a entrada e a saída do volume de controle adotado.

Dessa forma, com a obtenção de $d \dot{Q}_{l(i)}$, pode-se desenvolver a seguinte equação de balanço de energia para a fase líquida:

$$
\dot{m}_{l(i)} H_{l(i)}+d \dot{m}_{N H_{3}(i)} H_{N H_{3}(i)}+d \dot{Q}_{l(i)}=d \dot{Q}_{c(i)}+\dot{m}_{l(i+1)} H_{l(i+1)}
$$

Onde, $H$ representa a entalpia específica $(\mathrm{kJ} / \mathrm{kg})$. Usualmente a entalpia específica é representada pela letra $h$ minúscula, porém a mesma simbologia passou a ser utilizada para a representação dos coeficientes convectivos de transferência de calor. 
O cálculo da quantidade de calor transferida em sistemas compostos por mais de uma resistência térmica deve levar em consideração um coeficiente global de transferência $U$ definido por uma expressão análoga à lei do resfriamento de Newton. A Eq.(4.49) fornece o calor transferido do filme para o fluido de resfriamento.

$$
d \dot{Q}_{c(i)}=U d A\left(T_{m l}-T_{c}\right)
$$

O coeficiente $U$ combina as resistências térmicas no caminho do fluxo de calor desde a interface existente entre o filme e o vapor até o fluido de resfriamento. Sendo expresso pela Eq. (4.50).

$$
\frac{1}{U}=\frac{1}{h_{c}}+\frac{1}{h^{*} l}+\frac{e}{\alpha_{t u b o}}
$$

Onde, e representa a espessura da parede dos tubos e $\alpha_{\text {tubo }}$ o coeficiente de condutividade térmica do material.

Para a fase vapor obtém-se o seguinte balanço de energia:

$$
\dot{m}_{v(i)} H_{v(i)}=\dot{m}_{v(i+1)} H_{v(i+1)}+d \dot{m}_{N H_{3}(i)} H_{N H_{3}(i)}+d \dot{Q}_{v(i)}
$$

O fluxo de calor existente entre a interface e a fase vapor pode ser obtido pela Eq.(4.52), o qual também considera o coeficiente convectivo modificado.

$$
d \dot{Q}_{v(i)}=h^{*}{ }_{v} d A\left(T_{m v}-T_{i n t}\right)
$$




\subsection{Condições de entrada e características geométricas}

Nos itens anteriores deste capítulo foram apresentadas as equações que fazem parte do modelo matemático que foi solucionado no software EES. Como já citado anteriormente, alguns dos valores de entrada na simulação são obtidos através do programa PSSRA, desenvolvido por Ortigosa e Simões-Moreira (2007). Serão tomados como referência para esta simulação, alguns parâmetros básicos fornecidos pelo PSSRA para um ciclo de refrigeração por absorção de $5 \mathrm{TR}$, operando com temperaturas de condensação e evaporação iguais a $40^{\circ} \mathrm{C}$ e $-10^{\circ} \mathrm{C}$, respectivamente. Adotou-se água como fluido de resfriamento e desconsiderou-se sua variação de temperatura ao longo dos tubos do absorvedor. No entanto, será avaliado o comportamento do absorvedor para diferentes temperaturas do fluido de resfriamento.

A Tabela (4.2) apresenta os valores de entrada que serão comuns a todas as simulações realizadas.

Tabela 4.2 - Parâmetros de entrada para simulação do absorvedor

\begin{tabular}{|c|c|c|c|c|}
\hline & $T\left({ }^{\circ} \mathrm{C}\right)$ & $x$ & $P($ bar $)$ & $\dot{m}(\mathrm{~kg} / \mathrm{s})$ \\
\hline Solução pobre & - & 0,098 & 2,9 & 0,031 \\
\hline Vapor & 26,42 & 1 & 2,9 & 0,015 \\
\hline
\end{tabular}

Para a resolução das equações constituintes do modelo, apresentadas no capítulo anterior, tornam-se necessárias as definições de alguns aspectos geométricos do equipamento, assim como existe a necessidade de se estabelecer o material utilizado em sua constituição. Neste trabalho, serão definidos os comprimentos dos tubos e seus diâmetros internos e externos. Já o número de colunas será fornecido como resultado da simulação, mais especificamente em função do número máximo de Reynolds admitido para o filme líquido. 
A Tabela 4.3 apresenta o material e as dimensões adotadas para os tubos.

Tabela 4.3 - Dimensões e material dos tubos

\begin{tabular}{cc}
\hline Material dos tubos & Aço Inox 316 \\
\hline Diâmetro externo dos tubos $\left(D_{e}\right)$ & $17 \mathrm{~mm}$ \\
\hline Diâmetro interno dos tubos $\left(D_{i}\right)$ & $15 \mathrm{~mm}$ \\
\hline Comprimento dos tubos $(W)$ & $200 \mathrm{~mm}$ \\
\hline
\end{tabular}

\subsection{Procedimento de Solução}

É apresentado na Fig. (4.4), um fluxograma descrevendo as etapas de resolução das equações que compõem o modelo. Pode-se observar que o critério de parada adotado, no programa de simulação, baseia-se na hipótese de absorção completa da fase vapor, ou seja, quando a vazão mássica do filme líquido é igual à soma das vazões de vapor e líquido no início do absorvedor. 


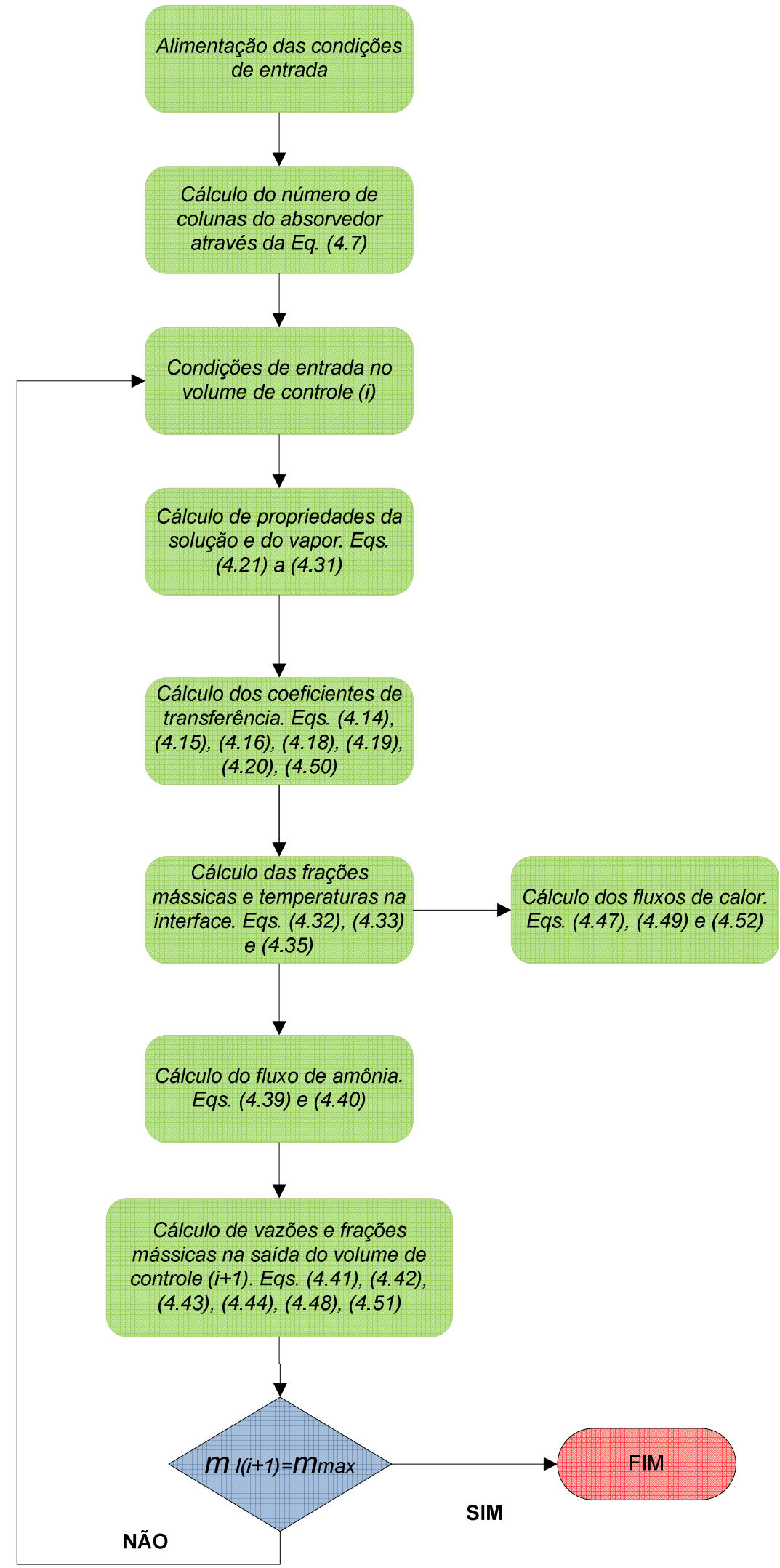

Figura 4.4 - Fluxograma do procedimento de cálculo 


\section{RESULTADOS E DISCUSSÃO}

No capítulo anterior foram apresentadas todas as equações que compõem o modelo proposto. Buscou-se, na literatura, correlações para obtenção de coeficientes de transferência de massa e calor, que fossem adequados ao problema em estudo.

Considerando-se a mistura amônia-água como ideal, apresentou-se também as equações que possibilitaram a obtenção das propriedades das fases líquida e vapor ao longo do absorvedor, levando-se em conta as variações de temperatura e composição que ocorrem no decorrer de todo o processo.

Já neste capítulo, são apresentados e discutidos os resultados da simulação realizada no EES, considerando-se todas as condições propostas no item anterior. Realizou-se avaliações paramétricas levando-se em conta a variação do número máximo de Reynolds do filme ( $R e_{l \max }$ ), temperatura de entrada da solução $\left(T_{l e}\right)$, temperatura do fluido de resfriamento $\left(T_{c}\right)$ e pressão de trabalho do absorvedor $(P)$. Os resultados são, em geral, expostos na forma curvas que se desenvolvem ao longo do comprimento do equipamento.

O método de obtenção dos resultados se baseou na resolução simultânea das equações de balanço, tomando-se um volume de controle de comprimento $d L$. O EES possibilita a execução de mecanismos que fazem com que as equações sejam duplicadas de acordo com o número de volumes de controle estabelecidos, onde resultados de saída de um elemento se tornam valores de entrada no elemento subsequente e assim sucessivamente até o alcance de um critério de parada estabelecido. Dessa maneira, obteve-se um razoável conjunto de dados, os quais possibilitam a observação e a análise de algumas variáveis importantes quando se trata de um absorvedor de película descendente. $O$ que possibilitou o alcance das condições que são mais adequadas e favoráveis a operação do absorvedor no que se refere ao tamanho e disposição do equipamento.

Determinou-se comprimento, quantidade de colunas e de tubos necessário para cada condição de simulação estabelecida, assim como obteve-se também 
perfis de vazões e frações mássicas, espessura de filme, temperatura e coeficientes de transferência de calor massa.

\subsection{Influência de $\mathbf{R e}_{\text {Imax }}$}

A primeira avaliação realizada é a do efeito do número de Reynolds máximo admitido para o filme considerando-se as condições de entrada apresentadas na Tabela 4.2. Simulou-se o comportamento do absorvedor com escoamento laminar do filme líquido, adotando-se valores de $R e_{I \max }$ iguais a 75, 100, 200 e 300.

Neste trabalho a imposição destes valores de $R \boldsymbol{e}_{\text {Imax }}$, representa a determinação do número de colunas do absorvedor, restando apenas a determinação de sua altura para a definição de todas as dimensões geométricas. Deve-se enfatizar que a definição de um número de máximo Reynolds para a fase

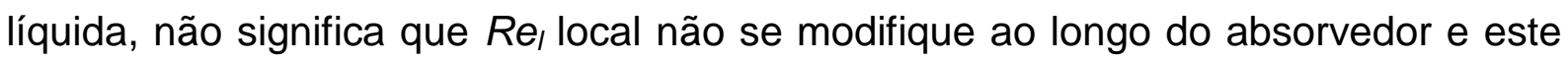
seja considerado nas simulações, já que o valor máximo de Reynolds é obtido apenas ao final equipamento, onde a vazão de líquido é também máxima.

Parte-se do pressuposto que a distribuição da fase líquida no topo do absorvedor é perfeita e uniforme, ou seja, os distribuidores alimentam a vazão homogeamente tanto ao longo do comprimento dos tubos como nas colunas que compõem o conjunto. É importante salientar que o desempenho de absorvedores tubulares de filme descendente é severamente controlado pela distribuição de solução ao longo dos tubos. Uma distribuição uniforme favorece a existência de uma maior área de contato entre as fases, elevando assim as taxas de transferência. Em função dos complexos fenômenos de superfície e instabilidades do escoamento, essa distribuição uniforme é bastante difícil de ser mantida e, como consequência, a superfície molhada dos tubos gradualmente descresce.

Através da Fig 5.1, pode-se observar que os comportamentos das vazões de líquido para os quatro valores de $R \boldsymbol{e}_{\text {Imax }}$ admitidos, são semelhantes. As curvas são todas crescentes ao longo do comprimento do absorvedor, comportamento que se mostra condizente com o esperado, já que a vazão mássica de líquido vai sendo incrementada em decorrência do fluxo de amônia que migra da fase vapor para a 
fase líquida (filme). Nota-se que todas as curvas terminam quando a vazão mássica atinge o valor de 0,46 kg/s, que é a soma das vazões de líquido e vapor ingressantes no absorvedor, já que adota-se no equacionamento, a hipótese de absorção completa da fase vapor.

Para $R e_{\text {Imax }}$ iguais a 200 e 300, nota-se que no início do absorvedor a vazão mássica não apresenta alterações relevantes, havendo um incremento significativo, de forma mais acentuada, a partir de aproximadamente 0,025 m $(2,5 \mathrm{~cm})$ e 0,05 m $(5 \mathrm{~cm})$. Esse comportamento se deve ao fato de que a resistência imposta, nesses dois casos particularmente, é consideravelmente maior se comparada as resistências estabelecidas por $R_{e_{\text {Imax }}}$ iguais a 75 e 100. Isso ocorre em virtude da maior espessura inicial de filme observada nestes casos.

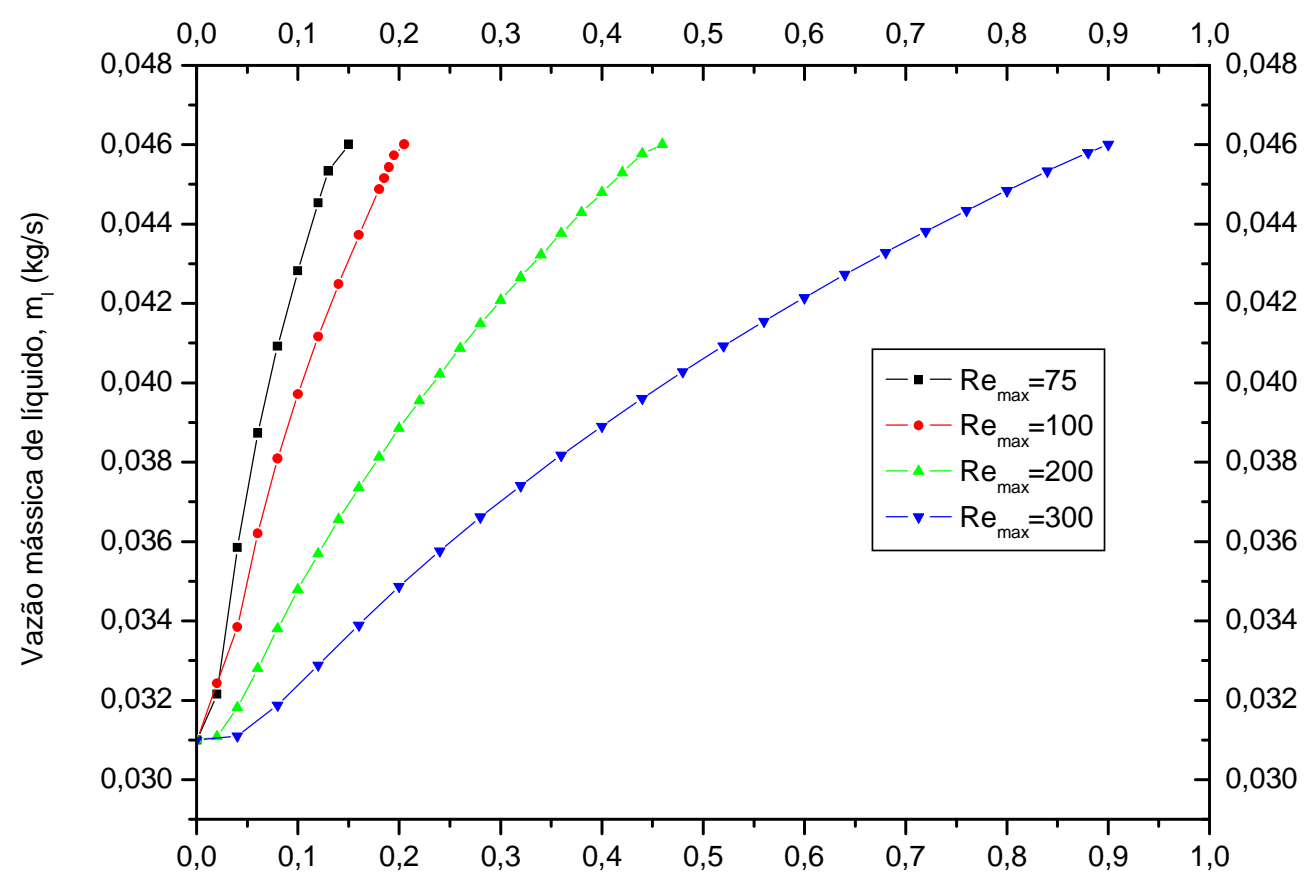

Comprimento, $L(m)$

Figura 5.1 - Vazão mássica de líquido ao longo do absorvedor para $R e_{\mid \max }=75$, $R e_{I_{\max }}=100, R e_{I_{\max }}=200$ e $R e_{I \max }=300$ 
A influência de $R e_{I \max }$ na vazão de líquido é considerável ao passo que quanto menor este valor, menor também se torna o comprimento requerido para a absorção da fase vapor. No entanto, o número de colunas que compoem o absorvedor se eleva. Por outro lado, conforme eleva-se o valor de $\boldsymbol{R e}_{\operatorname{lmax}}$ há uma redução no número de colunas necessárias para a absorção na condição de operação estabelecida, porém o comprimento do equipamento se torna maior.

A redução de $R e_{\text {Imax }}$, conforme a metodologia adotada, ocasiona redução da vazão mássica em cada uma das colunas, ao longo das quais o filme líquido se distribui. Consequentemente, a espessura desse filme se torna menor. Dessa forma, é imposta uma menor resistência aos processos de transferência de calor e massa, já que a espessura do filme está diretamente relaciodada ao valor de de $h^{*}$, , conforme a Eq. (4.18).

Naturalmente, como se pode visualizar nas tendências das curvas da Fig. (5.2), a espessura do filme cresce continuamente ao longo do absorvedor, consequência do acréscimo de massa decorrente da migração de amônia da fase vapor para a fase líquida. Com isso, os coeficientes de transferência de calor e, principalmente, de massa se modificam no decorrer do processo, tanto em função da alteração das propriedades, ocasionada a partir do aumento de concentração de amônia e da temperatura, como, majoritariamente, em função da resistência imposta à condução térmica, pelo aumento da espessura do filme.

A Fig. (5.3) ilustra o comportamento dos coeficientes de transferência de calor na fase líquida versus a espessura do filme para os quatro valores de $R_{e_{\text {Imax }}}$ considerados. Observa-se que, uma menor espessura do filme líquido é amplamente favorável ao alcance de maiores coeficientes de transferência de calor, os quais descrescem a medida que a espessura de filme aumenta. Como esperado, o valor inicial de $h^{*}$, para $R e_{\text {Imax }}=75$ foi o maior dos obtidos, em torno de $13000 \mathrm{~W} / \mathrm{m}^{2}{ }^{\mathrm{C}}$ no topo do absorvedor e decrescendo ao longo do comprimento, atingindo o valor final de aproximadamente $4500 \mathrm{~W} / \mathrm{m}^{2} \mathrm{C}$. Já para $R e_{\text {Imax }}=300$, obteve-se aproximadamente $8000 \mathrm{~W} / \mathrm{m}^{2 \circ} \mathrm{C}$ e $3000 \mathrm{~W} / \mathrm{m}^{2} \mathrm{C}$, como maior e menor valor de $h^{*}$, para esta condição de simulação, respectivamente. 


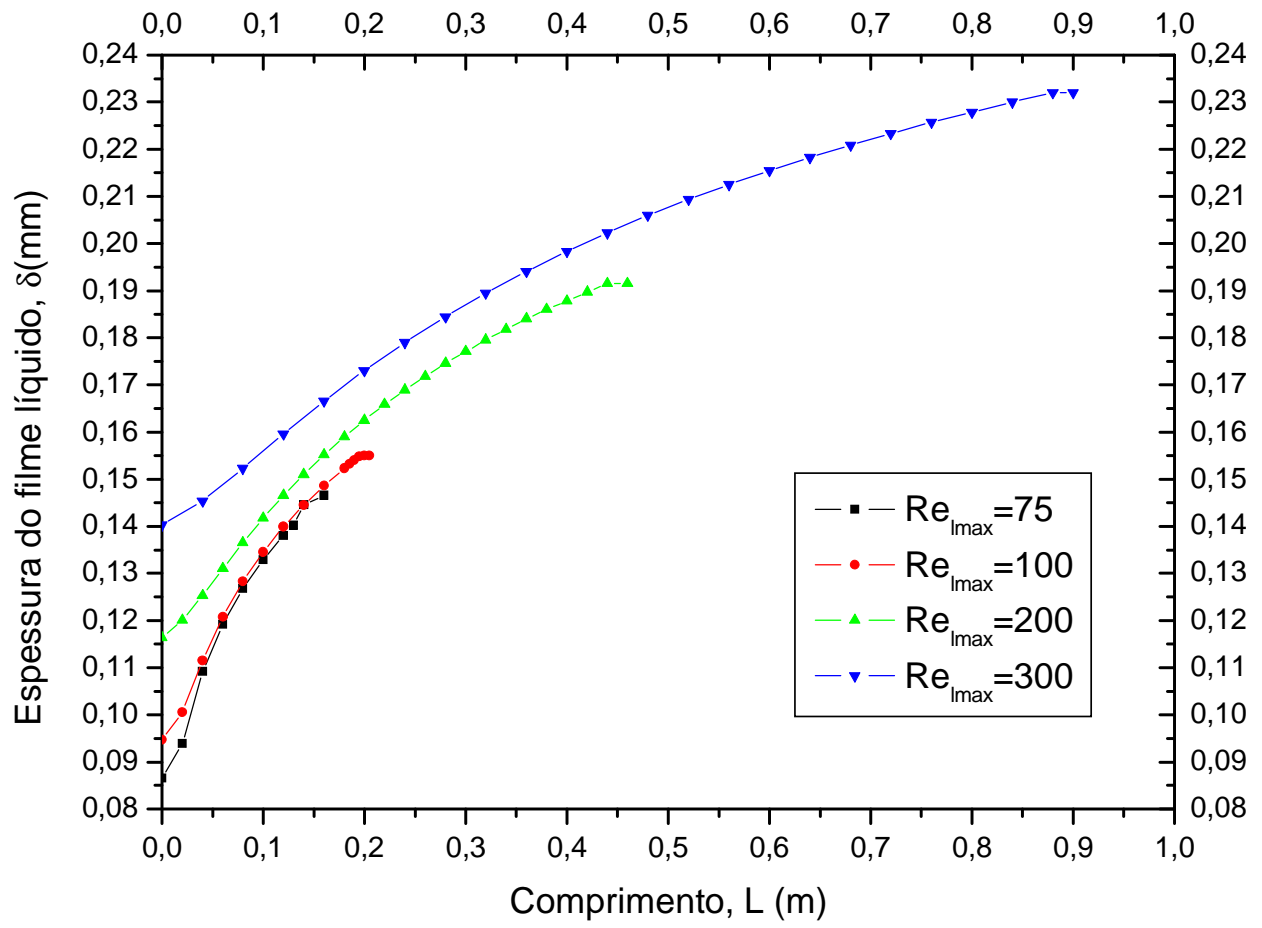

Figura 5.2 - Espessura do filme líquido ao longo do absorvedor para $\operatorname{Re}_{\operatorname{lmax}}=75$, $R e_{I \max }=100, R e_{I \max }=200$ e $R e_{\text {Imax }}=300$

Como a obtenção dos coeficiente de transferência de massa $K_{/}$é feita através da aplicação da analogia de Chilton-Colburn, a qual depende diretamente dos valores de $h^{*}$, o comportamento dos gráficos dessas duas variáveis é quase que idêntico, como pode ser constatado através das Figs. (5.4) e (5.5). Para $R e_{\text {Imax }}$ iguais a 75 e 100 os resultados obtidos não diferem significativamente, havendo momentos em que os valores são praticamente iguais, fazendo com que as curvas se sobreponham. Já para $R e_{\text {Imax }}$ iguais a 200 e 300, a diferença entre as curvas é notória. Para $R e_{l \max }=200$ tem-se uma curva mais acentuada em relação a de $R e_{\text {Imax }}=300$, apresentando maiores valores iniciais $h^{*}$, e, consequentemente, maiores valores de $K_{/}$no topo do absorvedor.

Para o cálculo de $h_{c}$, considerou-se que o escoamento do fluido de resfriamento é turbulento, possuindo $R e_{c}$ constante e igual a 4500. Também adotouse que esse fluido é água, a temperatura e pressão constantes e iguais a ${ }^{2} 5^{\circ} \mathrm{C}$ e 1 
bar, respectivamente. Frente a estas imposições, pôde-se determinar a vazão mássica de água que escoa no interior dos tubos, sendo esta igual a aproximadamente $0,048 \mathrm{~kg} / \mathrm{s}$. Assim, o valor de $h_{c}$ é também constante e igual a $795,4 \mathrm{~W} / \mathrm{m}^{2} \mathrm{C}$.

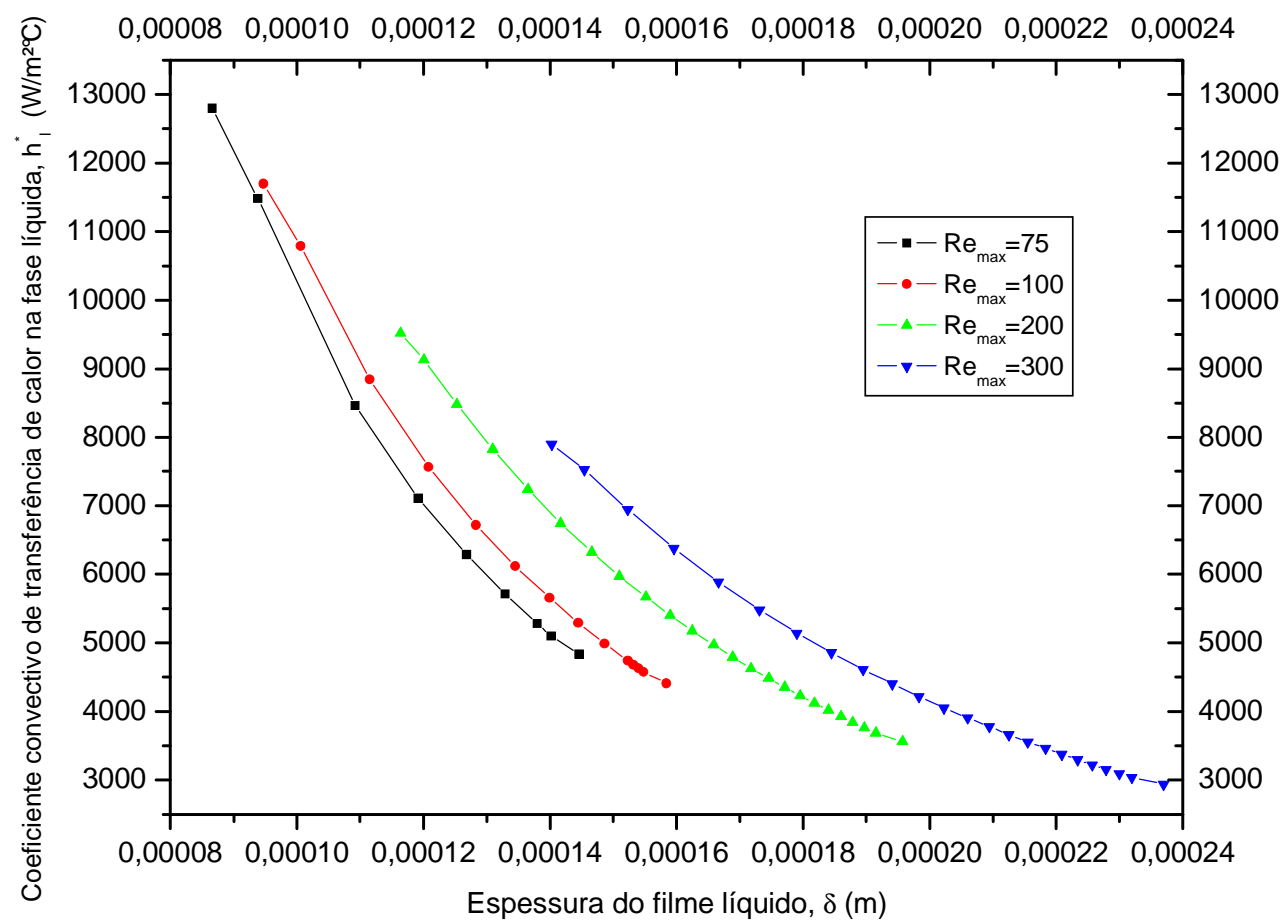

Figura 5.3 - Coeficientes de transferência de calor modificados na fase líquida em função da espessura do filme para $R \boldsymbol{e}_{\operatorname{lmax}}=75, \quad R \boldsymbol{e}_{\operatorname{lmax}}=100, \quad R \boldsymbol{e}_{\text {Imax }}=200 \mathrm{e}$ $\operatorname{Re}_{\operatorname{lmax}}=300$

Através da Fig. (5.6), verifica-se que o comportamento dos coeficientes de transferência de calor na fase vapor é bastante diferente do encontrado para os coeficientes da fase líquida. Primeiramente, nota-se que as curvas são incialmente crescentes até um determinado ponto máximo, onde ocorre inversão do sentido e os valores passam a decrescer. Isso se deve ao fato de que ao longo do processo de absorção, a temperatura do vapor se eleva conjuntamente com sua condutividade térmica, fazendo com que seus efeitos inicialmente se sobreponham aos efeitos de redução de $R e_{v}$, que será sempre decrescente, afetando diretamente $h_{v}^{*}$, conforme análise da Eq. (4.16). O número de Prandtl da fase vapor é 
praticamente constante não apresentando variações significativas, possuindo valores sempre em torno de 0,8 para toda a extensão do absorvedor. Porém, no decorrer do processo, o efeito da redução de $R e_{v}$, passa a se sobrepor ao efeito da condutividade térmica, invertendo a tendência da curva de $h_{v}^{*}$, a qual passa a ser decrescente até o final do absorvedor.

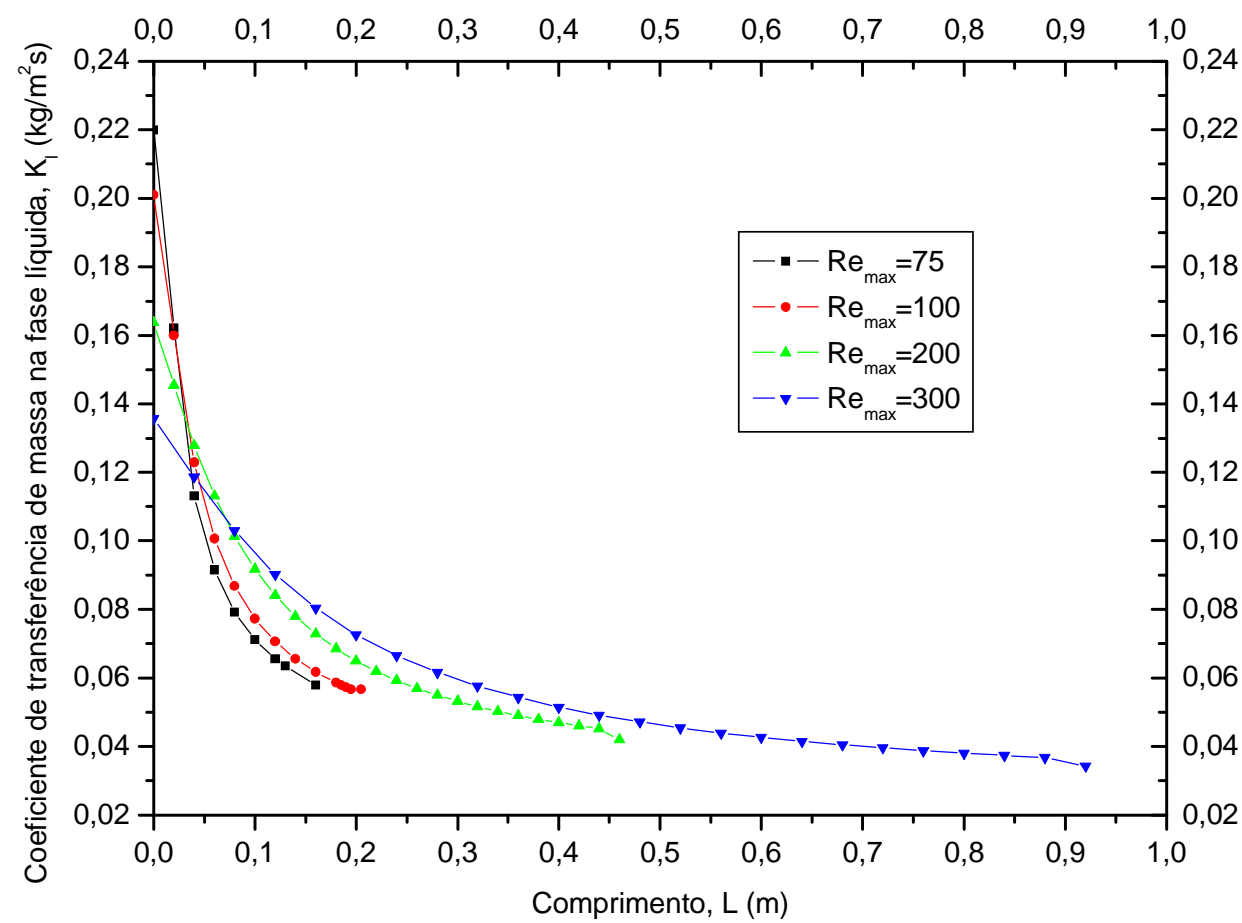

Figura 5.4 - Coeficientes de transferência de massa na fase líquida em função do comprimento para $R e_{I \max }=75, R e_{I \max }=100, R e_{I \max }=200$ e $R e_{I \max }=300$ 


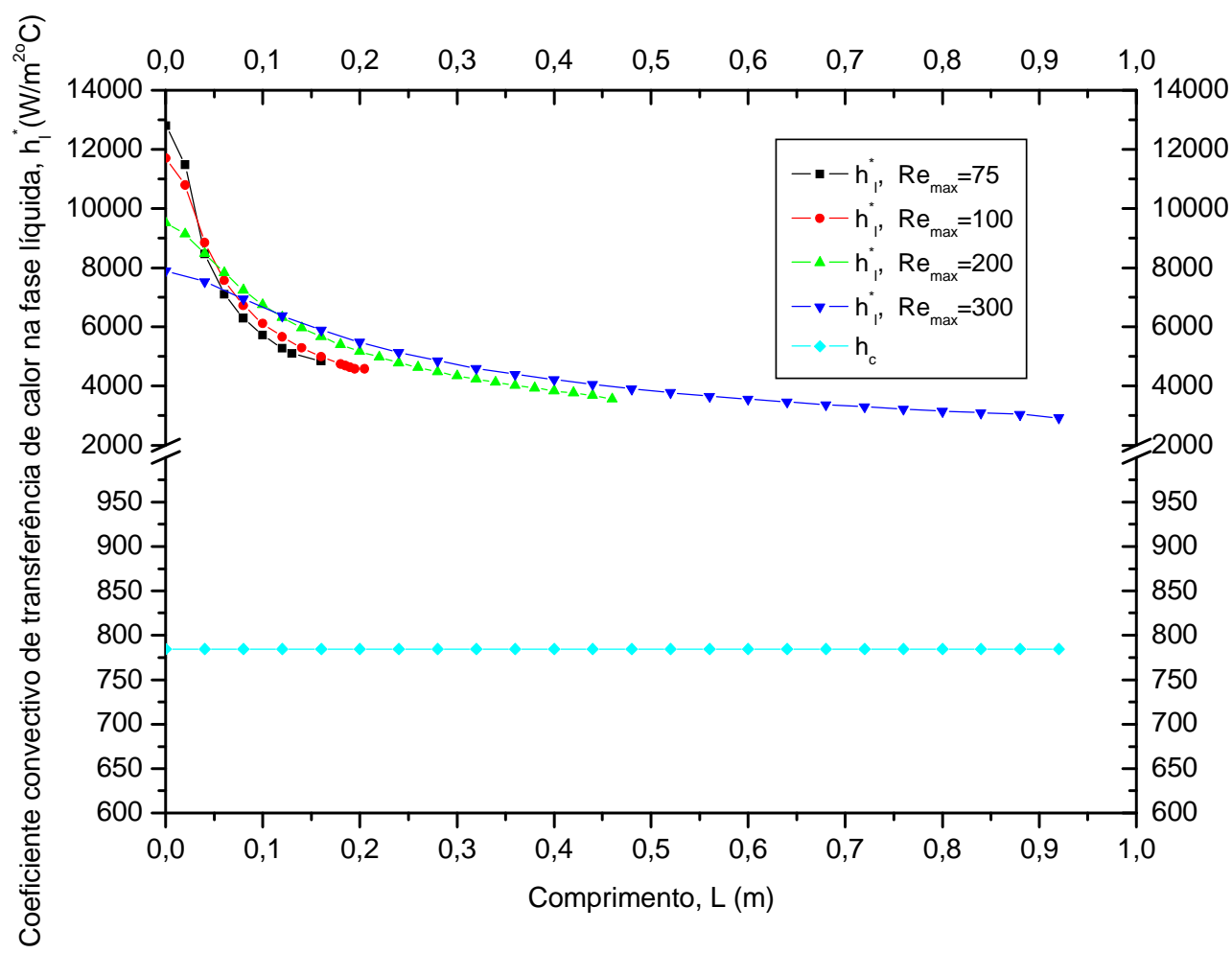

Figura 5.5 - Coeficientes de transferência de calor na fase líquida e no fluido de resfriamento em função do comprimento para $R e_{l \max }=75, R e_{\mid \max }=100, R e_{I \max }=200 \mathrm{e}$ $R e_{\text {max }}=300$

Diferentemente do comportamento observado para as curvas de $h_{l}^{\star}$, através da Fig (5.5), constata-se na Fig. (5.6) que quanto menor $R \boldsymbol{e}_{\text {Imax }}$, menor também será $h_{v}{ }_{v}$. Isso porque, uma maior quantidade de tubos impõem, necessariamente, uma menor vazão de vapor distribuida por coluna e, naturalmente, $R e_{v}$ tem seus valores locais reduzidos, influenciando diretamente o valor de $h_{v}^{*}$.

É importante frisar que a mesma hipótese de distribuição igualitária e homogênea da fase líquida é também considerada para a alimentação da vazão do vapor de amônia. 


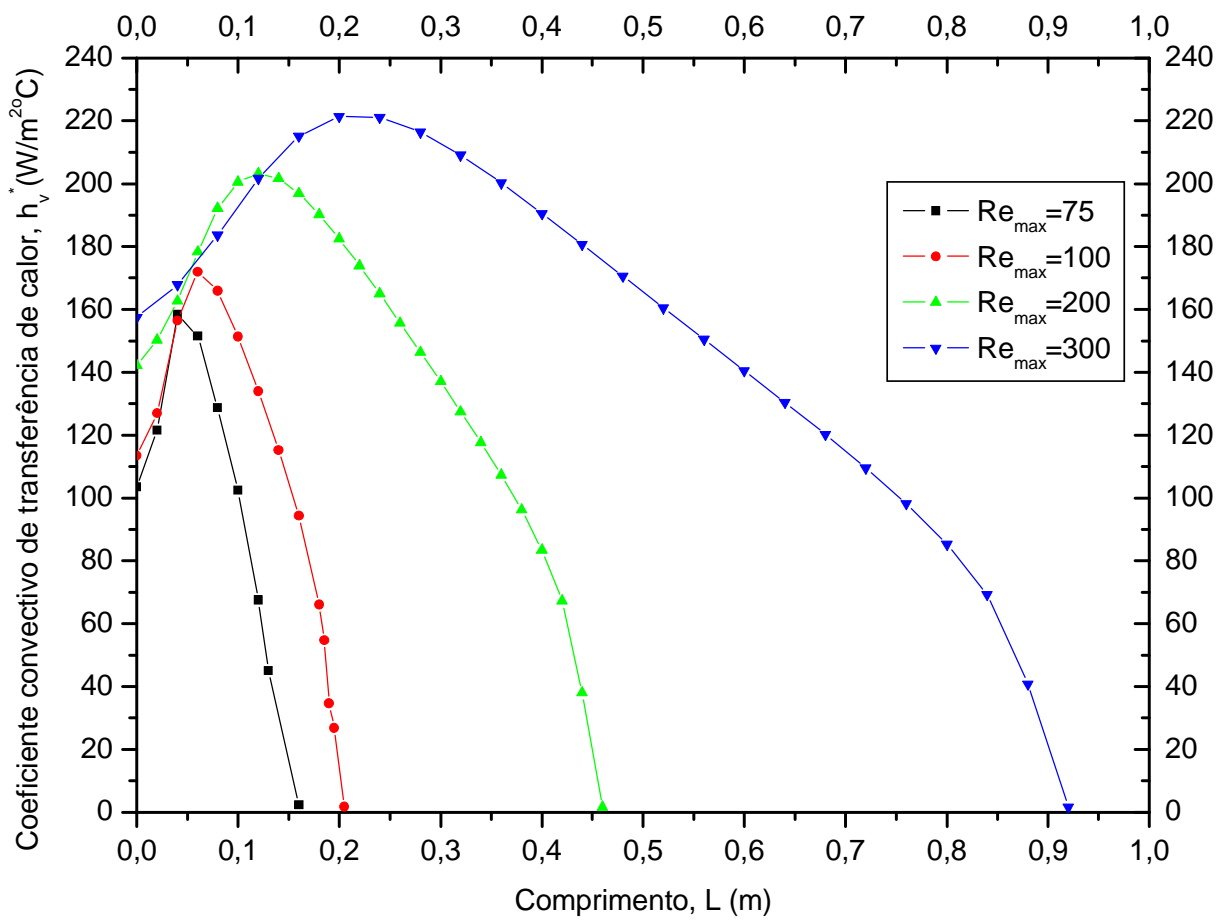

Figura 5.6 - Coeficientes de transferência de calor modificados na fase vapor ao longo do absorvedor para $R e_{I \max }=75, R e_{I \max }=100, R e_{I \max }=200$ e $R e_{I \max }=300$

Na Fig. (5.7) encontram-se os perfis dos coeficientes globais de transferência de calor, $U$, os quais são predominantemente decorrentes dos valores obtidos para $h^{*}$, já que as demais parcelas da Eq. (4.50) são dependentes da espessura da parede dos tubos e do coeficente convectivo da água que escoa em seu interior, ambos constantes e de menor influência na composição de $U$. Novamente, a situação se repete e menores $R \boldsymbol{e}_{\operatorname{lmax}}$, ou seja, um absorvedor de maior número de colunas, proporciona maiores coeficientes globais de transferência de calor.

A partir da Fig. 5.8, a qual ilustra os perfis das frações mássicas para $R e_{\text {max }}=300$, observa-se que a hipótese de amônia pura no vapor faz com que a sua fração mássica, $y$, se mantenha constante ao longo de todo o absorvedor e a fração mássica de vapor na interface, $y_{\text {int, }}$ se aproxime rapidamente de $y$. Isso faz com que com que o fluxo de amônia na fase vapor tenda a zero, já que o gradiente de concentração se torna extremamente pequeno. Dessa forma, o fluxo de massa nessa fase é fortemente penalizado. Soma-se o fato de que o coeficiente de 
transferência de massa na fase vapor $K_{v}$, é bastante reduzido se comparado ao coeficiente convectivo de transferência de massa na fase líquida $K_{l}$, conseqüência dos baixos valores de $h_{v}^{*}$ reportados anteriormente.

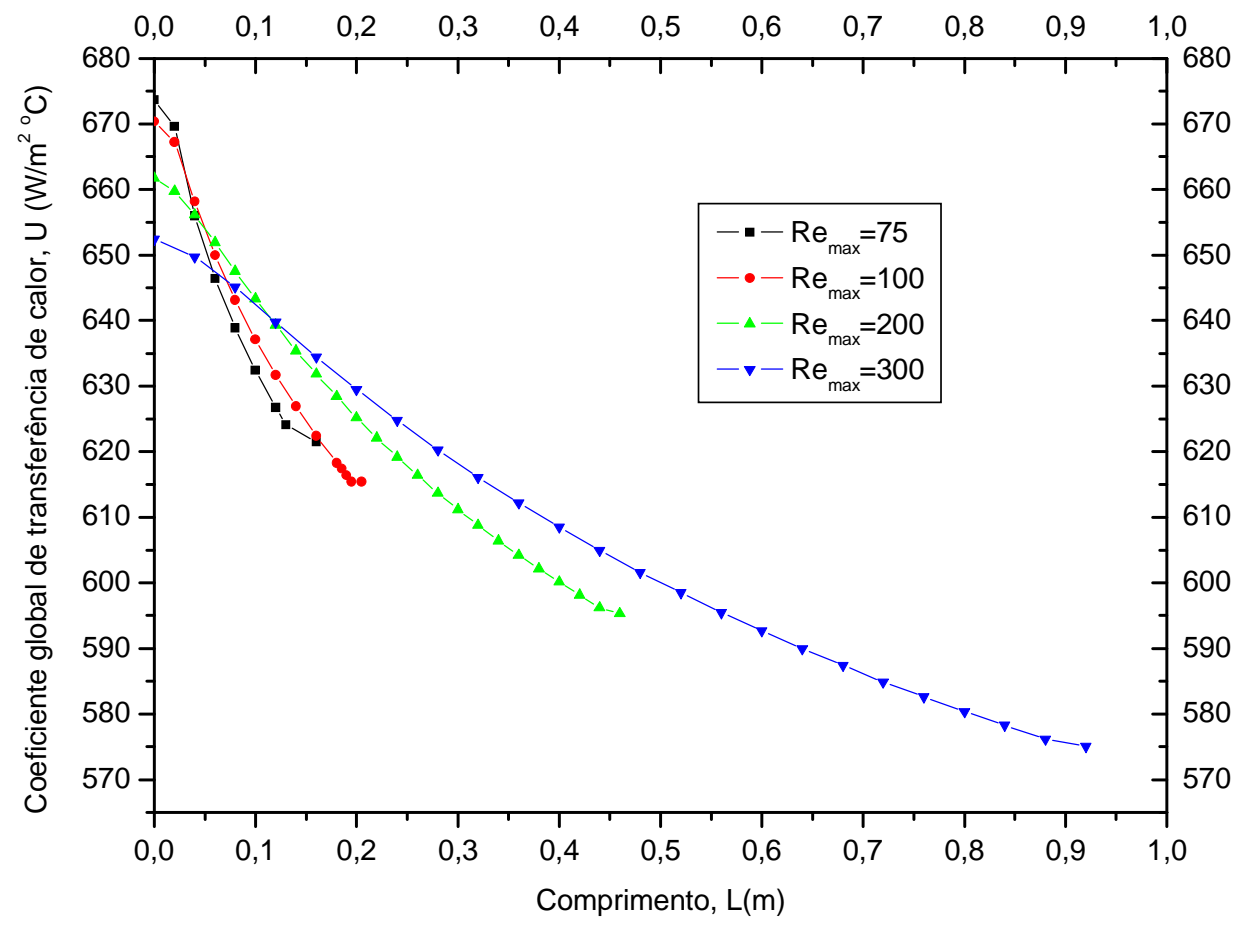

Figura 5.7 - Coeficientes globais transferência de calor para $R e_{\text {max }}=75, R e_{I \max }=100$, $R e_{\text {Imax }}=200$ e $R e_{\text {Imax }}=300$

Também, deve-se acrescentar o fato de que na fase líquida o gradiente de concentração existente é praticamente constante ao longo de todo o comprimento, excetuando-se os primeiros centímetros do absorvedor onde a diferença das frações mássicas de amônia na fase líquida e na fase vapor é crescente. Dessa forma, a partir de aproximadamente $0,15 \mathrm{~m}$, o fluxo na fase líquida, passa a ser majoritariamente dependente dos valores de $K_{l}$.

A literatura é divergente no que se refere a qual resistência é dominante quanto à transferência de massa em processos de absorção amônia-água. Os resultados obtidos por Gommed et al. (1999) and Potnis et al. (1997), sinalizaram que a resistência existente na fase vapor é dominante, enquanto Kim (1998) e 
Perez-Blanco (1988) concluíram que a resistência na fase líquida é quem controla o processo. De acordo com Bird et al (1960), a resistência oferecida por ambas as fases decresce com o aumento do coeficiente de transferência de massa ou aumento da fração mássica na mesma fase. Neste trabalho a fração da fase vapor foi considerada constante e igual 1 , já na fase líquida a concentração de amônia foi sempre crescente, além seus coeficientes de transferência de massa serem muito superiores aos coeficientes da fase vapor. Assim, pode-se concluir que a resistência existente no vapor é muito maior em relação à resistência existente na fase líquida.

Os gráficos das frações mássica para os outros valores de $R \boldsymbol{e}_{\text {Imax }}$, são semelhantes, diferenciando-se apenas pelo fato de que os comprimentos obtidos são diferentes.

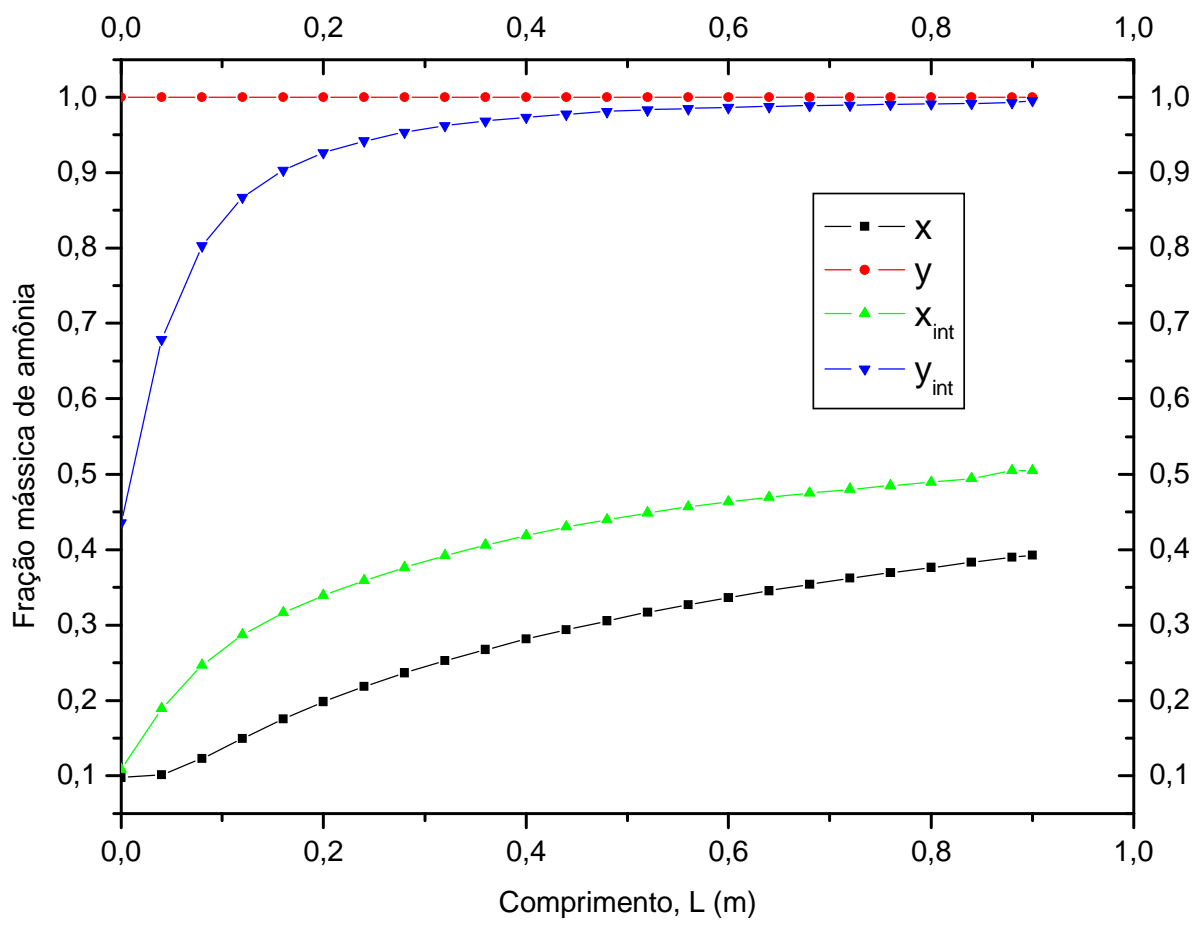

Figura 5.8 - Frações mássicas ao longo do absorvedor, para $R e_{I \max }=300$

Na Fig. (5.9) são apresentados os coeficientes de transferência de massa na fase líquida como função dos coeficientes de transferência de calor para as quatro condições de $R e_{\text {Imax }}$ propostas. Conforme discutido anteriormente, verifica-se que 
quanto maiores os valores de $h^{*}$, maiores também serão os valores de $K_{\text {, }}$, fazendo com que o fluxo de amônia existente entre a interface e o seio do filme líquido se intensifique.

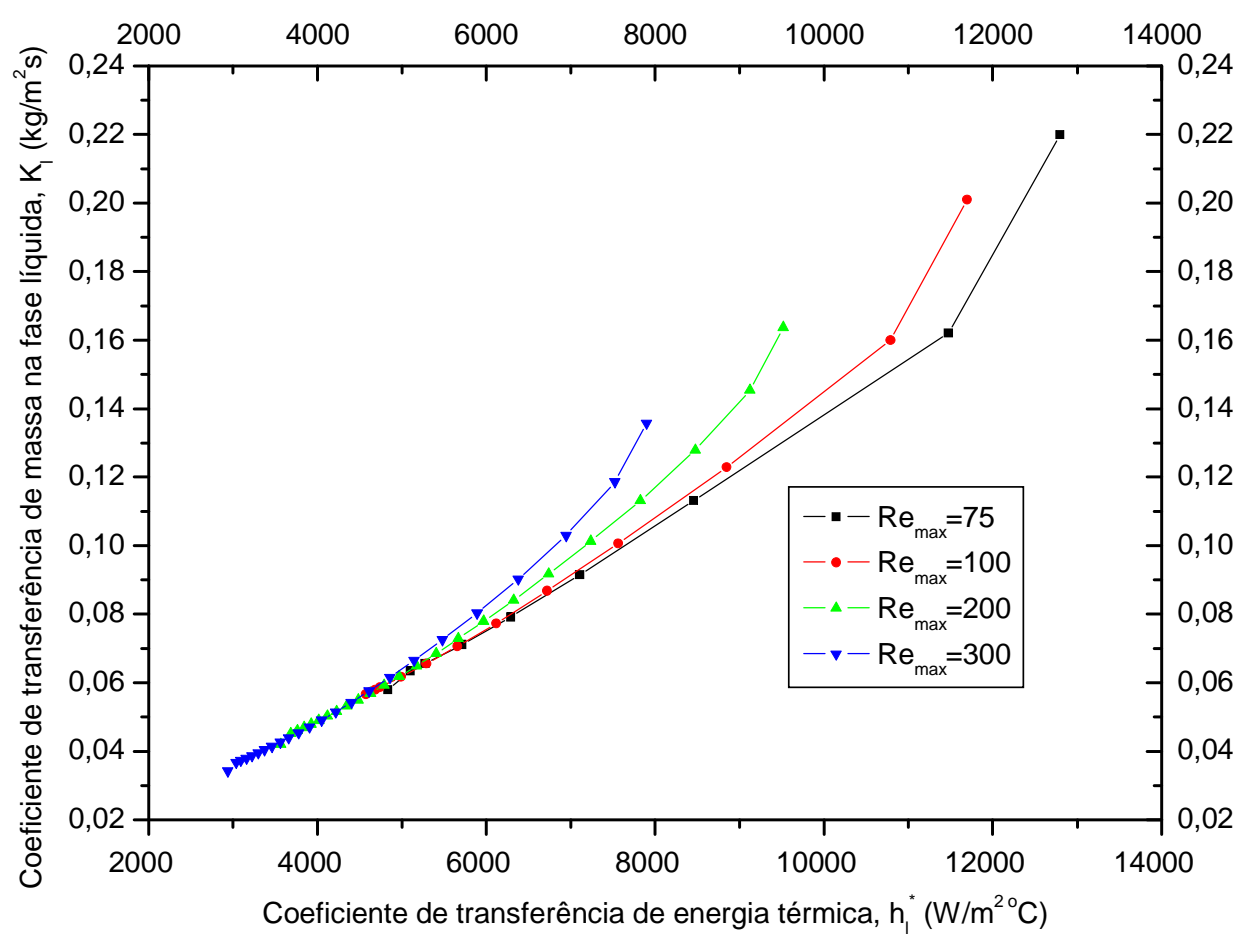

Figura 5.9 - Coeficientes de transferência de massa na fase líquida, em função dos coeficientes de transferência de calor $h_{l}^{*}$ para $R e_{I \max }=75, R e_{I \max }=100, R e_{I \max }=200 \mathrm{e}$ $R e_{\text {max }}=300$

A Tabela (5.1) sumariza os resultados dimensionais dos absorvedores simulados, levando-se em consideração os quatro números máximos de Reynolds admitidos. Como discutido, quanto menor $R e_{\text {Imax }}$ maior serão os coeficientes de transferência na fase líquida e, consequentemente, menor será o comprimento exigido para a completa absorção da fase vapor. No entanto, é importante considerar dois outros aspectos que são bastante importantes quando se trata de absorvedores destinados a ciclos de refrigeração por absorção. São eles: custo de construção e compacidade do equipamento.

Naturalmente, o custo está associado à quantidade e tipo do material empregado. Conforme a Tabela (5.1), a simulação que forneceu a menor área 
necessária foi a correspondente a $R e_{\text {Imax }}$ igual 100, apesar de esta resultar em um absorvedor aproximadamente $0,045 \mathrm{~m}(4,5 \mathrm{~cm})$ mais longo que $R \boldsymbol{e}_{\text {Imax }}$ igual a 75 .

Tabela 5.1 - Resultados para $T_{C}=25^{\circ} \mathrm{C}$ e $T_{l e}=116,6^{\circ} \mathrm{C}$, considerando diferentes valores de $R e_{l \max }$

\begin{tabular}{ccccc}
\hline $\boldsymbol{R} \boldsymbol{e}_{\text {Imax }}$ & $\mathbf{7 5}$ & $\mathbf{1 0 0}$ & $\mathbf{2 0 0}$ & $\mathbf{3 0 0}$ \\
\hline $\begin{array}{c}\text { Comprimento, } L(\boldsymbol{m}) \\
\text { Número de colunas, } \\
\boldsymbol{N}_{\boldsymbol{c}}\end{array}$ & 0,160 & 0,205 & 0,460 & 0,920 \\
$\begin{array}{c}\text { Número de tubos } \\
\text { por coluna, } \boldsymbol{N}_{\boldsymbol{t}}\end{array}$ & 10 & 13 & 7 & 4 \\
\begin{tabular}{c} 
Área total, $\boldsymbol{A}_{\boldsymbol{t}}\left(\boldsymbol{m}^{2}\right)$ \\
\hline
\end{tabular} & 1,816 & 1,805 & 2,094 & 2,350 \\
\hline
\end{tabular}

Contudo, maiores $\boldsymbol{R e}_{\text {Imax }}$ proporcionam absorvedores que requerem maior área de contato e mais longos, elevando assim o custo de construção. Porém, a largura obtida para o equipamento se torna consideravelmente menor, já que para maiores valores de $\boldsymbol{R e}_{\text {Imax }}$, menor será a quantidade de colunas de tubos necessárias para a distribuição das vazões.

É importante comentar que, neste estudo não está sendo avaliada questão da possível existência de regiões secas ao longo dos tubos "dry patchs", situação que pode ser decorrente de uma distribuição inadequada da vazão líquida ou da adoção de um número máximo de Reynolds do filme muito baixo. Executou-se as simulações a partir de um valor mínimo de $R \boldsymbol{e}_{\operatorname{lmax}}(75)$, o qual é considerado em uma das referências bibliográficas utilizadas. Além disso, garantiu-se o escoamento laminar em todas as situações, de acordo com a imposição da Eq.(4.18).

\subsection{Influência da temperatura do fluido de resfriamento}


A influência da temperatura do fluido de resfriamento no comportamento do absorvedor é ilustrada nas Figs. (5.10) e (5.11) e (5.12). Executou-se a simulação para quatro temperaturas diferentes, sendo elas iguais a $15^{\circ} \mathrm{C}, 20^{\circ} \mathrm{C}, 25^{\circ} \mathrm{C}$ e $30^{\circ} \mathrm{C}$ com o número máximo de Reynolds igual a 100, condição esta que se mostrou a mais adequada conforme descrito no capítulo anterior. A temperatura de entrada da solução pobre adotada é de $116,6^{\circ} \mathrm{C}$ (condição previa mente definida pelo PSSRA). Com a imposição de $R e_{\text {Imax }}$ o número de colunas do equipamento é previamente definido e igual a 13 para todas as temperaturas de resfriamento, restando ser definido o seu comprimento mínimo necessário.

Conforme esperado e discutido ao longo da revisão bibliográfica, a redução da temperatura da água de resfriamento resulta em aumento do fluxo de calor do filme líquido para o interior dos tubos, o que por consequência eleva as taxas de absorção, acarretando redução do comprimento mínimo suficiente para a absorção completa do vapor de amônia. Tal fato se justifica a partir do maior gradiente de temperatura que passa a existir entre a temperatura do filme líquido, $T_{l}$, e a temperatura da água no interior dos tubos, $T_{c}$. No entanto, considera-se neste trabalho, a hipótese de que $T_{c}$ é sempre constante, condição não correspondente a uma aplicação real, onde haverá elevação dessa temperatura, fazendo com que ocorra certa redução no gradiente, diminuindo assim o fluxo de calor entre o filme e o fluido de resfriamento.

Pode-se observar, através da Fig. (5.10), que para $T_{C}=15^{\circ} \mathrm{C}$ tem-se a mais acentuada redução de temperatura do filme ao longo do absorvedor, já que a remoção de calor nessa situação é a mais eficiente. Consequentemente, o comprimento requerido do absorvedor é o menor encontrado dentre as quatro temperaturas simuladas. Em contrapartida, para $T_{c}=30^{\circ} \mathrm{C}$, o perfil é o menos acentuado, o que denota uma remoção de calor menos eficiente, implicando em um maior comprimento mínimo necessário para a absorção total do vapor de amônia. 


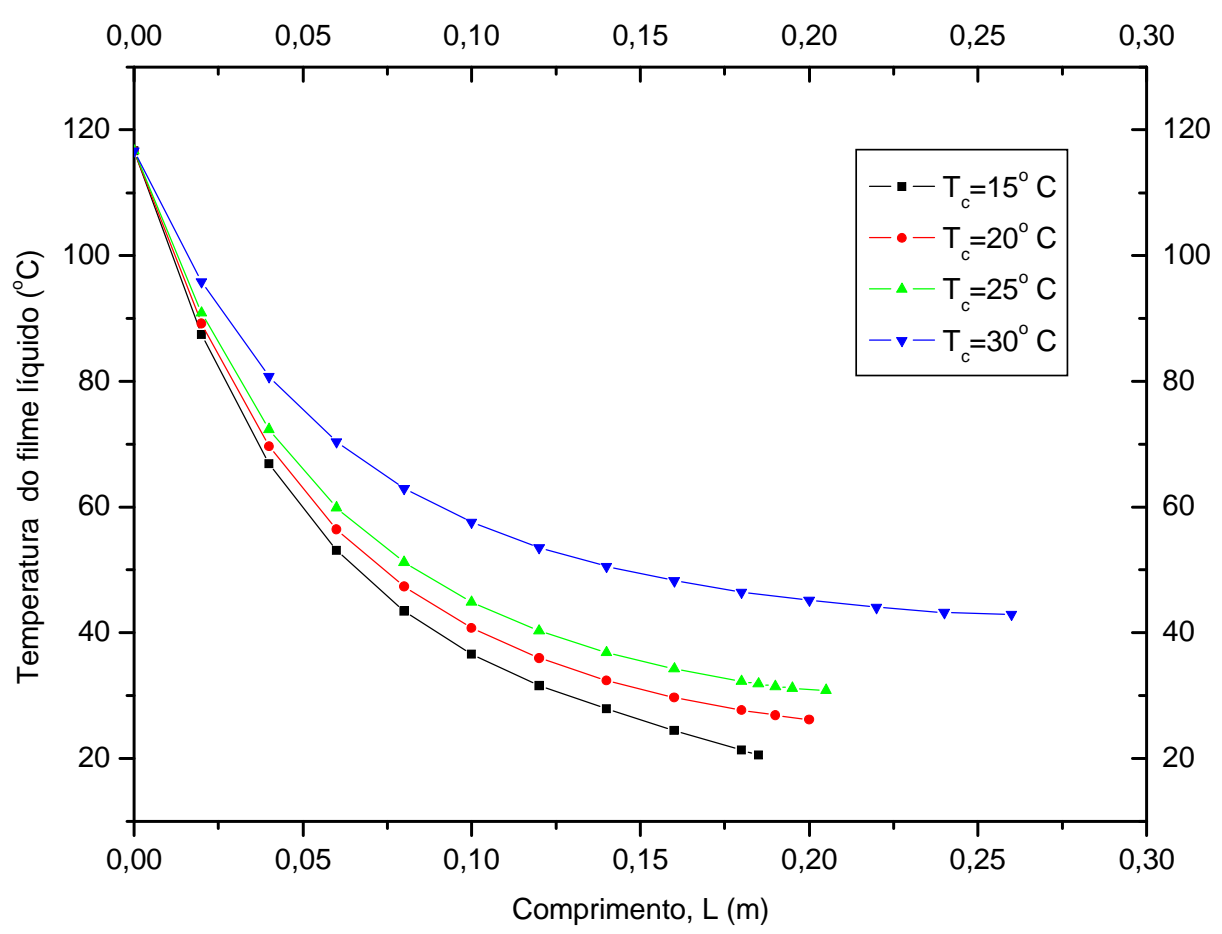

Figura 5.10 - Temperaturas do filme líquido ao longo do absorvedor, para $R e_{\text {Imax }}=100$ e $T C=15^{\circ} \mathrm{C}, T C=20^{\circ} \mathrm{C}, T C=25^{\circ} \mathrm{C}$ e $T C=30^{\circ} \mathrm{C}$

A Fig. (5.11) apresenta as curvas referentes às taxas de remoção de calor liberado no processo de absorção. Conforme discutido no parágrafo anterior, constata-se que quanto menor for $T_{c}$, maiores serão as taxas de remoção de calor e, portanto, o absorvedor se torna mais eficiente, necessitando de menor área de troca. Consequentemente, ocorre minimização de tamanho e custo de construção do equipamento.

A evolução das vazões mássica do filme líquido, para as quatro condições de simulação, pode ser visualizada na Fig. 5.12. Observa-se que as quatro curvas são praticamente idênticas até, aproximadamente, 0,05 m.

Esse comportamento pode ser atribuído ao fato de que nos primeiros centímetros do absorvedor, os gradientes de concentração no líquido ainda não estão bem estabelecidos, além dos coeficientes de transferência de calor e massa apresentarem valores semelhantes para as quatro situações. Isso faz com que as 
taxas de transferência de calor e massa sejam prejudicadas ao longo dessa pequena região, ocasionando a obtenção de valores de vazão mássica bastante parecidos para todas as temperaturas avaliadas.

Pode-se notar que a partir de $0,05 \mathrm{~m}$ todas as curvas se acentuam, no sentido de elevação da vazão mássica do filme, passando a existir uma evidente diferenciação entre as curvas.

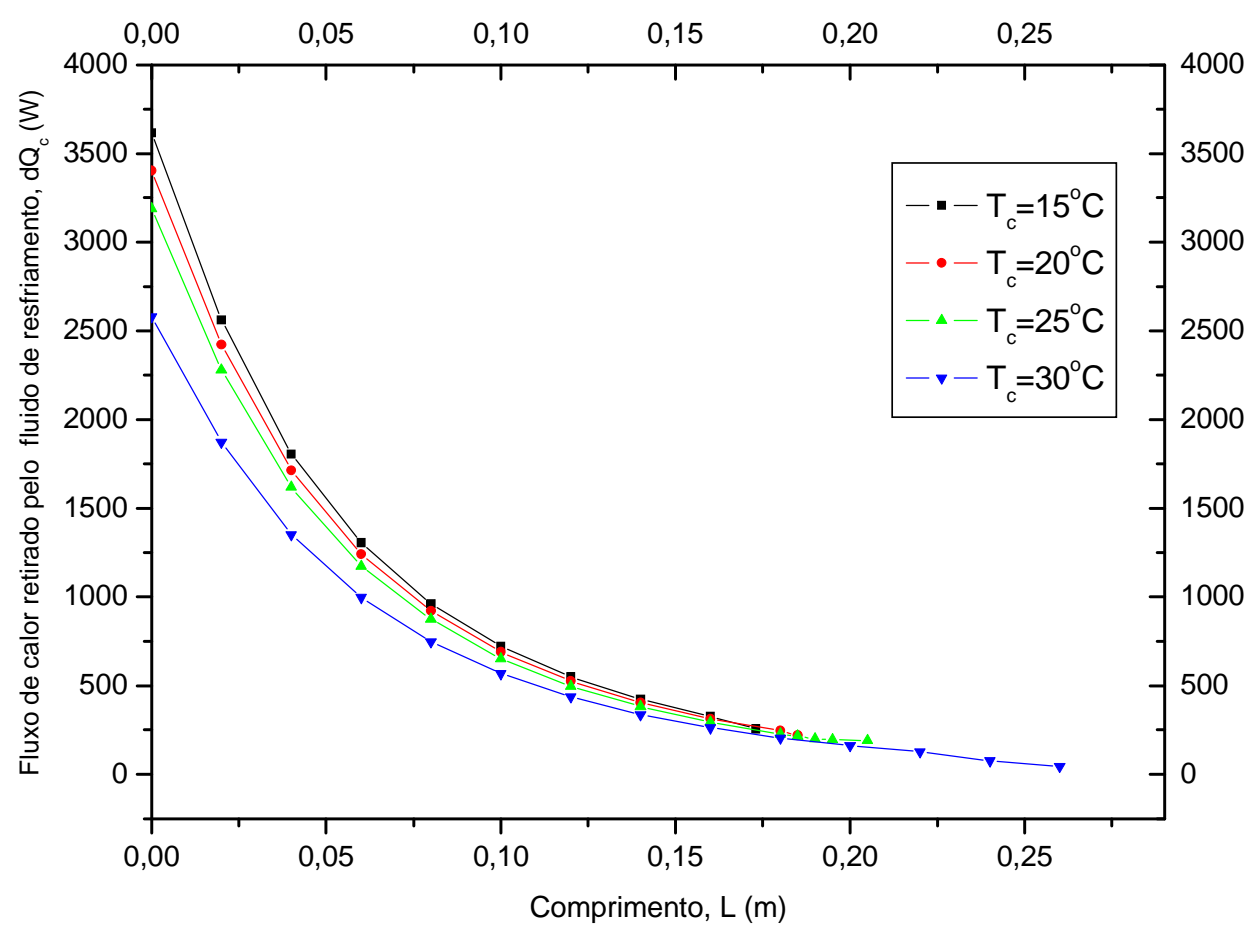

Figura 5.11 - Fluxo de calor ao longo absorvedor, para $R e_{\text {Imax }}=100 \mathrm{e}$ $T_{c}=15^{\circ} \mathrm{C}, T_{C}=20^{\circ} \mathrm{C}, T_{C}=25^{\circ} \mathrm{C}$ e $T_{C}=30^{\circ} \mathrm{C}$ 


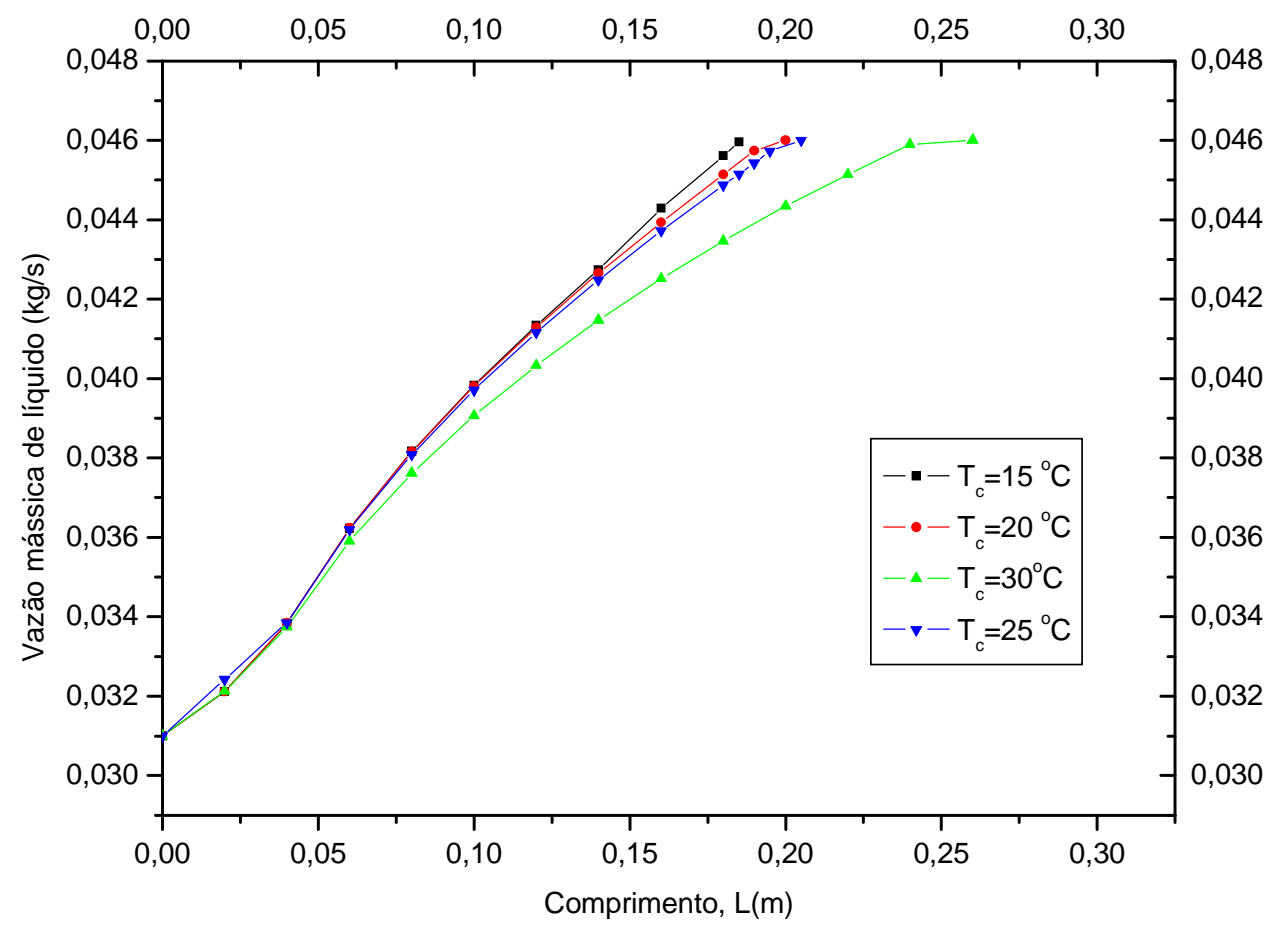

Figura 5.12 - Vazões mássica de líquido ao longo do absorvedor para $R e_{\text {Imax }}=100$ e $T C=15^{\circ} \mathrm{C}, T C=20^{\circ} \mathrm{C}, T C=25^{\circ} \mathrm{C}$ e $T C=30^{\circ} \mathrm{C}$

$\mathrm{Na}$ tabela (5.2), são apresentados os resultados dimensionais referentes às condições simuladas.

Tabela 5.2 - Resultados para $R e_{I_{\max }}=100$ e $T_{l e}=116,6^{\circ} \mathrm{C}$, considerando diferentes temperaturas do fluido de resfriamento

\begin{tabular}{|c|c|c|c|c|}
\hline$T_{c}\left({ }^{\circ} \mathrm{C}\right)$ & 15 & 20 & 25 & 30 \\
\hline Comprimento, $L(m)$ & 0,185 & 0,200 & 0,205 & 0,260 \\
\hline Número de colunas, $N_{c}$ & \multicolumn{4}{|c|}{13} \\
\hline Número de tubos por coluna, $N_{t}$ & 11 & 12 & 13 & 16 \\
\hline Área total, $A_{t}\left(m^{2}\right)$ & 1,527 & 1,666 & 1,805 & 2,222 \\
\hline
\end{tabular}




\subsection{Influência da temperatura de entrada da solução}

Diversos estudos teóricos e também muitas aplicações práticas, tais como Srikhirin et. al (2001), Goel e Goswami (2005) e Bohra (2007), indicam que o resfriamento prévio da solução anteriormente a sua entrada no absorvedor, cuja obtenção pode ocorrer através de um trocador de calor auxiliar alimentado pelas vazões de solução pobre (maior temperatura) e solução rica (menor temperatura), é bastante interessante, na medida em que reduz a quantidade de calor a ser dissipada no absorvedor, contribuindo para diminuir a área de troca necessária para o processo absortivo.

Com o intuito de se avaliar a influência desse parâmetro no desempenho do absorvedor, realizaram-se simulações distintas, considerando-se a temperatura da água de resfriamento $T_{c}$, igual a $2^{\circ} \mathrm{C}, R e_{\operatorname{lmax}}$ igual a 100 e quatro temperaturas de entrada da solução pobre $T_{l e}$, iguais a $5^{\circ} \mathrm{C}, 8^{\circ} \mathrm{C}, 100^{\circ} \mathrm{C}$ e $116,6^{\circ} \mathrm{C}$.

A Fig. (5.13) apresenta a evolução das temperaturas da película ao longo do absorvedor. Nota-se que a temperatura de entrada de $116,6{ }^{\circ} \mathrm{C}$, referente à condição de simulação no PSSRA, é a maior avaliada e também a que impõe maior necessidade de remoção de calor da fase líquida para a água de resfriamento. Isso se justifica em razão de haver, além do calor inerente ao processo absortivo propriamente dito, que ocorre na interface, existe também uma parcela maior de calor associada à diferença de temperatura entre o filme líquido e a água de resfriamento.

Como resultado dessa quantidade "extra" de calor a ser dissipada, em relação às demais temperaturas, a temperatura de $116,6^{\circ} \mathrm{C}$ de manda 0 absorvedor mais longo, e consequentemente de maior área superficial, aproximadamente $1,805 \mathrm{~m}^{2}$ ou $18050 \mathrm{~cm}^{2}$. 


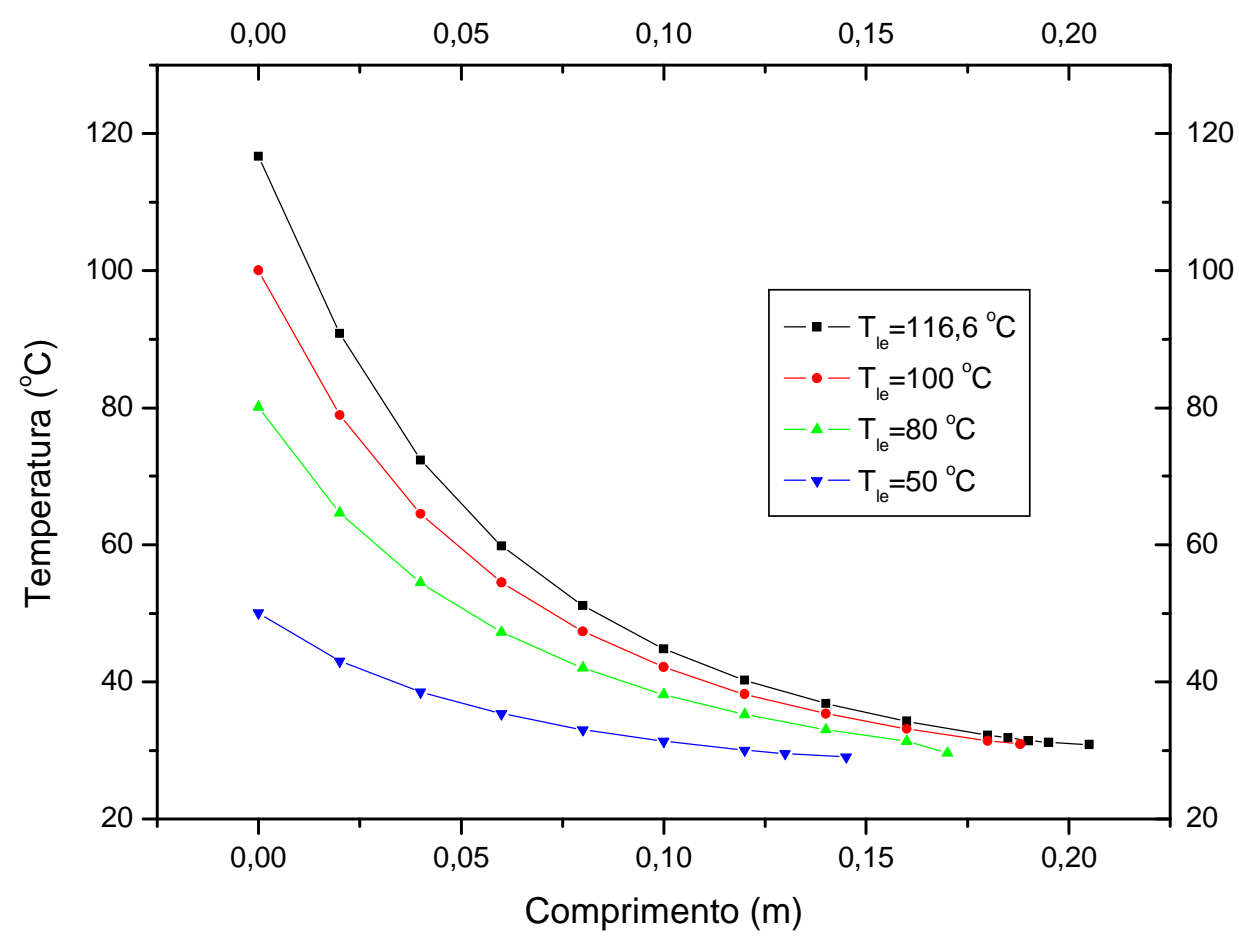

Figura 5.13 - Temperaturas do filme líquido ao longo do absorvedor para $R e_{I \max }=100$, $T C=25^{\circ} \mathrm{C}$ e $T_{l e}=50^{\circ} \mathrm{C}, T_{l e}=80^{\circ} \mathrm{C}$ e $T_{l e}=100^{\circ} \mathrm{C}$ e $T_{l e}=116,6^{\circ} \mathrm{C}$

Em contrapartida, para $T_{l e}=50^{\circ} \mathrm{C}$, que é a menor das temperaturas analisadas, exige-se que uma menor quantidade de calor seja retirada do filme líquido e naturalmente o absorvedor obtido para esta condição é o mais curto e, portanto de menor área.

Através do gráfico apresentado na Fig. 5.14 é possível constatar que existe uma relação linear entre a temperatura de entrada da solução e a quantidade de calor a ser retirada pelo fluido de resfriamento. A influência da temperatura de entrada é considerável, na medida em que uma redução relativamente pequena de $116,6^{\circ} \mathrm{C}$ para $100^{\circ} \mathrm{C}$ significa, aproximadamente, $2000 \mathrm{~W}$ de calor a menos que deverá ser retirada do processo.

Portanto, tomando-se novamente como referência o gráfico da Fig.5.14, observa-se que toda e qualquer diminuição de temperatura da solução pobre, proporciona redução na quantidade necessária de calor que deverá ser dissipada 
pelo fluido de resfriamento, implicando na redução da área superficial do absorvedor.

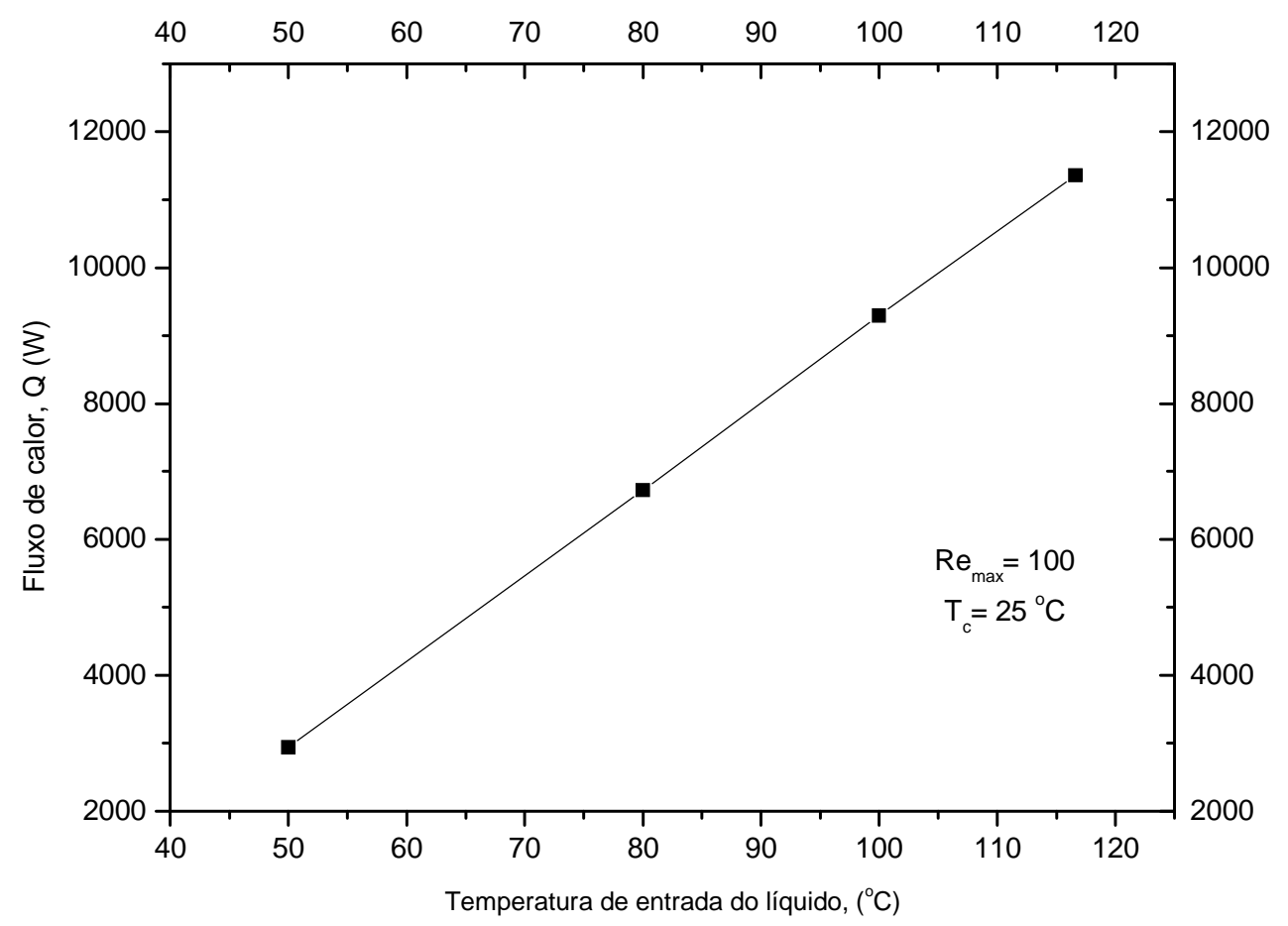

Figura 5.14 - Fluxo de calor retirado pelo fluido de resfriamento em função da temperatura de entrada da solução

Ainda analisando a influência da temperatura de entrada da solução pobre, apresenta-se a Fig. (5.15), na qual são observadas as vazões mássicas do líquido ao longo do comprimento do absorvedor. Verifica-se que conforme menor é a temperatura de entrada, maior se tornam as vazões de solução, com o deslocamento das curvas correspondentes às temperaturas menores para cima. Esse cenário se estabelece em função da elevação da concentração de equilíbrio na fase líquida em razão da menor temperatura da solução ao longo de todo o comprimento do absorvedor. Assim, através dessas maiores concentrações, o gradiente de concentração também se eleva, intensificando o fluxo de amônia para o filme e elevando a vazão mássica de solução.

A Fig. (5.16) ilustra como variam as frações mássicas na interface líquidovapor em função da temperatura existente nessa mesma interface. Os dois gráficos 
foram construídos a partir dos pontos obtidos de todas as simulações referentes à avaliação da temperatura de entrada da solução. Deste modo, abrange-se a faixa de temperaturas de entrada compreendidas entre $50^{\circ} \mathrm{C}$ e $116,6^{\circ} \mathrm{C}$.

Tomando-se como referência as Eqs. (4.39) e (4.40), verifica-se que a redução da temperatura na interface favorece a transferência de amônia na fase líquida, na medida em que a fração mássica de líquido na interface é aumentada. Em compensação a transferência na fase vapor é prejudicada, já que a fração mássica de vapor na interface também se eleva. Se considerarmos paralelamente 0 comportamento das curvas de fração mássica apresentadas na Fig. (5.8) é possível concluir que o gradiente de concentração da fase vapor é superior ao da fase líquida apenas nos primeiros centímetros do absorvedor se reduzindo rapidamente com a elevação da fração mássica de vapor de amônia na interface $y_{\text {int }}$. Já o gradiente na fase líquida é praticamente constante ao longo de todo o absorvedor.

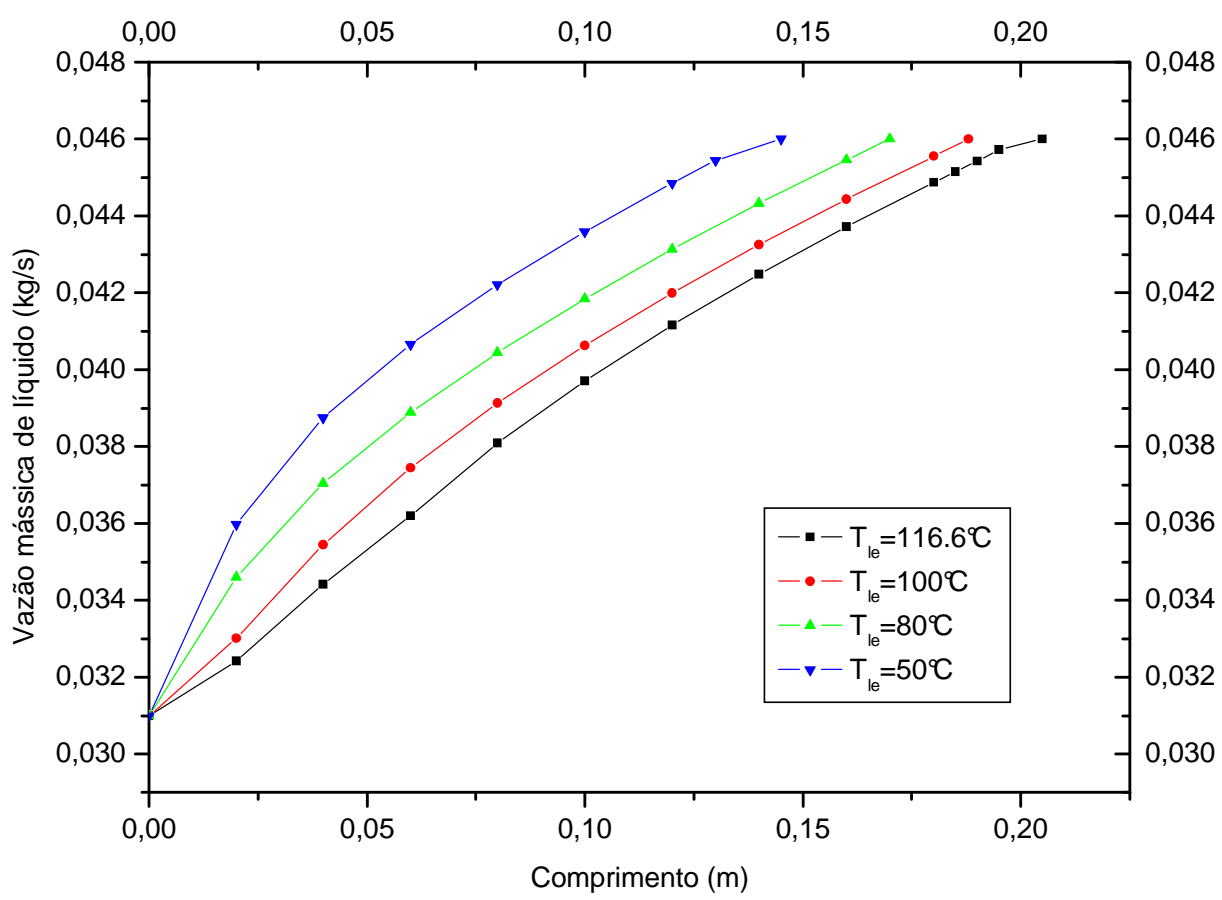

Figura 5.15 - Vazões mássica de líquido ao longo do absorvedor para $R e_{\operatorname{lmax}} 100$, $T C=25^{\circ} \mathrm{C}$ e $T_{l e}=50^{\circ} \mathrm{C}, T_{l e}=80^{\circ} \mathrm{C}$ e $T_{l e}=100^{\circ} \mathrm{C}$ e $T_{l e}=116,6^{\circ} \mathrm{C}$ 


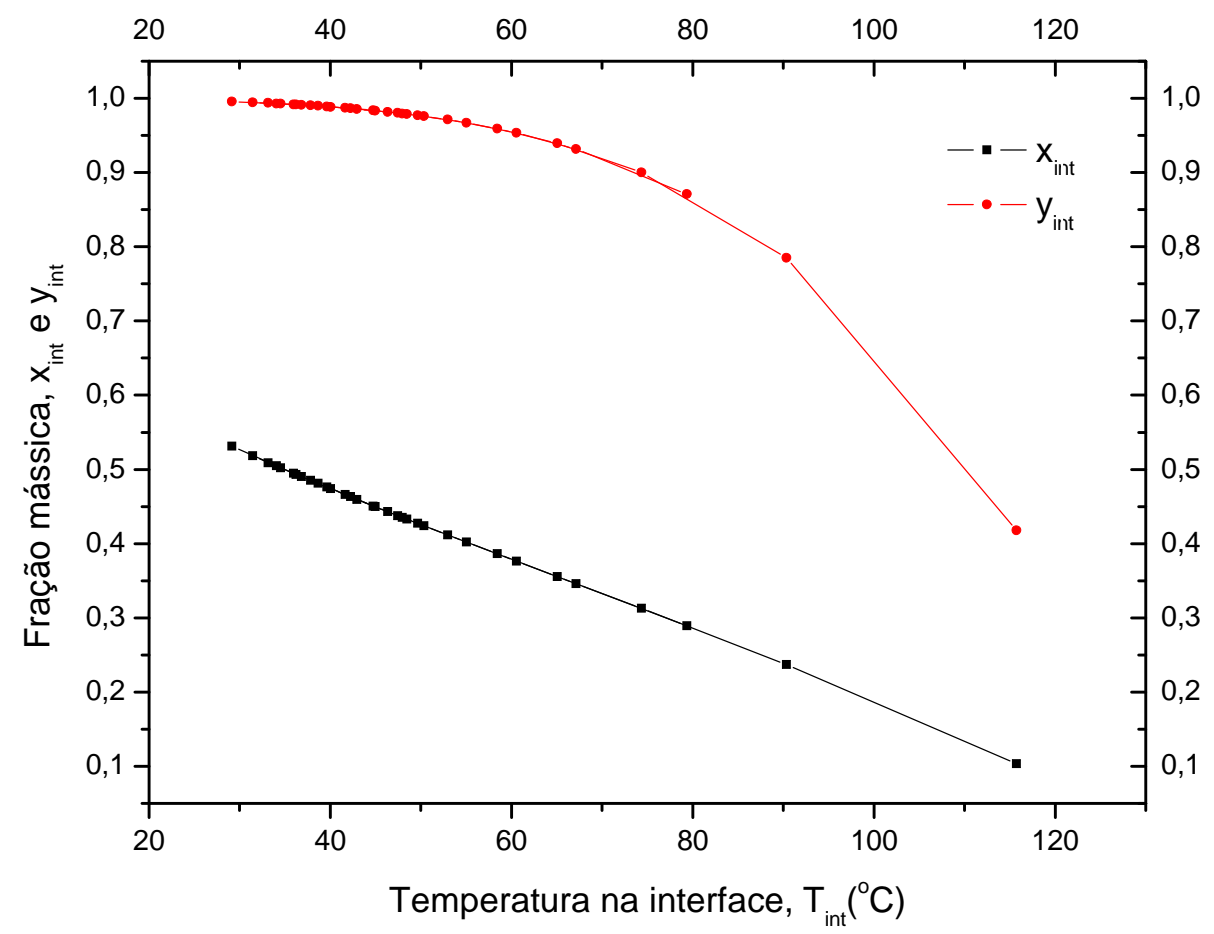

Figura 5.16 - Fração mássica versus temperatura na interface

Já na Fig. (5.17) são expostas as curvas referentes aos coeficientes de transferência de calor na fase líquida. É importante ressaltar que, diferentemente do observado para as concentrações de equilíbrio, onde a baixa temperatura de entrada favorece a elevação tanto da fração líquida como da fração de vapor na interface, os coeficientes convectivos de transferência de calor são fortemente prejudicados. Isso se deve ao fato de que a condutividade térmica do fluido decresce proporcionalmente à redução da temperatura, ocasionando, consequentemente, redução dos valores de $h^{*}$.

Contudo, ainda assim a redução de temperatura promove a redução do tamanho do absorvedor, como pode ser observado através do ponto final de cada um dos gráficos e dos comprimentos mínimos obtidos apresentados na Tabela (5.3). Isso significa que, nesse caso, o fluxo de massa na fase líquida se mostra mais dependente do gradiente de concentrações estabelecido do que do coeficiente de transferência de massa propriamente dito. 


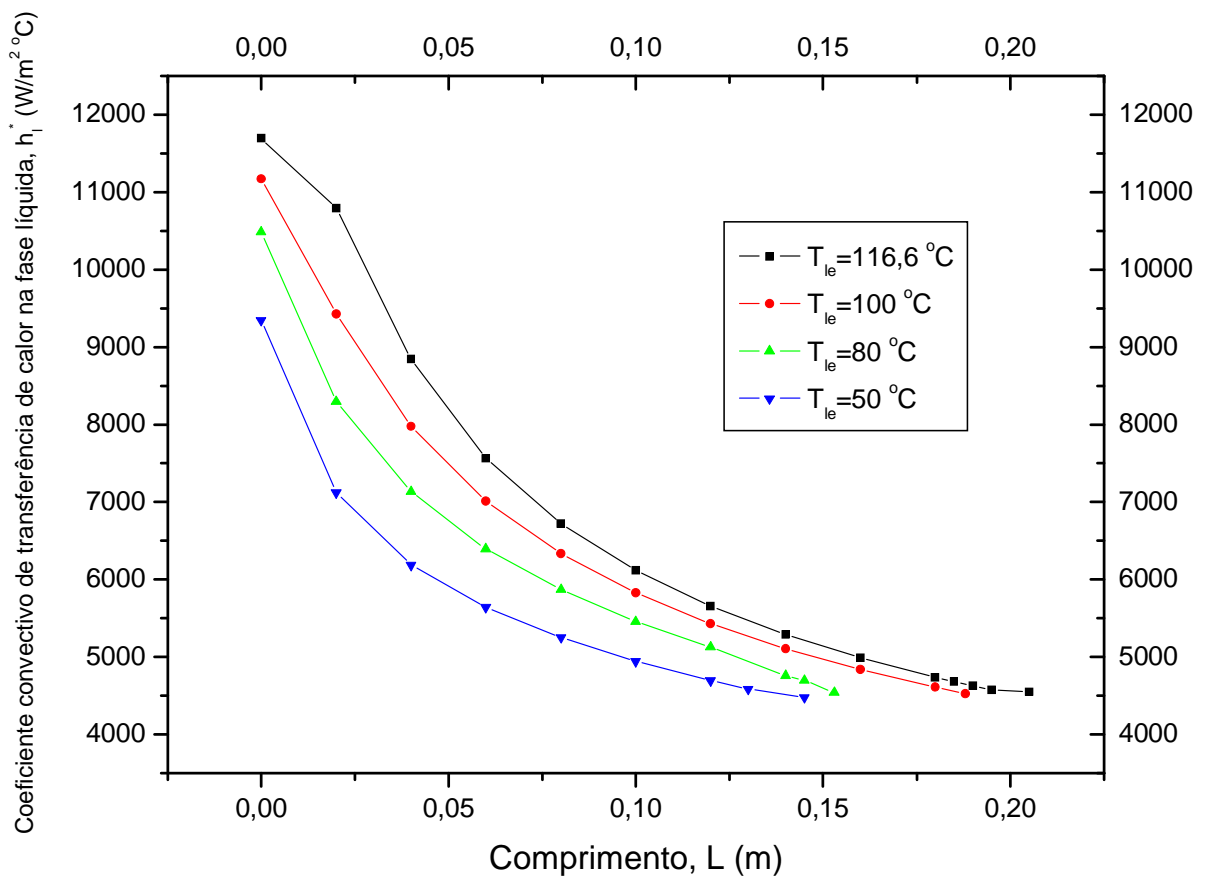

Figura 5.17 - Vazões mássica de líquido ao longo do absorvedor para $R e_{\max }=100$, $T C=25^{\circ} \mathrm{C}$ e $T_{l e}=50^{\circ} \mathrm{C}, T_{l e}=80^{\circ} \mathrm{C}$ e $T_{l e}=100^{\circ} \mathrm{C}$ e $T_{l e}=116,6^{\circ} \mathrm{C}$

Na tabela (5.3), são apresentados os resultados dimensionais referentes às condições simuladas.

Tabela 5.3 - Resultados para $R e_{\operatorname{lmax}}=100$ e $\mathrm{T}_{\mathrm{C}}=25^{\circ} \mathrm{C}$, considerando diferentes temperaturas de entrada da solução pobre

$$
\begin{array}{lllll}
T_{l e}\left({ }^{\circ}\right) & 50 & 80 & 100 & 116,6
\end{array}
$$

\begin{tabular}{ccccc}
\hline Comprimento $(\boldsymbol{m})$ & 0,145 & 0,153 & 0,188 & 0,205 \\
\hline Número de colunas, $\boldsymbol{N}_{\boldsymbol{c}}$ & & \multicolumn{2}{c}{13} & \\
$\begin{array}{c}\text { Número de tubos por } \\
\text { coluna, } \boldsymbol{N}_{\boldsymbol{t}}\end{array}$ & 9 & 9 & 12 & 13 \\
Área total, $\boldsymbol{A}_{\boldsymbol{t}}\left(\boldsymbol{m}^{2}\right)$ & 1,250 & 1,250 & 1,666 & 1,805 \\
\hline
\end{tabular}




\section{CONCLUSÕES}

A partir da resolução simultânea das equações constituintes do modelo na plataforma EES (Engineering Equation Solver), foi possível se construir o perfil de algumas importantes variáveis que devem ser consideradas no projeto de um absorvedor de filme descendente amônia-água. São elas: vazões e frações mássicas de vapor e solução, coeficientes de transferência, espessura e temperatura de filme e taxa de remoção de calor

Optou-se por trabalhar com vazões de solução pobre e vapor de amônia advindas do PSSRA, atrelando-se o número de colunas de tubos do equipamento ao número de máximo de Reynolds admitido para o escoamento. Observa-se que a variação de $R e_{I \max }$ de 75 a 300 , considerando a temperatura do fluido de resfriamento constante e igual a $25^{\circ} \mathrm{C}$, resulta em absorvedores de dimensões e áreas necessárias bastante distintas, sendo que $R e_{\text {Imax }}$ igual a 100 , apesar de não ter resultado no menor comprimento $(0,205 \mathrm{~m})$, necessitou da menor área para a absorção completa do vapor de amônia, esta igual 1,805 m².

Pode-se concluir que a influência de $R \boldsymbol{e}_{I \max }$ está associada basicamente as espessuras de filme obtidas ao longo de todo o absorvedor. Esta espessura que, por sua vez, é a principal parâmetro responsável pelo coeficiente convectivo de transferência de calor do filme. Quanto menores as espessuras maiores serão os coeficientes de transferência de calor. Além disso, o contato entre as fases se torna mais efetivo, na medida em que uma maior quantidade de solução pobre passa a estar em contato direto com o vapor de amônia. Portanto, recomenda-se fortemente, no sentido de minimizar tamanho e consequentemente o custo do equipamento, um número de colunas adequado a vazão de operação, que permita a obtenção de baixas espessuras de filme.

A utilização da analogia de Chilton-Colburn possibilitou a obtenção dos coeficientes de transferência de massa através dos coeficientes de transferência de calor. Dessa forma, o comportamento dos gráficos dessas duas variáveis é bastante semelhante. Naturalmente, $R e_{\operatorname{lmax}}$ iguais a 75 e 100 são as condições que possibilitam 0 alcance dos maiores valores de $K_{\text {l, }}$ os quais variam desde 
aproximadamente $0,21 \mathrm{~kg} / \mathrm{m}^{2} . \mathrm{s}$, no topo do equipamento, até aproximadamente 0,06 $\mathrm{kg} / \mathrm{m}^{2}$.s ao final do absorvedor.

A fase vapor se mostra dominante, no que diz respeito à resistência imposta a transferência de massa, isso decorrente dos baixos coeficientes de transferência de calor e gradientes de concentração encontrados.

A redução da temperatura da água de resfriamento possibilita a redução da área de troca de calor do equipamento. Isso ocorre porque a remoção de calor se torna mais eficiente em virtude do aumento do gradiente de temperatura existente entre $T_{l}$ e $T_{c}$. Além disso, a diminuição mais rápida da temperatura do filme promove a elevação da fração mássica na interface, favorecendo a parcela do fluxo de massa que é proveniente do gradiente de concentrações.

Da mesma forma, a redução da temperatura de entrada da solução pobre no absorvedor, favorece, significativamente, a redução da área necessária para a absorção. Tal fato provém da diminuição da quantidade de calor, além do calor gerado pela absorção, que deve ser dissipada pela água que escoa no interior dos tubos. Diminuindo-se $T_{l e}$ de $116,6^{\circ} \mathrm{C}$ para $1000^{\circ} \mathrm{C}$, proporciona-se uma redução $\mathrm{d}$ e área de troca necessária de $0,139 \mathrm{~m}^{2}$, o que corresponde a aproximadamente 6,5 tubos a menos na composição do absorvedor.

Pode-se afirmar que, apesar das limitações apresentadas pelo modelo, os resultados alcançados se mostraram condizentes com o esperado. Foi possível identificar configurações e condições de operação que propiciam maximização dos coeficientes de transferência de calor e massa, reduzindo assim o tamanho do componente e, consequentemente, seu custo de construção. Na avaliação de $R e_{I \max }$ obteve-se como melhor configuração, um absorvedor composto por 13 colunas, cada uma possuindo 13 tubos, fornecendo de uma área de troca de calor de 1,805 $\mathrm{m}^{2}$. Na avaliação da temperatura de resfriamento $\left(T_{C}\right)$, a menor temperatura $\left(15^{\circ} \mathrm{C}\right)$ foi a que forneceu melhores resultados, correspondendo a um absorvedor de 1,527 $\mathrm{m}^{2}$, constituído por 13 colunas, cada uma composta por 11 tubos. Já no estudo da temperatura de entrada da solução $\left(T_{l e}\right)$, obteve-se um absorvedor de 13 colunas com 9 tubos por coluna, o que fornece 1,250 $\mathrm{m}^{2}$ de área de troca de calor, o que corresponde à temperatura de $50^{\circ} \mathrm{C}$. 


\section{TRABALHOS FUTUROS}

É importante salientar que o modelo desenvolvido apresenta algumas limitações que podem e devem ser superadas em trabalhos futuros. As mais relevantes são as seguintes:

- temperatura do fluido de resfriamento, a qual sofre acréscimo e que neste trabalho foi considerada constante;

- o tipo de escoamento que efetivamente ocorre na superfície e na região entre dois tubos subseqüentes (gotejamento, lâmina, jato, etc.).

- fração de água em equilíbrio com o vapor.

Assim, propõem-se para futuros trabalhos, o desenvolvimento de modelos mais elaborados que levem em conta os itens citados acima.

Existem ainda algumas oportunidades de pesquisa que podem ser exploradas, seja em trabalhos experimentais ou numéricos. São elas:

- desenvolvimento de absorvedores compostos por microcanais;

- avaliação de superfícies de resfriamento modificadas;

- estudo do processo de absorção com a utilização de nanopartículas. 


\section{REFERÊNCIAS BIBLIOGRÁFICAS}

Abreu, A. F. Sistemas de refrigeração por absorção intermitente: concepção, dimensionamento, construção, ensaio e considerações econômicas, 1999. 199 p.Tese de Doutorado - Instituto de Eletrotécnica e Energia, Universidade de São Paulo, São Paulo, 1999.

Aguilar, E. W. Z. Modelagem Térmica da coluna de destilação de um ciclo de refrigeração por absorção de amônia/água, 2010. 141 p. Dissertação (Mestrado) - Escola Politécnica, Universidade de São Paulo, São Paulo, 2010.

Aguilar, E. W. Z.; Prata, J, E.; Simões-Moreira, J, R.; Thermal analysis of the distillation column and the absorber of an ammonia/water absorption refrigeration cycle. The $23^{\text {rd }}$ IIR International Congress Refrigeration, Prague, Czech Republic, 2011.

Ahora, C, R. Refrigeration and air conditioning, PHI, New Delhi, 2010.

Andberg, J, W.; Vliet, G, C. Design guidelines for water-lithium bromide absorbers. ASHRAE, v. 89, p. 220-232, 1983.

Aphornratana, S. Theoretical and experimental investigation of a combined ejector-absorption refrigerator, PhD thesis, University of Shef Field, UK, 1995.

ASHRAE. Handbook Fundamentals. American Society of Heating, Refrigeration and Air Conditioning Engineers, 1981.

M. Conde Engineering. Thermophysical properties of $\left\{\mathrm{NH}_{3}+\mathrm{H}_{2} \mathrm{O}\right\}$ mixtures for the industrial design of absorption refrigeration equipment. Formulation for industrial use, 44 p., Zurich, 2006.

Akita, K.; Yoshida, F. Bubble size, interfacial area, and liquid-phase mass transfer coefficient in bubble. Industrial Chemical Engineering, v.13, n.1, p.84-91, 1974.

Bhavaraju, S. M.; Russel, T. W. F.; Blanch, H. W. The design of gas sparged devices for viscous liquid systems. AIChe Journal, v.24, p.454-465, 1978.

Bohra, L. K. Analysis of binary fluid heat and mass transfer in ammonia-water absorption, 2007. 360 p. Thesis - Georgia Institute of Technology, Georgia, 2007.

Bird, R. B.; Stewart, W. E.; Lightfoot, E. N. Transport Phenomena, Wiley International Edition, John Wiley \&Sons, p. 654-656, 1960.

Carvalho, E. N. Modelagem e simulação de unidades resfriadoras de líquidos por absorção H2O-LiBr de simples e duplo efeito, incluindo o efeito de aditivos e clima local, 2007. 126 p. Dissertação (Mestrado) - Departamento de Engenharia Mecânica, Universidade de Brasília, Brasília, 2007.

Castro, J.; Oliet, C.; Oliva, R, A. Comparison of the performance of falling film and bubble absorbers for air-cooled absorption systems. International Journal of Thermal Sciences, v. 48, p. 1255-1366, 2009.

Cerezo, J.; Bourois, M.; Vallès, M.; Coronas, A.; Best, R. Experimental study of an ammonia-water bubble absorber using a plate heat exchanger for absorption refrigeration machines. Applied Thermal Engineering, p.in press, 2008. 
Cortez, L. A. Histórico e considerações sobre a refrigeração por absorção. Estudos técnicos e economia de energia em refrigeração, $1^{a} \mathrm{Ed}$, v. 1, Universidade do Amazonas, Manaus, 1998.

Chaves, F. D. Estudo experimental e desenvolvimento de um modelo de simulação de um refrigerador por absorção de pressão total única, 2009. 154 p. Tese de Doutorado - Universidade Federal de Minas Gerais.

Chun, K. R.; Seban R. A. Heat Transfer to Evaporating Liquid Films. Journal of Heat Transfer 1971, 93, 391.

Darwish, N.A.; Al-Hashimi, S.H.; Al-Mansoori A.S. Performance analysis and evaluation of a commercial absorption-refrigeration water-ammonia (ARWA) system, International Journal of Refrigeration v. 31 p. 1214-1223, 2008. York, 1995.

Dossat, R. J.; Horan, T. J. Princípios da refrigeração, John Wiley \& Sons, New

Erickson, D. C.; Gomezplata, A.; Papar, R. A.; Use of the colburn-drew equations to model mass transfer. Int. Comm. Heat Mass transfer, v. 25, n. 1, p. 93-98, 1998.

Felamingo, J.C. Produzindo frio através de calor de compressão e de gases de descarga de caldeira. Tecnologia em metalurgia e materiais, São Paulo., v.3, n.4, p. 36-39, 2007.

Fernández-Seara, J.; Sieres, J.; Rodrigues, C.; Vásquez, M. Ammonia-water absorption in vertical tubular absorbers. International Journal of Thermal Sciences., v. 44, p. 277-288, 2005.

Fernández-Seara, J.; Sieres, J. The importance of the ammonia purification process in ammonia-water absorption systems. Energy Convers. Manage., v. 47, n. 1314, p. 1975-1987, 2006.

Foley, G.; DeVault, R.; Sweetser, R. The Future of Absorption Technology in America, Advanced Building Systems-2000 Conference, 16 de Jun. 2000.

Foust, A. S.; Wenzel, L, A.; Clump, C, W.; Maus, L,; Andersen, L. B. Operações Unitárias, Ed. Guanabara dois, Rio de Janeiro, RJ, 1982.

Garimella, S.; Innovations in energy efficient and environmentally friendly space-conditioning systems, Energy, v. 28, Issue 15, pp.1593-1614, 2003.

Goel, M.; Goswami, D. Y. Analysis of a counter-current vapor flow absorber. International Journal of Heat and Mass Transfer, v.48, p.1283-1292, 2005.

Govindaraju, S. D. Analisys of absorber operations for the $5 \mathrm{KW}$ ammonia/water combined cycle, 2005. 109 p. Dissertação (Mestrado)- University of Florida. Florida, 2005.

Grossman, G.; DeVault, R. C.; and Creswick, F. A. Simulation and performance analysis of an ammonia-water absorption heat pump based on the generator-absorber heat exchange (GAX) cycle, ASHRAE Transactions, vol. 101, no. 1, p. 1313-1323, 1995.

Herold, K.E.; Radermacher, R.; Klein, S.A. Absorption Chillers and Heat Pumps. New York, CRC Press, 1996, 329p. 
$\mathrm{Hu}, \mathrm{X}$; Jacobi, A. M. The intertube Falling Film: Part 1 - Flow characteristcs, mode transictions, and hysteresis, Journal of Heat Transfer, Transactions of ASME, v. 118, p. 616-625, (1996a)

Hu, X.; Jacobi, A. M. The intertube falling film: Part 2 - Mode Effects ON Sensible Heat Transfer, Journal of Heat Transfer, Transactions of ASME, v. 118, p. 626-633, (1996b)

Hudson, D. W. Ammonia Absorption Refrigeration Plant, The Official Journal of AIRAH, August 2002, p. 26-30, 2002.

Hoffman, L.; Ziegler, F. Experimental investigation of heat and mass transfer with aqueous ammonia, International absorption heat pump conference, Montreal, Canadá, p. 383-392, 1996

Incropera, F. P.; Dewitt, D. P. Fundamentos de Transferência de Calor e de Massa. $4^{a}$ ed. Rio de Janeiro, LTC Livros Técnicos e Científicos Editora S. A., 1998. 494 p.

Infante Ferreira, C. A.; Keizer, C.; Machielsen, C.H. M. Heat and mass transfer in vertical tubular bubble absorbers for ammonia-water absorption refrigeration systems. International Journal of Refrigeration, v. 7, n. 6, Novembro, 1984.

Islam, Md. R. Absorption process of a falling film on a tubular absorber: An experimental and numerical study. Applied Thermal Engineering, v. 28, p. 1836-1394, 2008.

Yih, S. M. Modeling heat and mass transport in falling liquid films, Handbook of Heat and Mass Transfer: Mass Transfer and Reactor Design, Gulf Publishing Company, Houston, p. 111-120. 1986.

Jeong, S.; Garimella, S.; Falling-Film and Droplet Mode Heat and Mass Transfer in a Horizontal Tube $\mathrm{LiBr} /$ Water Absorber, International Journal of Heat and Mass Transfer 45, 1445-1458, 2002

Kang, Y. T.; Akisawa, A.; Kashiwagi, T. Analytical investigation of two different absorption modes: falling film and bubble types. International Journal of Refrigeration, v.23, p.430-443, 2000.

Kang, Y. T.; Nagano, T.; Kashiwagi, T. Mass transfer correlation of NH3-H2O bubble absorption. International Journal of Refrigeration, v.25, p.878-886, 2002.

Killion, J.D.; Garimella, S. A critical review of models of coupled heat and mass transfer in falling film absorption. International Journal of Refrigeration, v.24, p. 755-797, 2001.

Kim, J. K.; Akisawa, A.; Kashiwagi, T.; Kang, Y, T. Numerical design of ammonia bubble absorber applying binary nanofluids and surfactants. International Journal of Refrigeration, v. 30, p. 1086-1096, 2007.

Kim, B. J.; Kang, I.S. Absorption of water-vapor into wavy laminar falling film of aqueous lithium bromide. KSME IntJ. P. 115-122, 1995.

Kuehn, T. H.; Ramsey, J. W.; Threlkeld, J. L. Thermal environmental engineering, 3rd ed. Prentice-Hall Upper Saddle River, New Jersey, EUA, 1998, 740p. 
Kwon, K.; Jeong, S. Effect of vapor flow on the falling-film heat and mass transfer of ammonia/water absorber. International Journal of Refrigeration, v.27, p. 955964

Lee, K. B.; Chun, B. H.; Lee, J. C.; Lee, C. H.; Kim, S. H. Experimental analysis of bubble mode in a plate-type absorber. Chemical Engineer Science, v. 57, p. 1923-1929, 2002.

Lee, J. C.; Lee, K. B.; Chun, B.H.; Lee, C. H.; Ha, J. J.; Kim, S. H. A study on numerical simulations and experiments for mass transfer in bubble mode absorber of ammonia and water. International Journal of Refrigeration, v. 26, p. 551-558, 2003.

Makiyama, P. A. Aperfeiçoamento de um simulador de sistemas de refrigeração de absorção água-amônia e sua aplicação para projeto de um sistema movido a gás de escape de motor diesel, 2008. 162 p. Tese (Doutorado) - Universidade de Campinas, Campinas, 2008.

Milanés, R. L. P. Análise e simulação do absorvedor evaporativo de um sistema de absorção água-amônia para produção de gelo em escamas, 2002. 223 p. Tese (Doutado) - Universidade de Campinas, Campinas, 2002.

Miller W.A.; Keyhani, M. The correlation of simultaneous heat and mass transfer experimental data for aqueous lithium bromide vertical falling film absorption, Journal of Solar Energy Engineering, v. 123, p. 30-42, 2001.

Mitrovic, J. Flow structures of a liquid film falling on horizontal tubes, Chemical Engineering and technology, v. 28, p. 684-694, 2005.

Ohm, K. C.; Kashiwagi, T.. Characteristics of Heat and Mass Transfer Inside Vertical Falling Type of Absorber. Transactions of JSME, Part B 59, 557, 169-176, 1993

Ortigosa, A. S. P. Modelagem, simulação e otimização de um ciclo comercial de produção de água gelada por absorção de amônia, 2007. 69 p. Trabalho de Formatura Escola Politécnica, Universidade de São Paulo, São Paulo, 2007.

Ortigosa, A. S. P. et al. Modeling, and simulation of a commercial ammonia water absorption refrigeration cycle for production of chilled Water, ENCIT-2008, Belo Horizonte-M.G, 8p. 2008

Ortigosa, A. S. P.; Simões-Moreira, J. R. PSSRA-Programa de Simulação de Sistemas de Absorção Amônia-água. 2007

Perez-Blanco, $\mathrm{H}$. A model of an ammonia-water falling film absorber. ASHRAE, $n$. 3144, v. 94, part. 1, 1988.

Polhman, W. Manual de técnica frigorífica. Ed. Ômega, Barcelona, 1979.

Seader, J. D.; Henley, E. J. (1998). Separation Process Principles. New York: John Wiley \& Sons, Inc.

Sauer Jr., H, J.; Howell, R, H. Heat pump systems. New York: John Wiley \& Sons Inc, 1983. $721 \mathrm{p}$. 
Srikhirin, P.; Aphornratana, S.; Chungpaibulpatana, S. A Review of Absorption Refrigeration Technologies. Renewable Sustainable Energy Rev., v. 5, n 4, p. 343-372, 2001.

Suryanarayana, N.V. Engineering Heat Transfer, West Publishing Company, Mineapolis, St Paul, 1995.

Selim, A, M.; Elsayed, M, M. Performance of a packed bed absorber for aqua ammonia absorption refrigeration system. International Journal of Refrigeration System, v. 22, p. 283-292, 1999.

Sresnewsky, S, F, G, B. Estudos de ciclos de refrigeração quanto a sua aplicação e fonte energética. Escola Politécnica da Universidade de São Paulo, São Paulo, SP, 1983.

Stoecker,W.F.; Jones.J.W; Refrigeração e Ar Condicionado. $1^{\text {a }}$ ed., brasileira.McGraw-Hill Ltda, São Paulo, 1985.

Sultana , P.; Study of thermal performance of falling-film absorbers with and without film inversion. 288 p. Doctoral thesis, Departament of Mechanical Engineer National University of Singapore, 2006.

Thomas, G.; Parks, G.; Potential Roles of Ammonia in a Hydrogen Economy. US Dept of Energy, 2006

Treybal, R.E. Mass transfer operations, $3^{\mathrm{a}}$ ed., Singapore, McGraw-Hill Book Company, 1981. 784p.

Welty, J.; Wicks, C, E.; Wilson, R, E.; Rorrer, G, L. Fundamentals of momentum, heat and massa transfer. 4" ed., New York, Jon Willey \&Sons, Inc., 2001. p. 550-579, $753 p$.

Westerlund, L.; Dahl, J. Absorbers in the open absorption system. Applied Energy. v.48, p. 33-49, 1994.

Wilke, C, R.; Chang, P.; Correlation of difusion coefficients in dilute solutions. AIChE Journal, p 264-270, 1955.

Yih, S. M. Modeling heat and mass transport in falling liquid films, Handbook of Heat and Mass Transfer: Mass Transfer and Reactor Design, Gulf Publishing Company, Houston, p. 111-120. 1986. 


\section{APÊNDICE-Conjunto de equações solucionadas no EES}

"BALANÇOS DE MASSA" "(4 equações e 4 variáveis)"

DUPLICATE I=1,L-1

$\mathrm{dmNH} 3[\mathrm{i}]=\mathrm{Km} \_[\mathrm{i}]^{*} \mathrm{dA}[\mathrm{i}]^{*} \ln \left(\left(1-\mathrm{x} \_[\mathrm{i}]\right) /(1-\operatorname{xint}[i])\right)$

$m_{-}\left|[i+1]=m_{-}\right|[i]+d m N H 3[i]$

$m_{-} v[i+1]=m_{-} v[i]-d m N H 3[i]$

$m_{-} \mid[i+1]^{*} x \_[i+1]=m_{-}\left[[i]^{*} x \_\mid[i]+d m N H 3[i]\right.$

$\mathrm{m}_{-} \mathrm{v}[\mathrm{i}+1]^{*} \mathrm{y} \_\mathrm{v}[\mathrm{i}+1]=\mathrm{m}_{-} \mathrm{v}\left[\mathrm{i}^{\bar{*}} \mathrm{y} \_\mathrm{v}[\mathrm{i}]-\mathrm{dmNH} 3[\mathrm{i}]\right.$

"Balanços de Energia"

"Fase vapor"

$m \_v[1]^{*} \mathrm{H} \_v[1]=m \_v[2]^{*} \mathrm{H} \_v[2]+d Q v[1]+d m N H 3[1]^{*} H N H 3 \_v[1]$

"Fase líquida"

$\mathrm{m}_{-} \mid\left[\mathrm{i}^{*} \mathrm{H} \_\left|[\mathrm{i}]+\mathrm{dmNH} 3[i]^{*} \mathrm{HNH} 3 \_\right|[i]+\mathrm{dQ}\left|[\mathrm{i}]=\mathrm{dQc}[\mathrm{i}]+\mathrm{m}_{-}[\mathrm{i}+1]^{*} \mathrm{H} \_\right|[i+1]\right.$

$\mathrm{HN} H 3$ II [i] =Enthalpy(Ammonia;T=T_ml[i]; $\mathrm{P}=\mathrm{P}$ a)

HNH3_v[i]=Enthalpy(Ammonia; $\left.T=\bar{T} \_m v[i] ; P=\bar{P} \_a\right)$

End

CALL NH3H2O(123;T_[1];:P_a;x_[1]: Tle;Pa1;xl;H_[1];;1;u1;v1;q1)

CALL NH3H2O(123;T_v[1];P_a;y_v[1]: Tve;Pa2;yve;H_v[1];s2;u2;v2;q2)

CALL NH3H2O(234;P_a;x_I[2];H_I[2]: T_I[2];Pa3;xls;HIs;s3;u3;v3;q3)

"Interface"

"Fluxo de energia térmica entre a interface e o filme"

$d Q|[1]=h| s t a r[1]^{*} d A[1]^{*}\left(\operatorname{Tint}[1]-T \_m \mid[1]\right)$

"Fluxo de Energia Témica entre o vapor e a interface"

$d Q v[1]=h v s t a r[1]^{*} d A[1]^{*}\left(T \_m v[1]-\operatorname{Tint}[1]\right)$

"Fluxo de energia térmica entre o filme e o fluido de resfriamento"

$\mathrm{dQc}[1]=$ Uglobal[1] $]^{*} \mathrm{dA}[1]^{*}\left(\mathrm{~T} \_\mathrm{ml}[1]-\mathrm{T} \_\mathrm{c}\right)$

1/Uglobal[1] =1/h_cconvturb[1]+((OD-ID)/ktubo)+1/hlstar[1]

$\mathrm{c} 1=\left(\mathrm{dmNH} 3[1]^{*} \mathrm{C} p\left(\right.\right.$ Ammonia; $\left.\left.T=T \_I[1] ; P=P \_a\right)\right) / h \_$Iconv[1]

$c 2=\left(d m N H 3[1]^{*} \mathrm{Cp}\left(\right.\right.$ Ammonia; $\left.\left.T=T_{-} v[1] ; P=P \_a\right)\right) / h \_v c o n v[1]$

hlstar[1]=h_Iconv[1] ${ }^{*}(c 1 /(1-\exp (-c 1)))$

hvstar[1]=h_vconv[1] ${ }^{\star}(c 2 /(1-\exp (-\mathrm{c} 2)))$

ktubo=k_('Stainless_AISI316'; T_c)

$\mathrm{R}=0,007$

"CÁLCULO DE PROPRIEDADES"

"Calor específico do vapor de amônia" "J/kgK"

C_v=y_v[1] ${ }^{*} \mathrm{C} \_a m o n i a v+\left(1-y \_v[1]\right)^{*} \mathrm{C} \_$aguav

C_amoniav $=\mathrm{Cp}\left(\right.$ Ammonia; $\left.T=T \_v[1] ; P=P \_a\right)$

C_aguav $=C p\left(\right.$ Steam; $\left.T=T \_v[1] ; P=P \_a\right)$

"Calor específico dA[1] solução" "J/kgK"

C_l $=\left(\right.$ C_amonial $\left.{ }^{*} x \_\mid[1]\right)+C$ _agual ${ }^{*}\left(1-x \_\mid[1]\right)$

C_amonial $=\mathrm{Cp}\left(\right.$ Ammonia; $\left.\mathrm{T}=\mathrm{T} \_\mathrm{ml}[1] ; \mathrm{P}=\overline{\mathrm{P}} \_\mathrm{a}\right)$

C_agual $=C p\left(\right.$ Water $\left.; T=T \_m l[1] ; P=P \_a\right)$

"CondutividA[1]de térmica do vapor" " $\mathrm{W} / \mathrm{mK}$ "

$\mathrm{k} \_v=\left(y \_v[1]^{*} \mathrm{k} \_a m o n i a v\right)+\left(1-y \_v[1]\right)^{*} \mathrm{k} \_a g u a v$ 
k_amoniav=Conductivity (Ammonia;T=T_v[1];P=P_a)

$\mathrm{k} \_$aguav $=$Conductivity $\left(\right.$Steam; $\left.T=T \_v[1] ; P=P \_a\right)$

"CondutividA[1]de térmica dA[1] solução" "W/mK"

k_l= x_[1] $]^{*} k \_$amonial $+\left(1-x \_l[1]\right)^{*} k \_$agual

k_amonial=Conductivity(Ammonia; $\left.T=T \_m l[1] ; P=P \_a\right)$

$\mathrm{k} \_$agual $=$Conductivity $\left(\right.$Water $\left.; T=T \_m l[1] ; P=P \_a\right)$

"DensidA[1]de do vapor" " $\mathrm{Kg} / \mathrm{m3}$

rho_v=y_v[1] ${ }^{*}$ rho_amoniav $+\left(1-y \_v[1]\right)^{*}$ rho_aguav

rho_amoniav=Density (Ammonia; $\left.T=T \_v[1] ; P=P \_a\right)$

rho_aguav=Density $\left(\right.$ Steam; $\left.T=T \_v[1] ; P=P \_a\right)$

"DensidA[1]de dA[1] solução" "Kg/m3"

rho_I=x_I[1] $]^{*}$ rho_amonial+(1-x_I[1])*rho_agual

rho_amonial=Density (Ammonia; T=T_ml[1];P=P_a)

rho_agual= Density $\left(\right.$ Water; $\left.T=T \_m l[1] ; P=P \_a\right)$

"DifusividA[1]de do vapor amônia na solução" "m2/s"

Diff_l $=\left(117,282^{*}\left(10^{\wedge}(-18)\right)\right)^{*} T \_m l[1]^{*}\left(\left(\left(p s i I^{*} M M O L A R \_I\right)^{\wedge} 0,5\right) / m u \_I^{*}\left(V d \_l\right)^{\wedge} 0,6\right)$

psi_I $=\left(x \_\mid[1]^{*} 1,7\right)+\left(\left(1-x \_\mid[1]\right)^{*} 2,6\right)$

MMOLAR_l=x_l[1]*M_amonial+(1-x_[1]])*M_agual

M_amonial=MolarMass(Ammonia)

M_agual=MolarMass (Water)

Vd_I=MMOLAR_I/rho_amonial

"DifusividA[1]de do vapor de amonia" "m2/s"

Diff_v=(117,282* $\left.\left(10^{\wedge}(-18)\right)\right)^{*} T \_v[1]^{*}\left(\left(\left(p s i \_v^{*} M M O L A R \_V\right)^{\wedge} 0,5\right) / m u \_v^{*}\left(V d \_v\right)^{\wedge} 0,6\right)$

psi_v $=\left(\mathrm{y} \_\mathrm{v}[1]^{*} 1,7\right)+\left(\left(1-\mathrm{y} \_\mathrm{v}[1]\right)^{*} 2,6\right)$

MMOLAR_v=y_v[1]*M_amonial+(1-y_v[1])* $M \_a g u a l$

Vd_V=MMOLAR_v/rho_amoniav

"Cálculo dA[1] viscosidA[1]de dA[1] solução" "kg/ms"

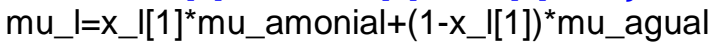

mu_amonial $=$ Viscosity $\left(\right.$ Ammonia; $T=T$ ml[1] $\left.; P=P \_a\right)$

mu_agual $=$ Viscosity $\left(\right.$ Water $\left.; T=T \_m l[1] ; P=P \_a\right)$

$\mathrm{mu} \_\mathrm{v}=\mathrm{y} \_v[1]^{*} \mathrm{mu} \_a m o n i a v+\left(1-\mathrm{y} \_v[1]\right)^{*} \mathrm{mu}$ aguav $\quad \mathrm{kg} / \mathrm{ms}$ "

mu_amoniav=Viscosity (Ammonia; $\left.T=T \_v[1] ; P=P \_a\right)$

mu_aguav=Viscosity $\left(\right.$ Water; $\left.T=T \_v[1] ; P=P \_a\right)$

"CondutividA[1]de térmica dA[1] água" "W/mK"

k_c=Conductivity (Water;T=T_c;P=P_c)

T_C $=293,15$

$P \_C=1$

\section{"CÁLCULO DE ADIMENSIONAIS"}

"Números de Reynolds" 
$R e \_\mid[1]=\left(4^{*} m \_\mid[1]\right) /\left(2^{*} N^{*} W^{*} m u \_l\right)$

$R e \_m a x[1]=\left(4^{*}\left(m \_[1]+m \_v[1]\right)\right) /\left(2^{*} N \_m a x[1]^{*} W^{*} m u \_l\right)$

"Critério de aplicação da correlação de hl"

Yih[1] $=\left.2460^{*} \operatorname{Pr}\right|^{\wedge}(-0,646)$

$R e \_\lim [1]=100$

" Critério de aplicação da correlação de hv"

"Número de Schmidt"

Sc_vemu_v/(rho_v*Diff_v)

Sc_l=mu_l/(rho_I ${ }^{*}$ iff_l)

"Número de Prandtl"

Pr_v $=\left(C \_v\right)^{*}\left(m u \_v / k \_v\right)$

$\operatorname{Pr} \_$I $=\left(C \_l\right)^{*}\left(m u \_/ \bar{k} \_l\right)$

"Cálculo do número de feixes"

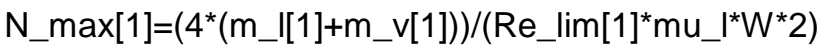

"Número de Re ao redor dos tubos"

Re_DO[1] $=100$

Re_vap[1]=(rho_v $\left.{ }^{*} V_{-} v a p[1]^{*} \mathrm{OD}\right) / \mathrm{mu} \_\mathrm{v}$

" Velocidade média do vapor ao redor dos tubos do vapor"

V_vap $[1]=\left(m \_v[1] /\left(2^{*} N \_m a x[1]^{*} \mathrm{~W}\right)\right) /\left(2^{*} \text { delta[1 }\right]^{*}$ rho_v $)$

\section{"CÁLCULO DOS COEFICIENTES DE TRANSFERÊNCIA"}

"Coeficiente de transferência de massa no vapor"

$K m \_v[1]=h \_v c o n v[1] /\left(C \_v^{*}\left(S c \_v / P r \_v\right)^{\wedge}(2 / 3)\right)$

"Coeficiente de transferência de massa no líquido" "kg/m2 s"

$\mathrm{Km} \_[1]=\mathrm{h} \_\mathrm{Iconv}[1] /\left(\left(\mathrm{C} \_\mathrm{l}\right)^{*}\left(\left(\mathrm{Sc} \_\mathrm{l} / \mathrm{Pr} \_\mathrm{l}\right)^{\wedge}(2 / 3)\right)\right)$

"Coeficiente de transferência de calor no vapor" "W/m2K"

h_vconv[1] $=\left(\mathrm{k} \_v / \mathrm{OD}\right)^{*} 0,683^{*}\left(\left(\operatorname{Re} \_ \text {vap }[1]\right)^{\wedge} 0,466\right)^{*}\left(\operatorname{Pr} \_v\right)^{\wedge} 0,3333$

"Coeficiente de transferência de calor no líquido" "W/m2K"

h_Iconv[1] $=1,88^{*}\left(\mathrm{k} \_\right.$I/delta[1])

"Coeficiente convectivo de transf. energia térmica fluido de resfriamento"

$\mathrm{h} \_$cconvlam $[1]=4,364^{*}\left(\mathrm{k} \_\mathrm{c} / \mathrm{ID}\right)$

"W/m2K"

h_cconvturb[1] $=\left(k \_c / I D\right)^{*}\left(0,024{ }^{*} \operatorname{Re} \_c[1]^{\wedge} 0,8^{*} \operatorname{Pr} \_c^{\wedge}(1 / 3)\right)$

v_coolant $=4$ 
Pr_c $=(\text { C_COOLANT })^{*}($ mu_COOLANT $/$ k_COOLANT $)$

C_COOLANT $=\mathrm{Cp}\left(\mathrm{H} 2 \mathrm{O} ; \mathrm{T}=\mathrm{T} \_\mathrm{c}\right)$

$\mathrm{mu} \_$COOLANT $=$Viscosity $\left(\mathrm{H} 2 \mathrm{O} ; \mathrm{T}=\mathrm{T} \_\mathrm{c}\right)$

k_COOLANT $=$ Conductivity $\left(\mathrm{H} 2 \mathrm{O} ; \mathrm{T}=\mathrm{T} \_\mathrm{c}\right)$

rho_COOLANT=Density $\left(\mathrm{H} 2 \mathrm{O} ; \mathrm{T}=\mathrm{T} \_\mathrm{c} ; \mathrm{P}=\mathrm{P} \_\mathrm{c}\right)$

"Reynolds do fluido de resfriamento"

Re_c[1]=(v_coolant*rho_COOLANT $\left.{ }^{*} I D\right) / m u \_C O O L A N T$

"Espessura do filme líquido" "m"

delta[1] $=\left(\left(3^{*}\left(m \_\mid[1] /\left(2^{*} N^{*} W\right)\right)^{*} m u \_l\right) /\left((\text { rho_I^2 })^{*} g\right)\right)^{\wedge}(1 / 3)$

"Vazão volumétrica do fluido de resfriamento $\mathrm{m}^{3} / \mathrm{s}$ "

Q_coolant[1]=v_coolant ${ }^{*}\left(\left(\operatorname{pi\# }^{*}\left(I^{\wedge} 2\right)\right) / 4\right)$

"Vazão mássica do fluido de resfriamento kg/s"

m_coolant[1]=Q_coolant[1] ${ }^{\star}$ rho_COOLANT

"Cálculo da temperatura na interface"

$\operatorname{Tint}[1]=\left(\left(\left(h \_v c o n v[1] / h \_\mid c o n v[1]\right)^{*} T \_v[1]\right)+T \_I[1]\right) /\left(1+\left(h \_v \operatorname{conv}[1] / h \_\mid c o n v[1]\right)\right)$

"Cálculo de xint e yint"

CALL NH3H2O(128;Tint[1];P_a;q_I: Tint_|;Pint_I;xint[1];hint_l;sint_l;uint_;;vint_;;int_l)

CALL NH3H2O(128;Tint[1];P_a;q_v: Tint_v;Pint_v;yint[1];hint_v;sintv;uint_v;vint_v;qint_v)

"DADOS DE ENTRADA"

$\mathrm{q} v=1$

q_l$=0,1285$

$P \_a=2,9$

T_ml[i] $=\left(T+c+T \_[1]\right) / 2$

T_mv[i] $=\left(\overline{T i n t}[1]+T_{-} v[1]\right) / 2$

T_I[1] $=389,75$

T_v[1] $=299,57$

$y \_v[1]=1$

X_l[1] $=0,098$

$m \_v[1]=0,00031$

m_l[1] $=0,04569$

"Geometria"

$\mathrm{OD}=0,017$

$\mathrm{ID}=0,015$ "m"

$\mathrm{W}=0,2$

$\mathrm{g}=9,8$

$\mathrm{dL}=0,02$

$\mathrm{dA}[\mathrm{i}]=\mathrm{dL}^{*} \mathrm{~W}^{*} \mathrm{~N}^{*} 2$ 